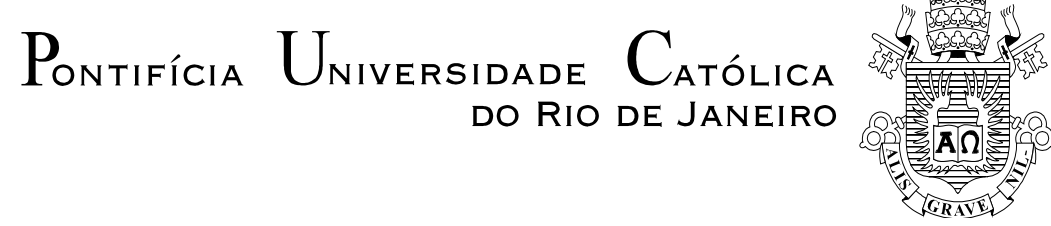

Luiz Armando dos Santos Aleixo

\title{
Uma Metodologia para a Extensão de Histórico de Produção Eólica
}

\section{Dissertação de Mestrado}

Dissertação apresentada ao Programa de Pós-Graduação em Engenharia Elétrica da PUC-Rio como requisito parcial para obtenção do título de Mestre em Engenharia Elétrica.

Orientador: Prof. Álvaro de Lima Veiga Filho

Rio de Janeiro

Dezembro de 2013 


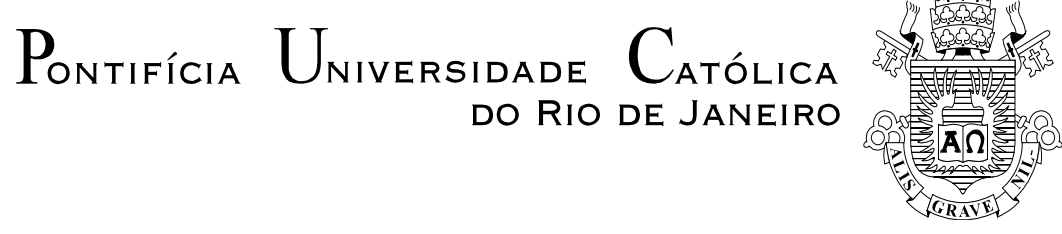

Luiz Armando dos Santos Aleixo

Uma Metodologia para a Extensão de Histórico de Produção Eólica

Dissertação apresentada como requisito parcial para obtenção do grau de Mestre pelo Programa de Pós-Graduação em Engenharia Elétrica do Departamento de Engenharia Elétrica do Centro Técnico Científico da PUC-Rio. Aprovada pela Comissão Examinadora abaixo assinada.

\author{
Prof. Álvaro de Lima Veiga Filho \\ Orientador \\ Departamento de Engenharia Elétrica - PUC-Rio \\ Prof. Cristiano Augusto Coelho Fernandes \\ Departamento de Engenharia Elétrica - PUC-Rio
}

Prof. Gerson Couto de Oliveira

PSR Consultoria

Prof. José Eugenio Leal Coordenador Setorial do Centro

Técnico Científico

Rio de Janeiro, 18 de dezembro de 2013 
Todos os direitos reservados. É proibida a reprodução total ou parcial do trabalho sem autorização da universidade, do autor e do orientador.

\section{Luiz Armando dos Santos Aleixo}

Graduou-se em Estatística pela Escola Nacional de Ciências Estatísticas, no Rio de Janeiro - RJ (2011). Durante o mestrado, trabalhou com modelagem e previsão da produção eólica através de modelos lineares.

\section{Ficha Catalográfica}

Aleixo, Luiz Armando dos Santos

Uma metodologia para a extensão de histórico de produção eólica. I Luiz Armando dos Santos Aleixo; orientador: Álvaro de Lima Veiga Filho. - 2013.

98 f.: il. (color.) ; $30 \mathrm{~cm}$

Dissertação (mestrado) - Pontifícia Universidade Católica do Rio de Janeiro, Departamento de Engenharia Elétrica, 2013.

Inclui bibliografia.

1. Engenharia elétrica - Teses. 2. Geração eólica. 3. Regressão 4. Stepwise. I. Veiga Filho, Álvaro de Lima. II. Pontifícia Universidade Católica do Rio de Janeiro. Departamento de Engenharia Elétrica. III. Título. 


\section{Agradecimentos}

Agradeço primeiramente a Deus, por toda força que me foi concedida durante este processo.

Agradeço de coração aos meus pais Armando Nazareno e Ana Coeli Aleixo por seu meu porto seguro durante toda a minha vida, retirando as preocupações que me afligiam, e por tudo.

Agradeço muito a minha amiga e colega Carolina Nascimento por estar presente durante esta jornada, pelos momentos que eu precisava desabafar com alguém e por ter alguém com quem contar. Agradeço de coração.

Ao meu amigo Ed Almeida por simplesmente ser uma das pessoas mais carismáticas e incríveis que eu tive o prazer de conhecer na minha vida, e que eu tenho o prazer de chamar de amigo.

Aos amigos de longe Neilton Araújo, Anderson Martins e Fernando Souza, pela amizade de longos anos, pelas conversas, pelas broncas, pelos momentos de distração quando precisava, enfim por tudo. Vocês são muito especiais para mim.

Ao meu orientador Álvaro de Lima Veiga Filho, pelos conselhos, pela confiança depositada e pela aprendizagem adquirida nesta etapa que certamente levarei comigo por toda a mina vida.

Ao meu co-orientador Cássio Freitas Pereira de Almeida pela toda ajuda neste processo, por estar presente, por me ajudar nos momentos de desespero.

A todos os amigos da ENCE.

A CAPES e CNPq pelo suporte financeiro. 


\title{
Resumo
}

\begin{abstract}
Aleixo, Luiz Armando dos Santos; Veiga Filho, Álvaro de Lima (Orientador). Uma metodologia para a extensão de histórico de produção eólica. Rio de Janeiro, 2013. 98p. Dissertação de Mestrado Departamento de Engenharia Elétrica, Pontifícia Universidade Católica do Rio de Janeiro.
\end{abstract}

Um dos principais problemas para a expansão do uso da energia eólica é a escassez de dados. No Brasil, exige-se um histórico de pelo menos 30 anos de produção para a certificação de um parque eólico. No entanto, é muito improvável que esses dados estejam disponíveis. Um recurso frequente é o de utilizar um histórico de medidas locais com uma duração bastante inferior (por exemplo 2 anos) e estendê-lo para 30 anos através do uso de modelos estatísticos. O objetivo dessa dissertação é propor e estudar o desempenho de uma metodologia de extensão de histórico baseada em um modelo de regressão linear. Como ilustração, a metodologia foi aplicada a 4 parques eólicos localizados no nordeste do Brasil.

\section{Palavras-chave}

Geração eólica, Regressão, Stepwise. 


\section{Abstract}

Aleixo, Luiz Armando dos Santos; Veiga Filho, Álvaro de Lima (Advisor). A methodology for the extension of wind energy historic data. Rio de Janeiro, 2013. 98p. MSc Dissertation - Departamento de Engenharia Elétrica, Pontifícia Universidade Católica do Rio de Janeiro.

One of the main problems for the expansion for the use of wind energy is the lack of data. In Brazil, it is required a historic data of at least 30 years of production for the certification of a wind farm. However, is very unlikely that these data is available. A frequent use is to use historic data of local measurements with a short duration (2 years for example) e extend for 30 years through the use of statistical models. The objective of this dissertation is to propose e study the performance of a methodology for the historic data extension based on a linear regression model. As an illustration, the methodology was applied to 4 wind farms located on the northeast of Brazil.

\section{Keywords}

Wind energy, Regression, Stepwise. 


\section{Sumário}

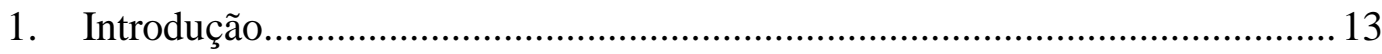

2. O vento e a energia eólica ............................................................................. 15

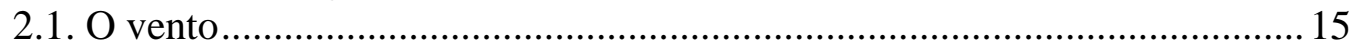

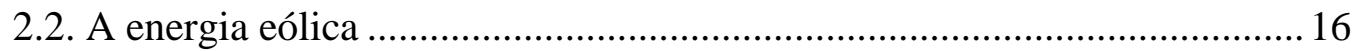

2.2.1 Histórico da energia eólica.................................................................... 17

2.3. Energia Eólica atualmente ....................................................................... 18

2.4. Potencial Eólico Brasileiro ………………………………………………....... 22

3. Conceitos básicos sobre a Energia Eólica.....................................................24

3.1. Turbinas ou aerogeradores .......................................................................24

3.1.1. Turbinas de eixo vertical .....................................................................25

3.1.2. Turbinas de Eixo Horizontal ................................................................25

3.2. Uso dos dados históricos dos ventos...........................................................26

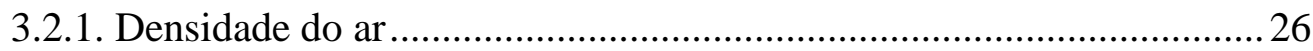

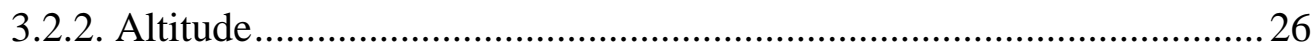

3.2.3. Terreno e rugosidade ........................................................................... 27

3.2.4. Distribuição Weibull ..............................................................................2

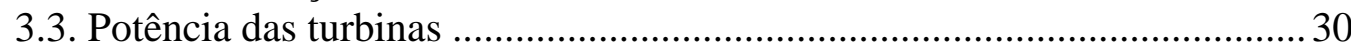

3.3.1. Curva de Potência...................................................................................... 30

3.3.2. Potência teórica do ar ............................................................................ 32

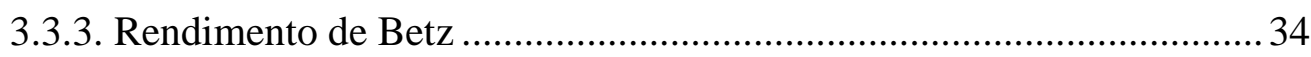

3.3.4. Densidade de energia eólica ................................................................... 38

3.4. Revisão bibliográfica ................................................................................... 38

3.4.1. Fontes que utilizaram diretamente a curva de potência ..........................38

3.4.2. Fontes que se referem à energia eólica.................................................... 40

4. Metodologia Estatística .................................................................................. 43

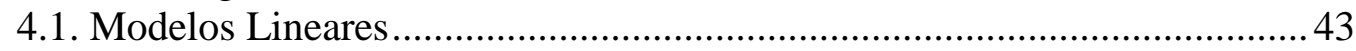

4.2. Estimação dos parâmetros ........................................................................... 44

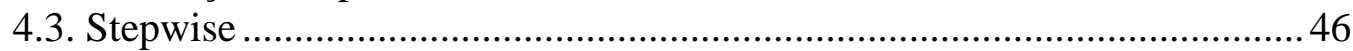

4.4. LASSO (Least Absolute Shrinkage and Selection Operator) ........................ 47

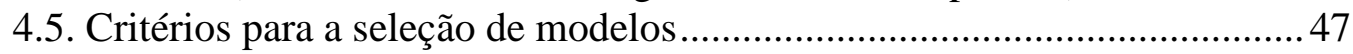

4.5.1. Critério de Informação de Akaike (AIC) ................................................ 47

4.5.2. Critério de Informação de Schwarz (BIC) .............................................. 48

4.6. Medidas de aderência do modelo estatístico..................................................... 48

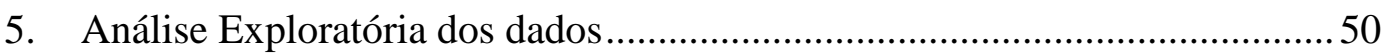

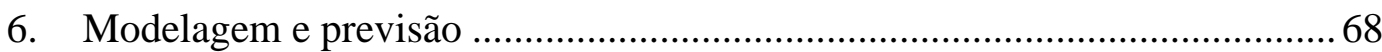

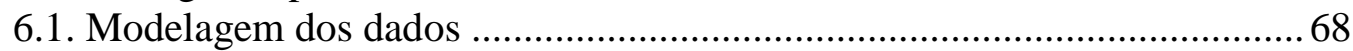

6.2. Previsão out-of-sample ……………………………………………….... 75

6.3. Reconstrução do Histórico ........................................................................... 81 


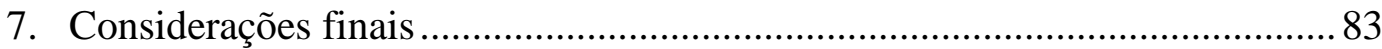

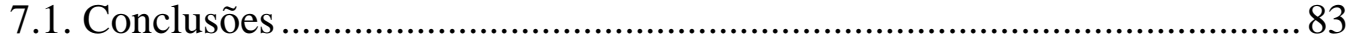

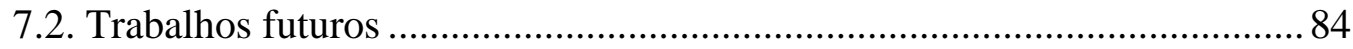

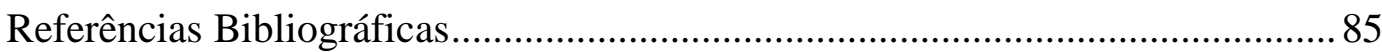

Apêndice A - Análise Exploratória dos dados de geração eólica para as fazendas Canoa Quebrada, Enacel e Icaraizinho................................................... 88

Apêndice B - Análise Exploratória dos dados das fazendas eólicas Canoa Quebrada, Enacel e Icaraizinho

Apêndice C - Coeficientes dos modelos completos e stepwise para as estações

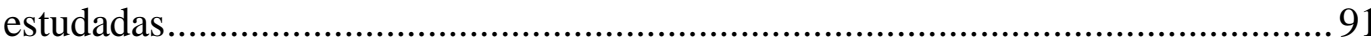

Apêndice D - MAE e Pseudo $\mathrm{R}^{2}$ out of sample por tipo e patamar das estações

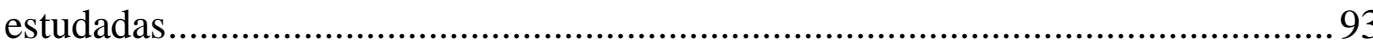

Apêndice E - MAE e Pseudo $\mathrm{R}^{2}$ out of sample por tipo e patamar das estações estudadas, retirando os zeros da geração eólica observada .................................... 95

Apêndice F - Extensão do histórico de geração eólica para as fazendas estudadas pelos modelos completo e stepwise

Apêndice G - Histogramas da geração eólica observada e estimada através da extensão do histórico pelo modelo linear ............................................................ 98 


\section{Lista de Tabelas}

Tabela 3-1: Rugosidade superficial de acordo com o tipo de terreno. 27

Tabela 5-1: Estatísticas descritivas das variáveis que compõem o banco de dados ERAI da fazenda eólica de Bons Ventos.

Tabela 5-2: Estatísticas descritivas das variáveis que compõem o banco de dados NNRP da fazenda eólica de Bons Ventos.

Tabela 5-3: Estatísticas descritivas da densidade do ar calculada para os conjuntos de dados ERAI e NNRP.

Tabela 5-4: Estatísticas descritivas das velocidades a 100 metros e a 80 metros projetadas pela Lei da Potência e a Lei Logarítmica do banco de dados ERAI.... 61

Tabela 5-5: Estatísticas descritivas das velocidades a 100 metros e a 80 metros projetadas pela Lei da Potência e a Lei Logarítmica do banco de dados NNRP. . 61

Tabela 5-6: Estimativas dos parâmetros da distribuição Weibull das duas fontes de dados.

Tabela 5-7: Estatísticas descritivas das potências calculadas para a fazenda de 24 turbinas de Bons Ventos.

Tabela 5-8: Estatísticas descritivas da Geração Eólica.

Tabela 6-1: $\mathrm{R}^{2}$, $\mathrm{R}^{2}$ ajustado, AIC, BIC e p-valores dos testes de White e Jarque-Bera do modelo (6.2), de acordo com a direção de decomposição e sem decomposição.

Tabela 6-2: $\mathrm{R}^{2}, \mathrm{R}^{2}$ ajustado, AIC, BIC e p-valores dos testes de White e Jarque-Bera do modelo (6.3), de acordo com a direção de decomposição e sem decomposição.

Tabela 6-3: $\mathrm{R}^{2}, \mathrm{R}^{2}$ ajustado, AIC, BIC e p-valores dos testes de White e Jarque-Bera do modelo (6.4), de acordo com a direção de decomposição e sem decomposição.

Tabela 6-4: $\mathrm{R}^{2}, \mathrm{R}^{2}$ ajustado, AIC, BIC e p-valores dos testes de White e Jarque-Bera do modelo (6.4) somente com os dados ERAI, de acordo com a direção de decomposição e sem decomposição.

Tabela 6-5: $\mathrm{R}^{2}, \mathrm{R}^{2}$ ajustado, AIC, BIC e p-valores dos testes de White e Jarque-Bera do modelo (6.4) somente com os dados NNRP, de acordo com a direção de decomposição e sem decomposição.

Tabela 6-6: $\mathrm{R}^{2}$, $\mathrm{R}^{2}$ ajustado, AIC, BIC, MAE e RMSE in-sample para os modelos (6.4) completos e stepwise de Bons Ventos, Canoa Quebrada, Enacel e Icaraizinho

Tabela 6-7: Porcentagem de incidência de previsões menores que zero, para cada os modelos completo e stepwise das fazendas estudadas. 
Tabela 6-8: Estatísticas MAE, RMSE e Pseudo $\mathrm{R}^{2}$ out-of-sample para os modelos completos e stepwise de Bons Ventos, Canoa Quebrada, Enacel e Icaraizinho.

Tabela 6-9: Estatísticas MAE, RMSE e Pseudo $\mathrm{R}^{2}$ out-of-sample para os modelos completos e stepwise de Bons Ventos, Canoa Quebrada, Enacel e Icaraizinho sem as defasagens da geração eólica.

Tabela 6-10: Incidência de previsões menores que zero e maiores que a capacidade da fazenda na reconstrução do histórico de cada fazenda pelo modelo completo e stepwise. 


\section{Lista de Figuras}

Figura 2-1: Capacidade de energia eólica total instalada no mundo (MW) e uma previsão para o segundo semestre de 2012 .................................................. 19

Figura 2-2: Nova capacidade eólica até a primeira metade de 2012 e uma previsão para o segundo semestre. ..................................................................... 19

Figura 2-3: Taxa de crescimento do mercado mundial (\%)................................. 20

Figura 2-4: Países com as maiores capacidades instaladas (MW). ...................... 20

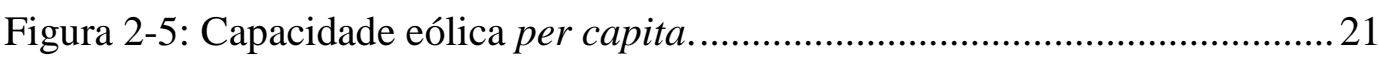

Figura 2-6: Capacidade eólica por área $\left(\mathrm{KW} / \mathrm{km}^{2}\right)$............................................ 21

Figura 2-7: Capacidade eólica por PIB (KW/milhões U\$)................................... 21

Figura 3-1: Ilustração de uma curva de potência..................................................... 31

Figura 3-2: Ilustração das moléculas de ar em movimento................................... 33

Figura 3-3: Ilustração das moléculas de ar atravessando a área transversa da

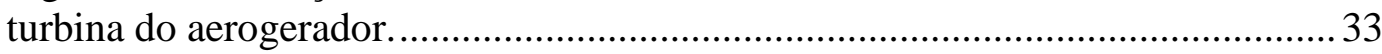

Figura 3-4: Ilustração de um tubo de corrente para a passagem do vento.............. 34

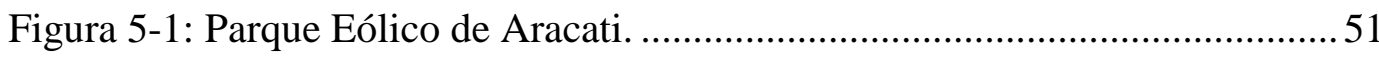

Figura 5-2: Séries históricas de pressão, temperatura, velocidade e direção do vento, respectivamente para o conjunto de dados ERAI (a) e NNRP (b). ....... 52

Figura 5-3: Histogramas das variáveis pressão, temperatura, velocidade e direção do vento, respectivamente para o conjunto de dados ERAI (a) e NNRP (b).

Figura 5-4: Autocorrelações simples das variáveis pressão (a), temperatura

(b), velocidade (c) e direção (d) do vento, do conjunto de dados ERAI.

Figura 5-5: Autocorrelações simples das variáveis pressão (a), temperatura

(b), velocidade (c) e direção (d) do vento, do conjunto de dados NNRP. .55

Figura 5-6: Rosa dos ventos para os conjuntos de dados ERAI (a) e NNRP (b)

Figura 5-7: Série histórica da velocidade do vento (a), projetada pela Lei Logarítmica (b) e projetada pela Lei da Potência (c), para o conjunto de dados ERAI.

Figura 5-8: Série histórica da velocidade do vento (a), projetada pela Lei Logarítmica (b) e projetada pela Lei da Potência (c), para o conjunto de dados NNRP.

Figura 5-9: Potência teórica calculada para uma fazenda eólica (24 turbinas), utilizando as fontes ERAI e NNRP.

Figura 5-10: Gráfico de dispersão entre potência teórica calculada e a velocidade para a fazenda eólica (24 turbinas) de Bons Ventos, utilizando as fontes ERAI (a) e NNRP (b). 
Figura 5-11: Série Histórica (a), Histograma (b) e Auto correlação simples (c) da geração eólica.

Figura 5-12: Gráfico de dispersão da potência calculada para a fazenda contra a Geração Eólica de Bons Ventos dos bancos de dados ERAI (a) e NNRP (b)....67

Figura 6-1: Histograma dos resíduos do modelo (6.1), considerando $\mathrm{D}=90^{\circ}$.....69

Figura 6-2: Autocorrelação simples dos resíduos do modelo (6.1), considerando $\mathrm{D}=90^{\circ}$.

Figura 6-3: Histogramas dos resíduos (a), gráfico de dispersão da geração eólica com os valores ajustados pelo modelo (b) e com os resíduos do modelo (c) e autocorrelação simples dos resíduos (d) do modelo (6.2) considerando $\mathrm{D}=90^{\circ}$.

Figura 6-4: Histogramas dos resíduos, gráfico de dispersão da geração eólica com os valores ajustados pelo modelo (b) e com os resíduos do modelo (c) e autocorrelação simples dos resíduos (d) do modelo (6.3), considerando $\mathrm{D}=90^{\circ}$

Figura 6-5: Histogramas dos resíduos, gráfico de dispersão da geração eólica com os valores ajustados pelo modelo (b) e com os resíduos do modelo (c) e autocorrelação simples dos resíduos (d) do modelo (6.4), considerando $\mathrm{D}=90^{\circ}$

Figura 6-6: MAE out-of-sample horário, diário, semanal e mensal para os modelos completo e stepwise das fazendas estudadas. .78

Figura 6-7: Pseudo $\mathrm{R}^{2}$ out-of-sample horário, diário, semanal e mensal para os modelos completo e stepwise das fazendas estudadas.

Figura 6-8: MAE out-of-sample horário, diário, semanal e mensal para os modelos completo e stepwise das fazendas estudadas, considerando os instantes onde a geração foi maior que 0

Figura 6-9: Pseudo $\mathrm{R}^{2}$ out-of-sample horário, diário, semanal e mensal para os modelos completo e stepwise das fazendas estudadas, considerando os instantes onde a geração foi maior que 0 


\section{1}

\section{Introdução}

Muitas vezes para suprir a demanda de energia no mundo, as indústrias optam por formas de obtenção questionáveis onde, não raramente, o meio ambiente sai prejudicado. Estas formas geralmente envolvem a produção de energia utilizando os recursos naturais não renováveis, tais como o petróleo e o gás natural, que ocasionam a emissão de gases poluentes na atmosfera, como o dióxido de carbono $\mathrm{CO}_{2}$. A concentração destes gases na atmosfera é responsável por danos à saúde dos seres vivos e pelo chamado efeito estufa que, por sua vez, produz o aumento da temperatura no planeta. Mesmo a energia nuclear, que constitui uma fonte eficaz para a produção de energia elétrica, produz uma séria poluição ambiental devido aos resíduos radioativos que precisam ser armazenados no fundo dos oceanos, outro risco para a saúde do planeta.

Em virtude das consequências danosas dos meios de produção de energia apresentados anteriormente, tem crescido o interesse no uso e desenvolvimento das chamadas fontes renováveis de energia. Estas fontes não poluem o meio ambiente e costumam ser relativamente mais baratas. As energias eólica, hídrica, solar e de biomassa são alguns exemplos de fontes de energia renováveis.

Uma fonte renovável que tem apresentado um considerável destaque nos últimos anos é a energia eólica. Esta fonte mostra-se eficaz na redução do impacto ambiental, além de possuir outras propriedades econômicas bastante relevantes. Outro importante aspecto da produção de energia eólica é a possibilidade de compartilhar a área destinada à construção dos parques eólicos, com atividades relacionadas a outros fins econômicos, tais como agricultura e pecuária [20].

Embora a energia obtida pela força dos ventos se apresente como uma excelente alternativa para a obtenção de energia elétrica, ela exige cuidados especiais para que sua implantação seja economicamente viável. Neste sentido, torna-se necessário um estudo profundo sobre a intensidade e comportamento espacial do vento na região onde se pretende construir um parque eólico.

Em algumas localidades existe um longo histórico das características do vento (velocidade, direção) sem, entretanto constar um histórico correspondente 
para a produção de energia eólica. Com isso em mente, tem-se o objetivo desta dissertação que é o de reconstrução da série histórica de geração eólica a partir de características do vento em determinadas localidades.

No Capítulo 2, serão apresentadas as características e o comportamento do vento pelo planeta e um breve histórico do desenvolvimento da energia eólica. Já no Capítulo 3, será mostrada a metodologia desenvolvida no estudo da produção eólica de uma região. No Capítulo 4, será apresentada a metodologia estatística envolvida na elaboração deste trabalho. Nos Capítulos 5 e 6, mostram-se os resultados obtidos com a utilização destes dados de velocidade para complementar o histórico da produção de energia eólica. O Capítulo 7 apresenta as conclusões deste trabalho, com sugestões para estudos futuros. 


\section{2}

\section{O vento e a energia eólica}

\section{1 \\ O vento}

O vento é o deslocamento do ar em torno da Terra. Este deslocamento ocorre de regiões de alta para baixa pressão atmosférica. Duas das principais causas da circulação atmosférica são o aquecimento diferenciado entre a linha do equador e os pólos terrestres e o movimento de rotação da Terra.

Devido à forma esférica da Terra, a radiação emitida pelo Sol ocorre de forma irregular, com algumas áreas do planeta tendo uma incidência maior desta radiação (linha do equador) em comparação com outras (os pólos terrestres). Essa irregularidade pode ser atribuída ao movimento de translação da Terra ao longo de sua órbita, associado com o seu movimento de rotação em torno de um eixo inclinado de $23,5^{\circ}$ em relação ao plano desta órbita. Outro fator que também ocasiona a irregularidade na emissão dos raios solares para a Terra pode ser atribuído a orientação com que estes são emitidos pelo Sol. Estes fatores, relacionados ao recebimento irregular do calor emitido pelo Sol, produz e contribui para a formação das correntes de ar na atmosfera terrestre.

O aquecimento diferenciado entre a linha do equador e os pólos associado ao relevo terrestre cria mecanismos de produção dos ventos. Estes ventos planetários, chamados de continentais, são constantes e podem ser classificados em [1], [7]:

- Alísios: Ventos predominantes em baixas altitudes, que geralmente se originam nos trópicos e se movimentam em direção ao equador. Estes também se caracterizam por serem úmidos que, muitas vezes, produzem chuvas nas regiões que atravessam;

- Contra-alísios: Ventos predominantes em altas altitudes, que se originam no equador e caminham em direção aos pólos. Estes se caracterizam pela baixa umidade, ocorrendo nas regiões desérticas; 
- Ventos de oeste: Ventos que se orientam da direção dos trópicos aos pólos terrestres;

- Polares: ventos que se movimentam dos pólos com destino às zonas temperadas, sendo geralmente de ar frio.

Além dos ventos continentais, existem também os ventos cujos ciclos são diários. Neste caso, podem ser incluídas as brisas produzidas do oceano para o continente. Durante o dia, a capacidade de refletir o calor é maior na faixa de terra, ocasionando o aumento de temperatura do ar em relação ao mar. Associado a este aumento de temperatura, tem-se a diminuição da pressão continental em relação ao mar, produzindo uma corrente de ar que se movimenta do mar para a terra.

Com o cair da noite, tem-se o fenômeno oposto. A temperatura da terra cai bruscamente e se torna mais baixa que a temperatura do mar, ocasionando o trajeto da brisa que se desloca da terra para o mar. Também existem outros tipos de ventos, cuja periodicidade não é diária. Um exemplo que pode ser citado são as monções que ocorrem no Sudeste Asiático e ocasionam fortes tempestades a cada seis meses.

Não é só a temperatura que influencia de forma direta o regime dos ventos de uma determinada região. Existem outros fatores que podem influenciá-lo, tais como: altitude, rugosidade do terreno, orografia e o relevo de determinadas regiões do planeta.

\section{2}

\section{A energia eólica}

Nas próximas seções serão apresentadas a evolução da energia eólica, desde a sua primeira utilização no oriente até o grande desenvolvimento dos aerogeradores e das turbinas eólicas nos dias de hoje. 


\subsection{1}

\section{Histórico da energia eólica}

O primeiro registro da utilização da energia eólica provém do uso dos cataventos para diminuir o esforço humano em tarefas como a moagem de grãos na Pérsia no ano de 500 A.C.. A utilização de cata-ventos se difundiu pelo oriente, atingindo localizações como a China por volta de 200 A.C. [24].

Após o declínio das Cruzadas na Europa por volta do século XIII, o uso dos cata-ventos se alastrou pelo território europeu, chegando aos territórios da Inglaterra, França e Holanda. A utilização destes cata-ventos/moinhos do vento associado aos avanços no sistema de controle e eixo destes dispositivos proporcionou à economia agrícola européia daquela época um grande desenvolvimento [6].

Com o inicio da Primeira Revolução Industrial, os cata-ventos perderam sua importância econômica, sendo a energia eólica substituída pela energia obtida pelas máquinas a vapor. Todavia, os cata-ventos não foram extintos e permanecem utilizados até os dias de hoje, sendo encontrados principalmente no meio rural onde, devido ao seu fácil manuseio e manutenção, são utilizados no bombeamento de água.

O uso da energia elétrica de origem eólica só se fez presente no continente americano em meados/final do século XIX, quando o americano Charles F. Brunch, em virtude do desenvolvimento da rede elétrica, construiu na cidade de Cleveland o primeiro cata-vento [8], [24]. Esta primeira turbina apresentava a configuração de 144 pás de madeira, contando com 17 metros de diâmetro e uma carga de $12 \mathrm{~kW}$, que era armazenada em baterias. Tal cata-vento permaneceu em funcionamento por mais de vinte anos. A construção desta turbina marca o prelúdio para a geração das grandes turbinas eólicas e, por conseguinte, das fazendas eólicas que estão sendo desenvolvidas nos dias de hoje [6].

Com o desencadeamento da II Guerra Mundial (1939 - 1945), as nações envolvidas tentavam cada vez mais desenvolver novas formas para a produção de energia elétrica, incentivando assim as pesquisas com este objetivo. Na realidade, tal desenvolvimento foi fortemente motivado pelo intuito de economizar combustíveis fósseis, então prioritariamente destinados aos objetivos bélicos. 
Com isso, diversas nações do leste europeu se envolveram cada vez mais no desenvolvimento de energia eólica por meio de aerogeradores. Dentre elas, tem-se Dinamarca, França e Alemanha. Das três nações mencionadas, a Dinamarca foi a que mais teve sucesso. Para isto, contribuiu o fato de seu território estar localizado em uma região pobre em recursos naturais, tornando-a fortemente dependente das fontes climáticas para a obtenção de energia.

Todavia, após a guerra a energia eólica voltou a sofrer mais um período de desinteresse pelas nações, uma vez que, as fontes de energia não-renováveis voltaram a ser utilizadas com maior intensidade. Com isso, o estudo e o desenvolvimento das fontes de energia eólica subsistiram apenas no âmbito das pesquisas.

Tal desinteresse continuou até a primeira crise do petróleo (1973), quando os governos de diversos países enfrentaram a difícil tarefa de desenvolver novas fontes de energia, para com isso depender cada vez menos desse tipo de recurso. Esta crise foi desencadeada pelo súbito aumento dos preços dos barris de petróleo pelas nações do Oriente Médio, detentoras em seu território da maior quantidade deste recurso no planeta.

Com a busca e o desenvolvimento das fontes alternativas, a energia eólica teve um novo impulso em sua utilização e criação para a obtenção da eletricidade. No entanto, a dependência em relação ao petróleo e ao carvão mineral continua intensa nos dias atuais, a despeito de seus malefícios ao meio ambiente e à saúde humana e o seu inevitável esgotamento futuro.

Uma das principais resoluções da Conferência de Kyoto, realizada no Japão no ano de 1997, foi a redução da emissão de dióxido de carbono na atmosfera, proveniente da queima de combustíveis fósseis. Pressionados por estes acordos então estabelecidos, vários países incentivaram o desenvolvimento das energias alternativas, em particular, da energia eólica.

\section{3}

\section{Energia Eólica atualmente}

Como já mencionado anteriormente, o fato de ser uma fonte de energia limpa e barata é responsável pelo desenvolvimento e uso da energia eólica nos dias atuais. Neste sentido, o crescimento da capacidade eólica mundial aumentou 
nos últimos anos, saindo de um patamar de 196630 MW no final de 2010 para 254000 MW no primeiro semestre de 2012, vide Figura 2-1, [27], [28].

Outro aspecto que demonstra o avanço da energia eólica é a nova capacidade instalada. A mesma tendência de aumento se observa com esta capacidade, como se pode observar pela Figura 2-2, [27], [28].

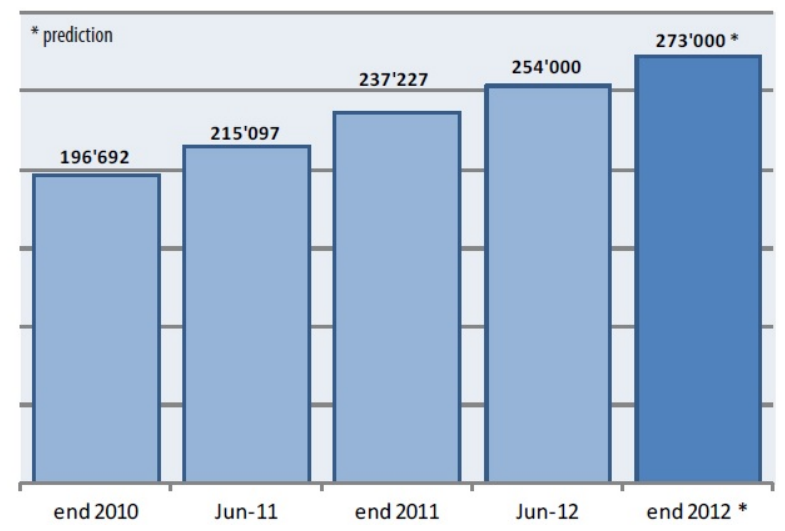

Figura 2-1: Capacidade de energia eólica total instalada no mundo (MW) e uma previsão para o segundo semestre de 2012.

Fonte: WWEA (2012).

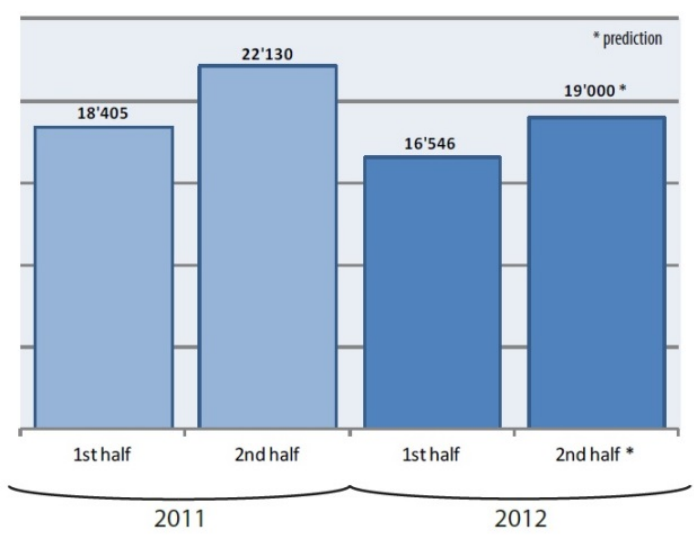

Figura 2-2: Nova capacidade eólica até a primeira metade de 2012 e uma previsão para o segundo semestre.

Fonte: WWEA (2012). 


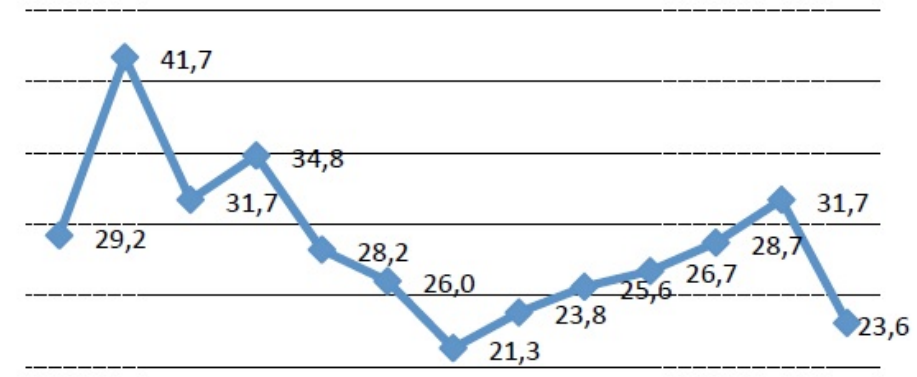

1998199920002001200220032004200520062007200820092010

Figura 2-3: Taxa de crescimento do mercado mundial (\%). Fonte: WWEA (2011).

Uma comprovação do crescimento do interesse no aproveitamento da energia eólica é o caso da China que se tornou nos últimos anos líder na geração de energia eólica. Durante o ano de 2010, após adicionar cerca de 18928 MW de capacidade instalada em seu território passou a deter mais da metade da capacidade mundial da produção de energia eólica, fazendo com quem o Estados Unidos perdesse sua posição de líder [27].

Pela Figura 2-3, tem-se a taxa de crescimento mundial da produção de energia eólica, onde esta é obtida pela relação entre a nova capacidade instalada e a capacidade instalada no período anterior. Observa-se que o ano de 2010 teve a segundo maior queda da taxa de crescimento do mercado mundial, podendo ser explicada pela falta de interesse do governo de alguns países [27].

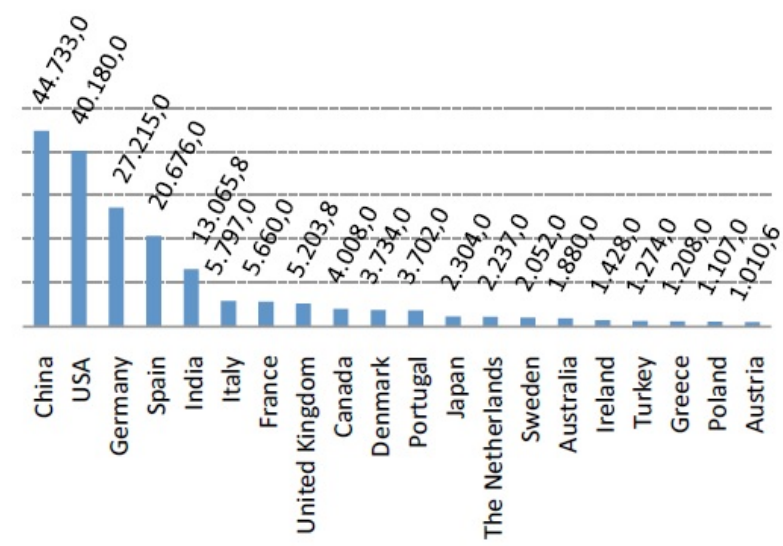

Figura 2-4: Países com as maiores capacidades instaladas (MW). Fonte: WWEA (2011). 
Embora a China tenha se destacado cada vez mais na produção eólica, esta parece sofrer uma desaceleração nos últimos dois anos, principalmente até junho de 2012. Naquele ano, esta nação foi responsável por 32\% do mercado de energia eólica mundial, enquanto que no ano anterior, tinha sido responsável por 43\%, [28].

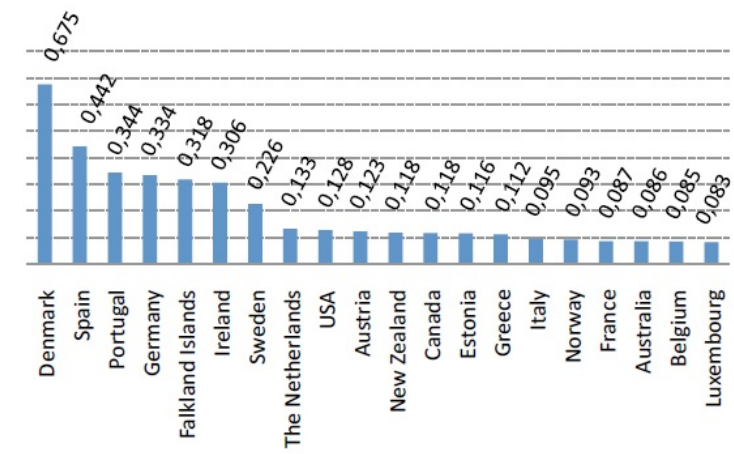

Figura 2-5: Capacidade eólica per capita. Fonte: WWEA (2011).

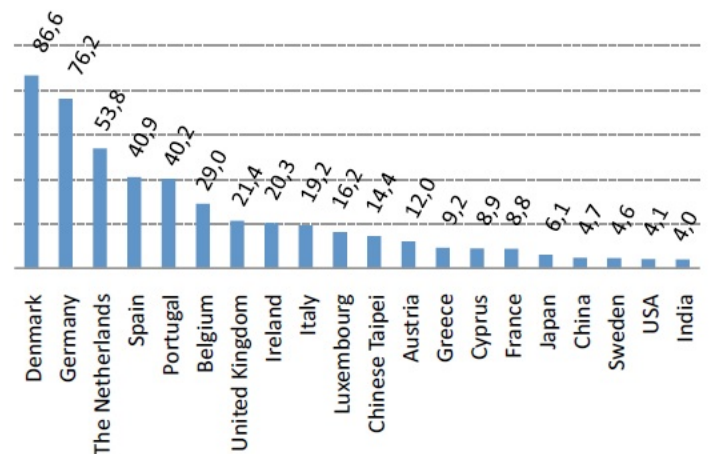

Figura 2-6: Capacidade eólica por área $\left(\mathrm{KW} / \mathrm{km}^{2}\right)$. Fonte: WWEA (2011).

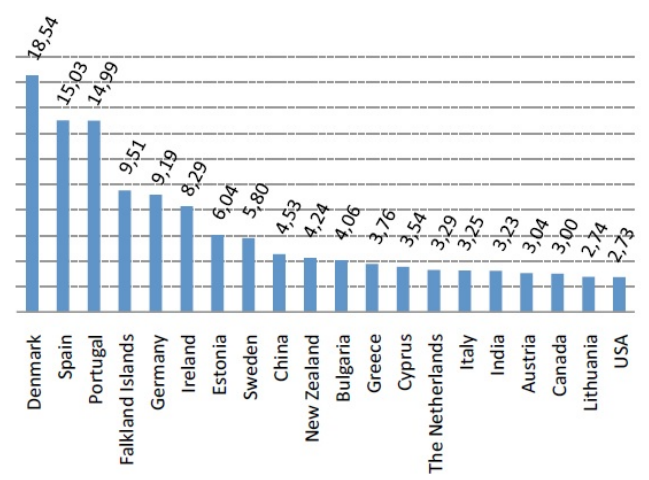

Figura 2-7: Capacidade eólica por PIB (KW/milhões U\$). Fonte: WWEA (2011). 


\section{4}

\section{Potencial Eólico Brasileiro}

Ceará. Os resultados obtidos com eles foram impressionantes e impulsionaram a sua instalação para outros estados, principalmente aqueles pertencentes ao Nordeste brasileiro. Com esta instalação no Nordeste, verificou-se que os ventos que passavam por esta região possuíam uma velocidade alta, quase não alterando a sua direção e a sua intensidade.

Outro fator que pode ser levado em consideração no que diz respeito à matriz energética brasileira é a complementariedade entre a energia eólica e a energia oriunda das hidrelétricas. Esta relação tende a ser benéfica para a produção de energia elétrica, uma vez que no período onde a produção de energia eólica tende a ser amplificada pela maior frequência de ventos coincide com a época na qual as hidrelétricas tendem a reduzir a sua produção devido a escassez de água produzida pelas secas.

Tendo em vista a redução de sua dependência em relação ao carvão mineral e ao petróleo e ao sucesso obtido com a produção de energia limpa, o Brasil criou o Programa de Incentivo às Fontes Alternativas de Energia Elétrica (Proinfa). Com isto, o país se dedicou à produção de energia elétrica através de fontes renováveis tais como a biomassa, eólica e solar, assim como a criação de pequenas centrais hidrelétricas (PCH) [8].

A despeito dos benefícios deste tipo de energia, tais como a redução do efeito estufa e a criação de empregos para a população, o Brasil ainda vive um desafio em relação ao seu custo de produção, com o preço por Megawatt-hora (MWh) sendo da ordem de $\mathrm{R} \$ 190,00$ [9]. No entanto ainda estima-se que a geração de energia eólica irá crescer muito nos próximos anos, alcançando uma capacidade instalada de 7.000 MW até 2014 [23]. Todavia, considerando o potencial eólico brasileiro, esta expectativa ainda se apresenta muito modesta, correspondendo a apenas $0,24 \%$ da capacidade instalada decorrente de 15 empreendimentos em operação, em 2011. Até este momento tem-se 77 em operação.

Ao lado de tantas vantagens a respeito da energia eólica, existem também impactos socioambientais atribuídos à construção das grandes turbinas, principalmente quando estas estão localizadas perto de áreas urbanizadas ou com 
um aglomerado de casas. O primeiro aspecto negativo está ligado ao ruído produzido pelas turbinas, que tende a ser muito elevado. Assim sendo, para evitar problemas com a população, este nível de ruído tem de obedecer a certas normas estabelecidas [3]. Outros dois aspectos negativos em relação à construção de turbinas eólicas estão ligados ao seu impacto visual e às interferências eletromagnéticas produzidas nos sistemas de comunicação. No caso do aspecto visual, ele se torna mais evidente para as fazendas eólicas, variando de acordo com o tipo de instalação, o posicionamento das turbinas. 


\section{3}

\section{Conceitos básicos sobre a Energia Eólica}

Como mencionado, o vento é basicamente uma massa de ar em movimento. Esse movimento é influenciado por diversos fatores ambientais, tais como a temperatura e consequentemente a pressão do ar. A umidade e a densidade do ar, bem como o próprio relevo terrestre (montanhas e vales), por exemplo, são outros fatores que podem influenciar o vento.

O vento é o responsável pela energia eólica e consequentemente pela energia elétrica produzida. A energia eólica é decorrente do trabalho realizado pela energia cinética das moléculas contidas em uma massa de ar, que ao passarem pelos aerogeradores produzem a energia elétrica. No entanto, apenas uma fração da energia de movimento das moléculas de ar é convertida em energia eólica. Esta perda é resultante da conjunção de vários fatores tais como dissipação por atrito, inelasticidade das colisões moleculares com as hélices, dissipação térmica por efeito Joule, etc. Assim sendo, é estabelecido um limite máximo para a extração de energia eólica por cada aerogerador. Este limite é conhecido como Limite de Betz, e assume o valor de 59\%.

\section{1}

\section{Turbinas ou aerogeradores}

As turbinas ou aerogeradores são constituídas de uma torre de grande altitude, cujo painel de controle se encontra no topo. Em vista dos grandes avanços tecnológicos alcançados nas últimas décadas, estas turbinas evoluíram muito no sentido de melhorar o seu desempenho. As turbinas são diferenciadas em relação ao posicionamento de seu eixo, que pode ser vertical ou horizontal. 


\subsection{1}

\section{Turbinas de eixo vertical}

Em geral, as turbinas de eixo vertical são menos utilizadas na geração de energia eólica, uma vez que elas possuem menor produtividade em relação às de eixo horizontal. Contudo, o fato delas não precisarem ser posicionadas para a direção onde o vento sopra com maior frequência representa um aspecto vantajoso.

Entretanto, existem vários fatores desvantajosos. O principal deles é a sua baixa velocidade de rotação devido a sua grande massa e estrutura pesada, o que faz com que o torque seja significativamente mais alto. Além desta podem ser citadas como desvantagens o coeficiente de potência baixo e a rotação de $360^{\circ}$ do aerofólio.

As turbinas de eixo vertical são classificadas em:

- Darrieus;

- Savonius;

- Gorlov;

- Giromill;

\section{1 .2}

\section{Turbinas de Eixo Horizontal}

As turbinas de eixo horizontal são as mais empregadas nos dias de hoje. Isto porque estas tendem a produzir mais energia e um maior aproveitamento do vento incidente.

No topo de suas torres está instalado um rotor e um gerador elétrico, posicionados na direção do vento incidente. Algumas, mais desenvolvidas, possuem um mecanismo, com o qual é ajustada a rotação das lâminas, de acordo com a demanda de produção de energia. As turbinas utilizadas em fazendas eólicas geralmente possuem três pás, alta eficiência e baixo torque, o que aumenta a confiabilidade em seu uso e desempenho. 


\section{2}

\section{Uso dos dados históricos dos ventos}

Esta seção discutirá as diferentes fórmulas e seu uso na análise do vento de e de suas propriedades em uma região.

\subsection{1}

\section{Densidade do ar}

A densidade do ar é um fator que influencia diretamente o vento. No entanto, muitas vezes a sua medida não é conhecida. Contudo, existe uma maneira de estimá-la a partir dos dados de temperatura e pressão do ar em uma determinada região. Para isto, se utiliza a seguinte expressão [11]:

$$
\rho=\frac{P}{R T}
$$

onde:

P é pressão atmosférica (em unidades de Pascal ou Newtons $/ \mathrm{m}^{2}$ );

R é a constante de gás especifica (287 J/kgKelvin);

T é a temperatura do ar em graus Kelvin;

e sendo $\rho$ obtido em $\mathrm{kg} / \mathrm{m}^{3}$.

\section{2 .2}

\section{Altitude}

A altitude é outro importante fator que pode influenciar a velocidade do ar, pois sabe-se que a medida que nos afastamos do nível do mar, o ar tende a ficar mais rarefeito, ocasionando a diminuição tanto da pressão atmosférica, quanto da densidade do ar e da temperatura. Considerando estes aspectos, as instalações de fazendas eólicas são feitas em áreas de baixas altitudes e com temperaturas mais 
baixas. Outro fator interessante a respeito da altitude, é que esta exerce maior influencia sobre a densidade do ar, do que a temperatura, Jha (2011) [15].

\subsection{3}

\section{Terreno e rugosidade}

Quando se faz um estudo do vento em uma determinada região a fim de verificar se esta pode ser aproveitada ou não para a construção de usinas eólicas, é instalado um anemômetro (instrumento que mede a velocidade do vento). No entanto, quando este é implantado para coletar tais observações, em geral, o mesmo não é posicionado na mesma altitude da turbina que será/foi instalada. Com isto, é necessário que seja utilizado um fator de correção nos dados de velocidade levando em conta esta diferença de altitude.

Os fatores ambientais, chamados de rugosidade superficial $\left(\mathrm{z}_{0}\right)$, também alteram o perfil da velocidade do vento com a altitude de uma determinada região. Existem valores de referência para a rugosidade superficial de acordo com o tipo de terreno estudado. Tais valores podem ser visualizados pela Tabela 3-1.

Tabela 3-1: Rugosidade superficial de acordo com o tipo de terreno.

\begin{tabular}{cc}
\hline Terreno & $\begin{array}{c}\text { Rugosidade } \\
(\mathrm{mm})\end{array}$ \\
Gelo & 0,01 \\
Mar Calmo & 0,2 \\
Mar Agitado & 0,5 \\
Neve & 3 \\
Grama Baixa & 8 \\
Pasto & 10 \\
Campo & 30 \\
Plantações & 50 \\
Poucas árvores & 100 \\
Muitas árvores, algumas construções & 250 \\
Florestas & 500 \\
Subúrbios & 1500 \\
Cidades & 3000 \\
\hline
\end{tabular}

Fonte: [8] 


\section{- Lei Logarítmica}

Para fazer a mudança da velocidade de vento em relação a duas altitudes diferentes, existem duas formas básicas: a Lei Logarítmica e a Lei da Potência. A Lei Logarítmica é fornecida pela relação abaixo [5]:

$$
\frac{v(h)}{v_{r e f}}=\frac{\ln \left(\frac{h}{z_{0}}\right)}{\ln \left(\frac{h_{r e f}}{z_{0}}\right)}
$$

onde $v_{\text {ref }}$ é a velocidade do vento na altura tomada como referência;

$h_{r e f}$ é a altura de interesse, ou seja, onde se tem medida a velocidade;

$z_{0}$ é a rugosidade superficial.

$v(h)$ e $h$ são as velocidade e altura, respectivamente onde se quer obter a velocidade.

\section{- Lei da Potência}

Outra forma de cálculo para a velocidade em altitudes diferentes é a Lei da Potência, que é obtida pela relação [5]:

$$
v(h)=v_{\text {ref }}\left(\frac{h}{h_{r e f}}\right)^{\alpha}
$$

onde os fatores $v_{\text {ref }}$ e $h_{\text {ref }}$ são definidos acima.

Por sua vez, o expoente $\alpha$, conhecido com expoente de Hellman, está intimamente ligado à rugosidade e ao terreno onde se quer avaliar a velocidade. Este expoente pode ser calculado através da fórmula abaixo [8]:

$$
\alpha=0,096 \log _{10}\left(z_{0}\right)+0,016\left[\log _{10}\left(z_{0}\right)\right]^{2}+0,24
$$

Existe outra expressão menos utilizada para o cálculo do expoente $\alpha$, dada por

$$
\alpha=\frac{0,37-0,088 \ln V\left(h_{r e f}\right)}{1-0,0088 \ln \left(\frac{h_{r e f}}{10}\right)}
$$


na qual são considerados os dados da velocidade e da altitude.

\subsection{4}

\section{Distribuição Weibull}

Esta distribuição foi inicialmente desenvolvida por Waloddi Weibull para a estimativa do tempo de vida de certos materiais. Contudo ao longo dos anos ela tem se mostrado útil para ajustar a velocidade de vento na previsão do tempo.

A distribuição de Weibull possui originalmente três parâmetros que são: o parâmetro de forma $(k)$, o parâmetro de escala $(c)$ e o parâmetro de localização $\left(V_{0}\right)$, e que estão relacionados através da seguinte densidade de distribuição

$$
f(V)=\left(\frac{k}{c}\right)\left(\frac{V-V_{0}}{c}\right)^{k-1} \exp \left[-\left(\frac{V-V_{0}}{c}\right)^{k}\right]
$$

No entanto, devido a sua pouca importância, este último parâmetro $\left(V_{0}\right)$ não é comumente estimado. Os estudos geralmente atribuem a ele o valor zero na distribuição Weibull, mantendo apenas os dois parâmetros restantes [8]. Com isto em mente, a densidade obtida segundo esta distribuição possui a seguinte forma:

$$
f(V)=\left(\frac{k}{c}\right)\left(\frac{V}{c}\right)^{k-1} \exp \left[-\left(\frac{V}{c}\right)^{k}\right]
$$

O parâmetro ( $k$ ) é conhecido como parâmetro de forma e esta relacionado ao comportamento da velocidade do vento. Assim sendo, se este parâmetro possui um valor muito alto, pode-se dizer que a velocidade do vento na localidade estudada tende a variar muito, sofrendo altas oscilações, que podem estar relacionadas com os fatores ambientais (relevo). Já se o seu valor for baixo, podese chegar a conclusão que a velocidade do vento na localidade tende a ser estável. Em geral, o valor deste parâmetro tende a variar entre 1,5 e 3. No entanto, nada impede que possa ser atribuído a ele um valor mais alto. O parâmetro (c), denominado parâmetro de escala, é característico da distribuição, possuindo a mesma unidade da grandeza avaliada (vento). 
A estimativa destes parâmetros está intimamente ligada à velocidade do vento, a partir das relações a seguir [8]. Tal estimativa é conseguida pelo Método dos Momentos.

$$
\begin{aligned}
& \frac{\overline{V^{3}}}{\overline{\bar{V}}^{3}}=\frac{\Gamma\left(1+\frac{3}{k}\right)}{\left(\Gamma\left(1+\frac{1}{k}\right)\right)^{3}} \\
& \bar{V}=c \Gamma\left(1+\frac{1}{k}\right)
\end{aligned}
$$

Pode se observar destas relações que é necessária a estimativa do parâmetro $(k)$, para que a determinação do parâmetro (c) se torne possível.

\section{3}

\section{Potência das turbinas}

Esta seção irá mostrar os principais elementos de caracterização da potência gerada por um aerogerador, desde o mecanismo envolvendo a transformação da energia cinética das moléculas de ar ao cálculo do valor do coeficiente de potência máximo.

\subsection{1}

\section{Curva de Potência}

Um instrumento muito relevante na avaliação da capacidade de produção de energia eólica é o uso da curva de potência, que relaciona a potência produzida com a velocidade do vento, de acordo com o tipo de turbina que foi utilizada. Um exemplo esquemático deste gráfico pode ser visualizado pela Figura 3-1. 


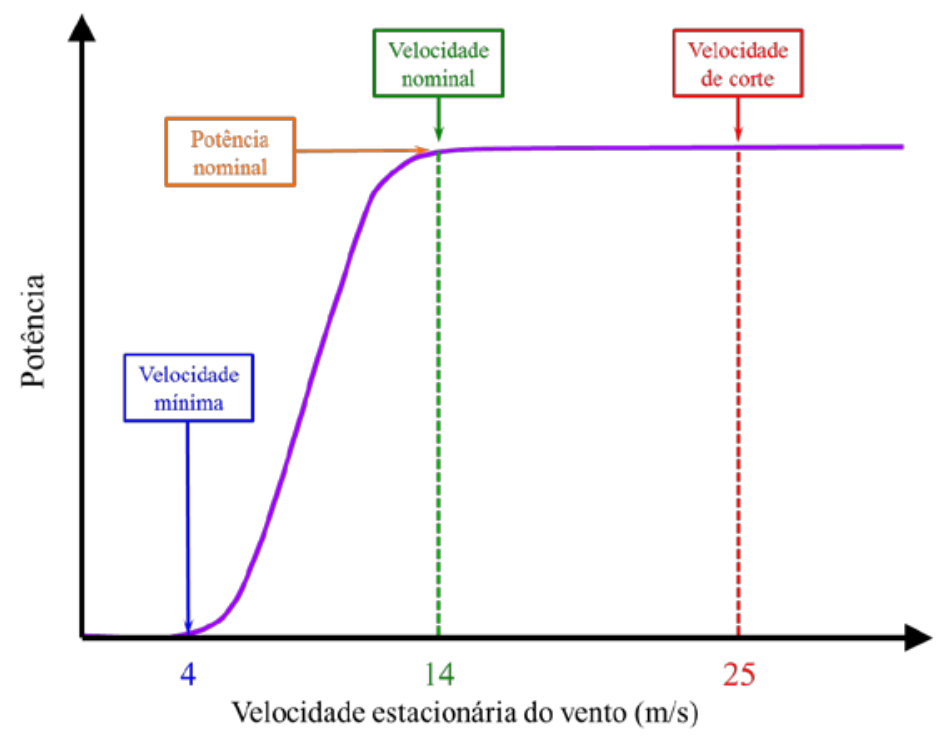

Figura 3-1: llustração de uma curva de potência.

Deste gráfico pode ser feita uma série de observações a respeito da velocidade do vento em relação à potência produzida. A velocidade pode ser dividida em três grandes blocos:

Velocidade mínima: Ventos com velocidades muito baixas não produzem torque suficiente para colocar as pás das turbinas em rotação. Só com o aumento da velocidade, a turbina começa a girar e produzir energia elétrica. A velocidade limiar para colocar as pás da turbina em rotação é chamada de velocidade mínima e o seu valor tipicamente deve estar entre 3 e $4 \mathrm{~m} / \mathrm{s}$.

Velocidade nominal ou potência nominal: Com o aumento da velocidade do vento acima de seu valor mínimo, o nível de saída de potência elétrica aumenta rapidamente, como pode ser visto. No entanto, tipicamente entre 12 e $17 \mathrm{~m} / \mathrm{s}$, a potência atinge um limite superior que o gerador eletrico é capaz de produzir. Este limite para a saída do gerador é chamado de potência nominal e a velocidade do vento no qual este é alcançado é chamado de velocidade nominal. Em velocidades do vento muito altas, o design da turbina é feito de forma a limitar a potencia a este nivel máximo. Como isto é feito varia de design à design, mas tipicamente para turbinas muito grandes, ajusta-se as lâminas de forma a manter a potência em nivel constante. 
Velocidade de corte: Conforme a velocidade do vento aumenta acima da velocidade nominal, as forças na estrutura da turbina continuam a crescer e, em algum instante, existe um risco de dano ao rotor. Como resultado, um sistema de freiagem é empregado para colocar o rotor em um estado de paralisação. Isto é chamado de velocidade de corte, cujo valor é geralmente de 25 m/s.

\subsection{2}

\section{Potência teórica do ar}

Seja uma coluna cilíndrica de ar definida por uma área transversa $A$ e uma altura $h=v t$ sendo $v$ a velocidade média com que as moléculas de ar se movimentam e $t$ um dado intervalo de tempo tomado para a avaliação da potência associada à energia de movimento do ar.

Tendo em vista que cada molécula de ar possui uma energia cinética $E_{c}=\frac{1}{2} m v^{2}$ sendo $m$ a massa da molécula, então a energia cinética total associada às $\Delta N$ moléculas contidas na coluna cilíndrica será dada por

$$
\Delta E_{T}=\Delta N E_{c}=\frac{1}{2} \Delta N m v^{2}
$$

Neste ponto pode-se observar que, se a densidade de moléculas de ar, assumida como constante, for dada por

$$
n=\frac{d N}{d V}=\frac{\Delta N}{\Delta V}=\text { cte }
$$




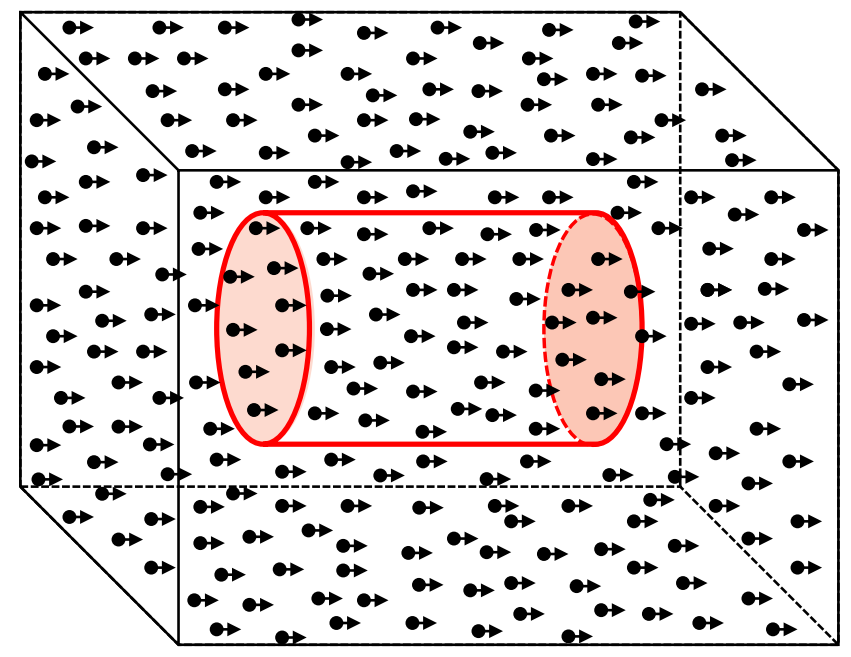

Figura 3-2: Ilustração das moléculas de ar em movimento.

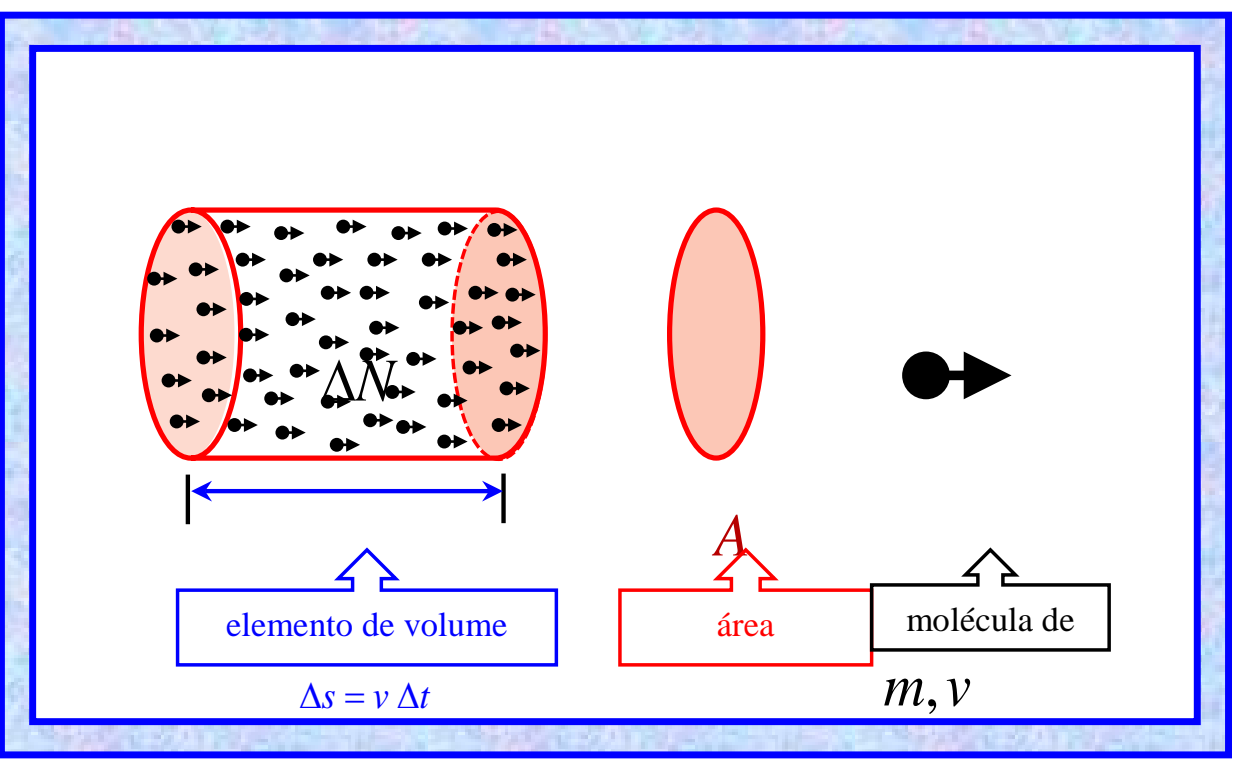

Figura 3-3: Ilustração das moléculas de ar atravessando a área transversa da turbina do aerogerador.

então tem-se que

$$
\Delta N=n \Delta V=n A v \Delta t
$$

pois o volume da coluna cilíndrica de ar é fornecido por $\Delta V=A \Delta s=A v \Delta t$. Nestas condições, ao usar a equação (3.12) na expressão (3.10) para a energia cinética total, mostra-se que

$$
\Delta E_{T}=\frac{1}{2} n m A v^{3} \Delta t .
$$


Contudo, deve-se observar que a densidade volumétrica de massa $\rho$ do ar contido na coluna é dada por

$$
\rho=\frac{\Delta M}{\Delta V}=\frac{\Delta(N m)}{\Delta V}=m \frac{\Delta N}{\Delta V}=n m
$$

de modo que, ao usar este resultado na equação (3.13), pode-se obter a relação final

$$
\Delta E_{T}=\frac{1}{2} \rho A v^{3} \Delta t
$$

Para encontrar a potência média associada ao movimento do ar basta tomar a taxa de variação temporal da equação (3.15) para a energia cinética e assim concluir-se que

$$
P_{a r}=\frac{\Delta E_{T}}{\Delta t}=\frac{1}{2} \rho A v^{3}
$$

Este resultado pode ser expresso em função do raio $r$ da hélice da turbina (raio de varredura do rotor) [10]:

$$
P_{a r}=\frac{1}{2} \rho v^{3} \pi r^{2}
$$

\subsection{3}

\section{Rendimento de Betz}

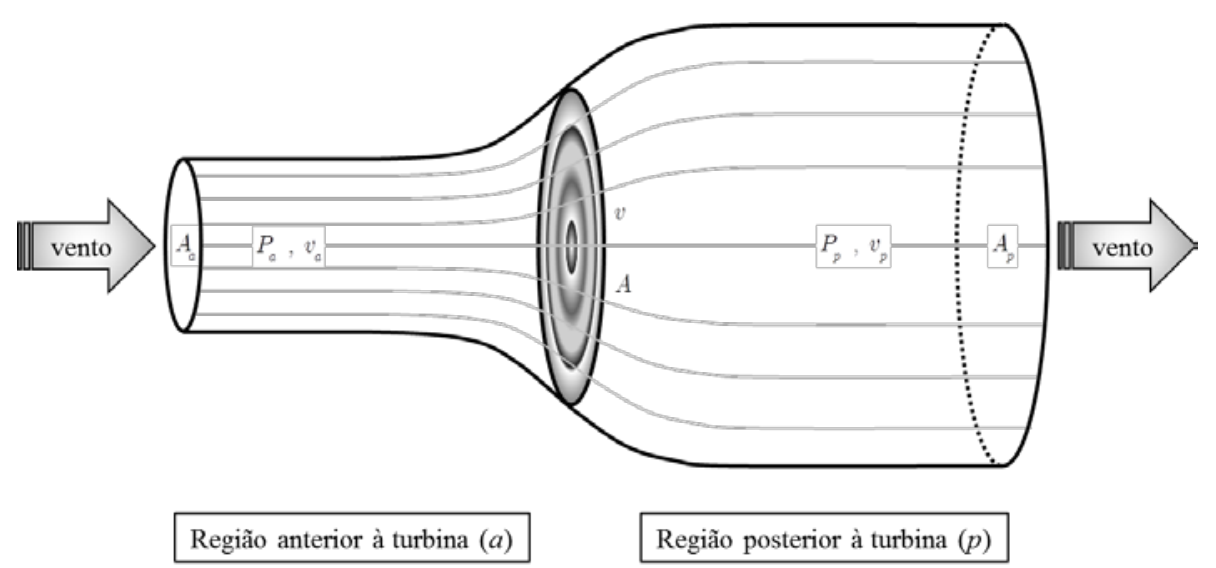

Figura 3-4: Ilustração de um tubo de corrente para a passagem do vento. 
A presença de uma turbina eólica reduz a velocidade efetiva do vento, agindo assim como um instrumento travador. O resultado disso é um aproveitamento menor da energia de movimento do ar em sua conversão como energia de rotação da turbina e, por conseguinte, na produção de energia elétrica.

É possível determinar um limite superior para o aproveitamento da energia eólica como energia mecânica da turbina partindo de uma modelagem em que o ar em movimento seja tratado como um fluido ideal. Para tanto considere-se um trecho de um tubo de corrente em que as suas partes anterior $(a)$ e posterior $(p)$ sejam separadas pela região em que se encontram as pás da turbina. Assumindo que o ar escoe pelo tubo em regime estacionário e levando em conta a conservação da massa tem-se que a massa de ar que flui com o tempo através de qualquer seção do tubo terá o mesmo valor, ou seja,

$$
\frac{d m}{d t}=\frac{d m_{a}}{d t}=\frac{d m_{p}}{d t} \Rightarrow \rho A v=\rho A_{a} v_{a}=\rho A_{p} v_{p}
$$

onde $A, A_{a}$ e $A_{p}$ são as áreas das seções transversais da turbina e dos trechos anterior e posterior a ela no tubo de corrente, respectivamente. As condições de escoamento estacionário e conservação da massa implicam que a velocidade do ar nas três regiões deve satisfazer à relação $v_{a}>v>v_{p}$. A mudança na velocidade do ar na passagem pela região da turbina resulta em um efeito dinâmico que altera a sua pressão a qual, levando em conta esta abordagem idealizada, pode ser avaliada através da equação de Bernoulli que, neste caso, implica em ter

$$
\frac{1}{2} \rho v_{a}^{2}+\rho g y_{a}+P_{a}=\frac{1}{2} \rho v_{p}^{2}+\rho g y_{p}+P_{p}
$$

onde $g$ é a aceleração local da gravidade e $y$ é a altura de cada trecho do tubo de corrente em relação ao solo. Neste ponto, considerando as dimensões reduzidas do tubo de corrente em relação à altitude da turbina, pode-se desprezar a variação de altura em cada trecho do tubo e assumir que $y_{a}=y_{p}$ para com isso concluir que

$$
P_{p}-P_{a}=\frac{1}{2} \rho\left(v_{a}^{2}-v_{p}^{2}\right)
$$


Esta diferença de pressão produz uma força sobre as pás da turbina que é dada por

$$
F_{T}=\left(P_{p}-P_{a}\right) A=\frac{1}{2} \rho A\left(v_{a}^{2}-v_{p}^{2}\right)
$$

donde resulta para a potência do vento transferida para a turbina a expressão

$$
P_{T}=v F_{T}=\frac{1}{2} \rho A v\left(v_{a}^{2}-v_{p}^{2}\right)
$$

Outra maneira de avaliar a força resultante sobre as pás da turbina é através da variação do momento linear $p=m v$ do ar em sua passagem por ela, neste caso dada por

$$
F_{T}=F_{a}-F_{p}=\frac{d p_{a}}{d t}-\frac{d p_{p}}{d t} \Rightarrow F_{T}=\left(\frac{d m_{a}}{d t}\right) v_{a}-\left(\frac{d m_{p}}{d t}\right) v_{p}
$$

ou seja,

$$
F_{T}=\rho A v\left(v_{a}-v_{p}\right)
$$

onde levou-se em conta a conservação da massa através do uso da primeira equação. Nestas condições a potência do vento transferida para a turbina será fornecida por

$$
P_{T}=v F_{T}=\rho A v^{2}\left(v_{a}-v_{p}\right)
$$

Como as duas expressões obtidas para a potência do vento transferida para a turbina devem levar ao mesmo resultado, ao compará-las pode-se concluir que a velocidade do vento nas pás da turbina deve ser dada pela expressão

$$
v=\frac{1}{2}\left(v_{a}+v_{p}\right)
$$

que corresponde à média aritmética de seus valores antes e após passar pela turbina.

Introduzindo, neste ponto, o coeficiente de velocidade induzida (a), que representa a fração da velocidade do vento incidente que não atua nas pás da turbina, através da expressão

$$
a=\frac{v_{a}-v}{v_{a}}
$$

pode-se escrever as duas outras velocidades envolvidas nesta avaliação como 


$$
v=(1-a) v_{a} \quad \text { e } \quad v_{p}=(1-2 a) v_{a}
$$

Portanto, levando estas relações na expressão da potência obtida acima, encontrase que

$$
P_{T}=P_{a}\left[4 a(1-a)^{2}\right]
$$

sendo $P_{a}=\frac{1}{2} \rho A v_{a}^{3}$ a potência do vento incidente, como foi mostrado anteriormente. Nestas condições o coeficiente de potência da turbina, definido como $C_{P}=P_{T} / P_{a}$, será dado por

$$
C_{P}=4 a(1-a)^{2}
$$

e o seu valor máximo em termos do coeficiente $a$, dado por $a_{0}$ é obtido ao impor as condições

$$
\left[\frac{d C_{P}}{d a}\right]_{a_{\mathrm{o}}}=0 \quad \text { e } \quad\left[\frac{d^{2} C_{P}}{d a^{2}}\right]_{a_{o}}<0
$$

resultará em ter

$$
a_{\mathrm{o}}=\frac{1}{3} \quad \text { e } \quad C_{P}^{(\text {Betz })}=C_{P}\left(a_{\mathrm{o}}\right)=\frac{16}{27} \approx 0,59
$$

que é conhecido como limite de Betz para o aproveitamento da energia eólica por uma turbina. Portanto qualquer turbina eólica deve apresentar coeficiente de potência $C_{P}<0,59$. Este coeficiente também denominado Rendimento de Betz, foi obtido em 1919, por Albert Betz observando o comportamento do vento em hélices [2]. Geralmente, o valor do coeficiente de potência na prática, tende a apresentar valores entre 0,35 a 0,45, portanto abaixo do limite de Betz [2]. Algumas referências argumentam que os rotores das turbinas de vento tendem a alcançar os valores máximos destes coeficientes por volta de 0,25 a 0,45 [14]. No entanto, outras referências afirmam que as turbinas modernas operam com coeficientes por volta de 0,4 [15]. Considerando uma usina eólica, a potência gerada por ela será a soma das potências de todas as turbinas nela instaladas. 


\subsection{4}

\section{Densidade de energia eólica}

Outro item que diz respeito à energia eólica é a sua densidade média de energia eólica (DEE), fornecida pela expressão [10], [12]:

$$
D E E=\frac{1}{2} \frac{1}{n} \sum_{i=1}^{n} \rho_{j} V_{j}^{3}
$$

onde $n$ é o número de observações de velocidades do vento;

e $\rho_{j}$ e $V_{j}$ são as j-éssimas densidade e velocidade do vento;

Esta expressão tem certa relevância, no que diz respeito ao planejamento da construção de uma usina eólica. É importante verificar que quanto maior for esse valor, mais apropriado será para a região o desenvolvimento da energia eólica.

É possível classificar as regiões pelo valor do coeficiente DEE. Geralmente, nomeia-se como áreas suscetíveis a maior produção eólica as áreas onde a $D E E$ encontrada pertença a uma das classes entre 3 e 7 . Na classe 3 estão as áreas que apresentam $D E E$ entre $300-400 \mathrm{~W} / \mathrm{m}^{2}$ enquanto que na classe 7 , estão as áreas com $D E E$ entre $800-2000 \mathrm{~W} / \mathrm{m}^{2}$.

\section{4 \\ Revisão bibliográfica}

Nesta seção, será apresentada a revisão bibliográfica que foi estudada. Esta conta com uma descrição dos diversos artigos, livros e outras fontes que ajudaram na elaboração desta dissertação.

\subsection{1}

\section{Fontes que utilizaram diretamente a curva de potência}

Sabe-se que um dos maiores instrumentos utilizados no que se diz respeito à produção de energia eólica é a curva de potência. Sendo assim, será apresentado 
aqui uma seção de artigos e livros no qual a curva de potência tem, de alguma forma, se apresentado para a geração eólica, tanto considerando apenas uma turbina quanto considerando a produção de uma fazenda eólica.

A referência Kusiak [17] estuda diversos tipos de modelos envolvendo abordagens de data minning e computação evolucionária para estimar a produção eólica de uma fazenda. Este estuda esta metodologia em dados médios medidos a cada dez minutos de oitenta e nove turbinas (após ser feita uma limpeza nos dados), sendo este dividido em dois data-sets (um de treinamento e um de teste), a fim de verificar a acurácia do modelo final.

Ao se comparar as diferentes metodologias impostas, descobre-se que o algoritmo de k-ésimo vizinho mais próximo é o mais adequado, pois foi o que apresentou medidas de erro (erro absoluto médio e desvio padrão absoluto) menores que as outras metodologias. A seguir, foi feita uma análise de componentes principais com o objetivo de reduzir a dimensionalidade do banco de dados. Verificou-se que apenas uma componente seria suficiente para estes dados.

No entanto, este modelo apresentou resultados insuficientes quando as condições de vento medidas pela turbina tendem a se diferenciar muito. Após uma limpeza criteriosa nos dados originais um algoritmo de computação evolucionária foi implementado para a obtenção de um modelo paramétrico não-linear, com este filtrando observações ruidosas pelos painéis de controle. O modelo final obteve bons resultados considerando condições normais de vento.

Outra abordagem baseada na curva de potência foi usada em [18], capturando a performance da turbina. Neste artigo, três modelos para as curvas de potência são ajustados: um por mínimos quadrados, o segundo pelo método de estimação de máxima verossimilhança e o terceiro utilizando uma abordagem não paramétrica baseada no algoritmo do k-ésimo vizinho mais próximo $(k-N N)$. A solução para cada um dos modelos é dada pela utilização de um algoritmo de computação evolucionária. Verifica-se pelos resultados que a curva de potência ajustada pelos mínimos quadrados sobrestimou os modelos que utilizaram a máxima verossimilhança.

Assim sendo, foi feita uma análise comparativa por monitoramento pela curva de potência ajustada utilizando um modelo paramétrico, obtido por mínimos quadrados e também um modelo não-paramétrico. Os resultados revelam que ambos se ajustam bem às condições de vento, detectando anomalias presentes nos 
dados. No entanto, o modelo não-paramétrico possui um custo computacional maior para encontrar tais anomalias.

Outro artigo que utilizou a abordagem pela curva de potência para estimar a curva de potência de uma fazenda eólica foi desenvolvido em [21]. A abordagem neste artigo utiliza apenas uma série de velocidades do vento, sendo esta representativa para toda uma área estudada. Esta velocidade é então amortecida por uma técnica denominada moving block averaging, usando uma partição do tempo de propagação sobre a área. Com isso, a curva de potência amortecida é então encontrada baseada na curva de potência padrão e no desvio padrão da distribuição espacial da velocidade do vento, então escalada para representar a capacidade de produção de uma área. Assim, a série de velocidade do vento agregada é então obtida aplicando a curva de potência padrão e amortecida a série temporal de velocidade do vento amortecida e ajustada.

\subsection{2}

\section{Fontes que se referem à energia eólica}

Existem também outras fontes, tais como artigos e dissertações, que não se atem somente a utilização da curva de potência. Estes utilizaram outros métodos estatísticos para a obtenção de seus objetivos. Nesta seção serão apresentados alguns destes artigos.

Dalmaz [8] estudou o potencial eólico de seis estações meteorológicas (CELESC) pertencentes ao estado de Santa Catarina, consistindo de dados medidos a cada seis minutos. O estudo deste potencial se deu pelos valores obtidos da densidade de energia eólica, o fator de capacidade de cada uma das seis estações. Após este procedimento, foram utilizados os dados obtidos pelo modelo meteorológico Eta para o treinamento das redes neurais, após serem colocados na mesma altitude dos dados da CELESC através da Lei da Potência. Estes conseguiram estimar a velocidade do vento e da potencia para um horizonte de seis horas. Os resultados mostraram que a abordagem pelas redes neurais é adequada, embora existam limitações em relação ao seu uso com estes dados.

Zhang [29] desenvolveu um modelo multivariado e multimodal para a velocidade e direção do vento, assim como a densidade do ar, ou seja, as condições de distribuição do vento. A adequação deste modelo foi medida 
utilizando dois critérios: coeficiente de determinação e o gráfico Quantil-Quantil, construído a partir do coeficiente calculado anteriormente. Este foi primeiramente ajustado e validado utilizando os dados de dez anos de vento da Rede de Agricultura e Clima do estado da Dakota do Norte - USA.

Depois foi aplicado o modelo a cem estações meteorológicas, nos quais os resultados revelaram a existência de uma distribuição multimodal do vento. Os resultados demostraram diferenças quando foram analisadas as distribuições do vento pertencentes a estações on-shore e off-shore.

Kubik [16] utiliza dados de vento oriundos de uma estação meteorológica para simular a geração eólica hipotética de uma turbina. Os dados da estação são primeiro extrapolados para a altura da turbina utilizando a Lei da Potência e depois utilizados na simulação. No entanto, a acurácia em relação a esta extrapolação depende largamente do expoente de gradiente do vento $(\alpha)$.

Neste artigo se investigou esta acurácia levando-se em consideração os dados pertencentes a fazenda eólica de North Rhins, Escócia e a estação de West Freugh. Os resultados alcançados mostram que embora um único valor anual para $\alpha$ tenha se ajustado adequadamente aos dados, ainda existiam diferenças significativas entre a simulação e os dados reais ao se considerar a produção horária.

Em Amaral [2] é estudado a vazão e o vento conjuntamente, com a construção de cenários integrados, com o objetivo de verificar assim o instante em que o despacho seria ótimo, visando o planejamento de estratégias para o cenário eólico. Com isto em mente, ajustou-se um modelo VARX utilizando a distribuição conjunta do vento e da vazão da água, com o uso do algoritmo de mínimos quadrados ponderados. Para a implementação deste algoritmo foram utilizadas as séries de fator de capacidade eólico, de vazão e de energia afluente, com a vazão e a energia, obtidas pelo programa Newave, utilizando as simulações Monte Carlo. Os resultados obtidos foram adequados, à medida que as séries obtidas pelas simulações preservaram as propriedades originais.

Soens [25] estima a curva de potência através das medidas de vento horarias de três estações meteorológicas no território da Bélgica, do período de 2001-2003. As séries de potência são calculadas para quatro cenários diferentes em relação à posição geográfica das turbinas, o tipo de turbina e a mudança do rotor quando o vento sopra. Com as séries de geração eólica calculadas, são 
criadas as matrizes de transição para estas. Estas matrizes são obtidas considerando o número de ocorrências em que a produção eólica cair, dado que a previsão é contada, no tempo prévio amostral. A amplitude de cada intervalo foi de $20 \%$. Com os resultados obtidos, verificou-se que o cenário que detinha a fazenda off-shore teve maiores flutuações em relação a sua potência calculada do que a fazenda on-shore.

Também avaliou-se neste estudo a produção obtida em cada cenário em relação a periodicidade diária e a estação do ano. O grau de flutuação em relação a periodicidade diária esta intimamente ligada à estação do ano, com as estações de primavera e outono obtendo resultados similares e as estações verão e inverno tendo resultados opostos. 


\section{4}

\section{Metodologia Estatística}

\section{1}

\section{Modelos Lineares}

Esta seção irá explorar a metodologia de modelos lineares, explicando suas premissas, assim como a estimação de seus parâmetros pelo método mínimos quadrados.

Um modelo linear é composto de uma variável denominada de variável resposta e de variáveis independentes, das quais através de uma combinação linear entre elas busca-se obter a variável resposta, usando uma expressão matemática que relaciona duas ou mais variáveis. No modelo linear, também está incluído um intercepto, que possui grandes propriedades na estimação dos parâmetros deste tipo de modelo.

$$
y_{t}=\beta_{0}+\beta_{1} x_{t}+\varepsilon_{t}
$$

A expressão (4.1) caracteriza o que é denominado de modelo linear simples, no qual, só conta com a presença de uma única variável explicativa $\left(x_{t}\right)$. Já o modelo (4.2) é denominado modelo linear múltiplo, uma vez que conta com $n$ variáveis explicativas.

$$
y_{t}=\beta_{0}+\beta_{1} x_{1 t}+\beta_{2} x_{2 t}+\cdots+\beta_{n} x_{n t}+\varepsilon_{t}
$$

Os modelos lineares geralmente estão associados ao propósito de estimar um valor condicional esperado, ou seja, quando se espera estimar $E(Y \mid X)$. A estimação dos parâmetros $\beta^{\prime}$ s existentes em um modelo linear é efetuada através do método de mínimos quadrados. Este método consiste de premissas que devem ser respeitadas no ajuste de um modelo [2]. Caso alguma delas não seja respeitada, o ajuste será sub-ótimo. A principal premissa é que os erros associados ao modelo linear $\left(\varepsilon_{t}\right)$ devem seguir uma distribuição normal, ou seja, 
$\varepsilon_{t} \sim N\left(0, \sigma^{2}\right)$. Para se conseguir este resultado, é necessário atribuir uma distribuição a este erro no qual $E\left(\varepsilon_{i} \mid X_{i}\right)=0$, para todo $i$. Isto indica que os resíduos (erros) e as variáveis explicativas não estão de forma alguma correlacionados uns aos outros. Para se calcular a variância é necessário que $\operatorname{Var}\left(\varepsilon_{i} \mid X_{i}\right)=E\left(\varepsilon_{i}{ }^{2} \mid X_{i}\right)=\sigma^{2}$ e que esta seja igual para todos os instantes de tempo, garantindo assim a homoscedasticidade dos resíduos do modelo. Em relação à variância é importante ressaltar que esta deve ser um número finito quando se trata das variáveis explicativas.

Outro item que deve ser respeitado a fim de assegurar todas as propriedades dos métodos de mínimos quadrados é que a correlação dos termos aleatórios em instantes diferentes deve ser igual a zero. As variáveis independentes devem ser tratadas como variáveis com valores fixos no tempo, ao invés de serem consideradas como variáveis aleatórias.

A multicolinearidade é outro problema que deve ser evitado no ajuste de modelos. Tal problema pode estar relacionado à existência de qualquer variável escrita como uma combinação linear das demais ou ao ajuste do modelo com um número de observações muito pequeno, quando comparado ao número de variáveis explicativas. Além destas, deve-se notar que a distribuição probabilística das variáveis independentes tem uma influência muito grande na precisão dos estimadores dos coeficientes destas.

\section{2}

\section{Estimação dos parâmetros}

O objetivo do método de mínimos quadrados é minimizar a soma dos quadrados dos resíduos, dada por (4.3), acarretando em um melhor ajuste das variáveis independentes à variável resposta. Para ilustrar esta demonstração, supõe-se que o modelo tenha $m$ variáveis explicativas. Ou seja,

$$
S=\sum_{i=1}^{m} r_{i}^{2}
$$

onde $r_{i}=y_{i}-\hat{y}_{i}$ sendo $y_{i}$ o valor da variável resposta observada e $\hat{y}_{i}$ o valor da variável resposta predita.

Sendo assim, podemos escrever o modelo recursivamente, no qual se tem que 


$$
y_{i}=\sum_{i=1}^{n} X_{i j} \beta_{i}+\varepsilon_{i}, \quad i=1, \ldots, n
$$

Desta forma se tem $m$ equações lineares em função de $n$ coeficientes $\beta_{1}, \ldots, \beta_{n}$ onde $n>m$. Pode-se expressar $r_{i}$ como sendo $r_{i}=y_{i}-\sum_{i=1}^{n} X_{i j} \beta_{i}$.

Para chegar aos estimadores de mínimos quadrados, a função S é minimizada, o que implica em ter o vetor gradiente nulo. Os elementos deste vetor são obtidos pelas derivadas parciais de $\mathrm{S}$ em relação aos parâmetros,

$$
\frac{\partial S}{\partial \beta_{j}}=2 \sum_{i=1}^{m} r_{i} \frac{\partial r_{i}}{\partial \beta_{j}} \quad(j=1, \ldots, n)
$$

O valor de $\frac{\partial r_{i}}{\partial \beta_{j}}$ é igual a $-X_{i j}$. Substituindo $r_{i}$ por $y_{i}-\sum_{k=1}^{n} X_{i k} \beta_{k}$ em (4.5) tem-se

que

$$
\frac{\partial S}{\partial \beta_{j}}=2 \sum_{i=1}^{m}\left(y_{i}-\sum_{k=1}^{n} X_{i k} \beta_{k}\right)\left(-X_{i j}\right) \quad(j=1, \ldots, n)
$$

Se $\hat{\beta}$ minimiza S, tem-se que

$$
2 \sum_{i=1}^{m}\left(y_{i}-\sum_{i=1}^{n} X_{i k} \hat{\beta}_{k}\right)\left(-X_{i j}\right)=0 \quad(j=1, \ldots, n)
$$

Efetuando a multiplicação na equação (4.7) tem-se que

$$
2 \sum_{i=1}^{m} \sum_{k=1}^{n} X_{i j} X_{i k} \hat{\beta}_{k}-2 \sum_{i=1}^{n} y_{i} X_{i j}=0
$$

E reorganizando os termos de (4.8), consegue-se chegar à expressão

$$
\sum_{i=1}^{m} \sum_{k=1}^{n} X_{i j} X_{i k} \hat{\beta}_{k}=\sum_{i=1}^{n} y_{i} X_{i j}
$$


Os termos que aparecem na equação (4.9) podem ser reescritos em sua forma matricial, obtendo-se com isso a expressão final

$$
\left(X^{\prime} X\right) \hat{\beta}=X \dot{y}
$$

O valor de $\hat{\beta}$ que minimiza a soma dos quadrados dos resíduos é dado por

$$
\hat{\beta}=\left(X^{\prime} X\right)^{-1} X \dot{y}
$$

No entanto, para que se obtenha esta solução deve-se notar que a matriz X tem de ter posto completo, ou seja, $\left(X^{\prime} X\right)$ tem de ser uma matriz positiva definida.

\section{3}

\section{Regressão Stepwise}

O método de regressão stepwise tem por objetivo diminuir o número de variáveis consideradas no ajuste do modelo, toda vez que este número apresentase alto, sobrando assim, somente as variáveis consideradas significantes para a análise. Este modelo tende a ser obtido por uma sucessão de testes F. No entanto, outras formas podem ser usadas, como $\mathrm{R}^{2}$, AIC, BIC. Este modelo possui as duas abordagens apresentadas abaixo.

i) Seleção para frente (forward selection): nesta seleção o modelo começa sem variáveis, que vão sendo adicionadas e mantidas no modelo toda vez que os resultados com sua inclusão apresentem melhorias significativas.

ii) Eliminação para trás (backward elimination): inicia-se com todas as variáveis cujo numero vai sendo reduzido gradativamente, até que se chegue em um modelo ideal.

Uma das maiores inconveniências no uso do stepwise é o grande número de modelos possíveis para uma única solução final. 


\section{4}

\section{LASSO (Least Absolute Shrinkage and Selection Operator)}

O método LASSO (Least Absolute Shrinkage and Selection Operator) é uma das formas alternativas do método dos mínimos quadrados. Basicamente ela consiste em fazer com que a norma L1 do vetor de parâmetros, definida como sendo a soma dos comprimentos das projeções de um segmento de linha no sistema de coordenadas cartesianas, seja menor que um determinado valor préestabelecido. Esta imposição sobre a normalização L1 no vetor de parâmetros faz com que um número menor de parâmetros tenha valores diferentes de zero, reduzindo com isso o número de variáveis.

\section{5}

\section{Critérios para a seleção de modelos}

Quando se está em busca de um ajuste perfeito com o uso de um modelo linear, testam-se diversos deles, partindo de inúmeras tentativas e variáveis, até encontrar aquele cujo ajuste se mostra o mais eficiente possível. Com isso em mente, calcula-se uma série de medidas que ajudam o usuário nesta decisão. As duas informações mais usadas são o AIC (Critério de Informação de Akaike) e BIC (Critério de Informação de Schwartz).

\subsection{1}

\section{Critério de Informação de Akaike (AIC)}

É uma das medidas mais usadas por estatísticos, quando se quer encontrar o modelo mais adequado para a análise. Este geralmente apresenta valores menores que o Critério de Schwartz, e seu cálculo se baseia na entropia da informação. Este além de informar o quão bom é o ajuste, também penaliza a função de verossimilhança pelo número de parâmetros estimados. É definido por,

$$
A I C=2 k-2 \ln (L)
$$

onde $k$ é o numero de parâmetros no modelo estatístico; 
$L$ é o valor máximo da função de verossimilhança do modelo estatístico.

\subsection{2}

\section{Critério de Informação de Schwarz (BIC)}

Este é também chamado de critério de informação bayesiano, sendo intimamente ligado ao critério de informação de Akaike. Neste caso,

$$
B I C=-2 \ln (L)+n \ln (k)
$$

onde $k$ é o numero de parâmetros no modelo estatístico;

$n$ é o numero de observações das variáveis;

$L$ é o valor máximo da função de verossimilhança do modelo estatístico.

\section{6}

\section{Medidas de aderência do modelo estatístico}

Quando se está ajustando um modelo cujo propósito é a previsão, é necessária uma série de medidas para informar a precisão com que o modelo consegue prever. Uma estratégia comumente usada é retirar uma parte dos dados e reajustar o modelo sem eles para depois compará-los. Esta comparação é feita por uma série de medidas denominadas medidas de aderência. Espera-se que os valores destas medidas sejam bem pequenos, garantindo assim que a previsão feita foi bem próxima aos valores reais.

As principais medidas de aderência utilizadas são MAPE (Mean Absolute Percent Error), MAE (Mean Absolute Error), MPE (Mean Percent Error), RMSE (Root Mean Square Error), SDPE (Standard Deviation Porcentage Error) e Pseudo $R^{2}$.

$$
\begin{gathered}
R M S E=\sqrt{\frac{1}{n} \sum_{i=1}^{n}\left(\hat{y}_{t}-y_{t}\right)^{2}} \\
M A E=\frac{1}{n} \sum_{i=1}^{n}\left|\hat{y}_{t}-y_{t}\right|
\end{gathered}
$$




$$
\begin{gathered}
M A P E=\frac{1}{n} \sum_{i=1}^{n}\left|\frac{\hat{y}_{t}-y_{t}}{y_{t}}\right|, y_{t} \neq 0 \\
M P E=\frac{1}{n} \sum_{i=1}^{n}\left(\frac{\hat{y}_{t}-y_{t}}{y_{t}}\right), y_{t} \neq 0 \\
S D P E=\sqrt{\frac{1}{n} \sum_{i=1}^{n}\left(\frac{\hat{y}_{t}-y_{t}}{y_{t}}-M P E\right)^{2}, y_{t} \neq 0} \\
\text { PseudoR } R^{2}=1-\frac{\sum_{i=1}^{n} r_{i}^{2}}{\sum_{i=1}^{n}\left(y_{i \text { (insample })}-\bar{y}_{\text {out-of -sample }}\right)^{2}}
\end{gathered}
$$




\section{Análise Exploratória dos dados}

Neste capitulo será detalhado o processo de análise de dados, tanto de velocidade quanto da geração da energia eólica. Os dados de geração eólica utilizados nesta dissertação foram gentilmente disponibilizados pela ONS (Operador Nacional do Sistema Elétrico). Estes dados correspondem ao que foi produzido nas fazendas eólicas Bons Ventos, Canoa Quebrada, Enacel e Icaraizinho, durante o período de 0 hora de 01/01/2011 até 23 horas do dia 30/09/2012.

No caso das variáveis, os dados foram disponibilizados das mesmas fazendas eólicas pela empresa norte-americana 3tier. Foram dois os bancos fornecidos por esta: ERA-Interim (também chamado de dados de reanalise 1) e NNRP (também chamado de dados de reanalise 2). A partir deste ponto os dois conjuntos de dados serão referidos como ERAI e NNRP, respectivamente. Vale a pena ressaltar que estes dados não são observados, sendo resultantes de uma estimativa. Cada banco de dados é composto pelas seguintes variáveis: pressão (em Pascal), temperatura (em Kelvin), direção (em graus) e velocidade (em m/s) do vento. Apesar de terem sido coletadas nas mesmas fazendas, o período de coleta das variáveis foi diferente, iniciando à 0 hora de 01/01/1981 e terminando às 23 horas de 31/10/2012. Nestas condições, foi usado nesta análise apenas o período de 0 hora de 01/01/2011 até 23 horas do dia 30/09/2012, que corresponde a superposição temporal dos dados das duas fontes.

Por sua vez, tendo em vista que o horário das informações das variáveis, tomadas em relação ao Meridiano de Greenwich, estava adiantado em 3 horas em relação ao horário de Brasília, para sincronizar as informações das duas fontes, retirou-se as três primeiras horas dos bancos das variáveis.

O parque eólico escolhido para a análise inicial da modelagem é o Parque de Bons Ventos, que é um dos três parques que constituem o Parque Eólico de Aracati. Este parque que se localiza na região costeira do município de Aracati, Ceará, conhecido também como "terra dos bons ventos", é constituído de 24 aerogeradores, com uma capacidade máxima de 50 MW. Esta região, pertencente 
ao Nordeste Brasileiro, possui uma grande escassez de chuvas e é marcada pelo seu clima semiárido e uma vegetação costeira.

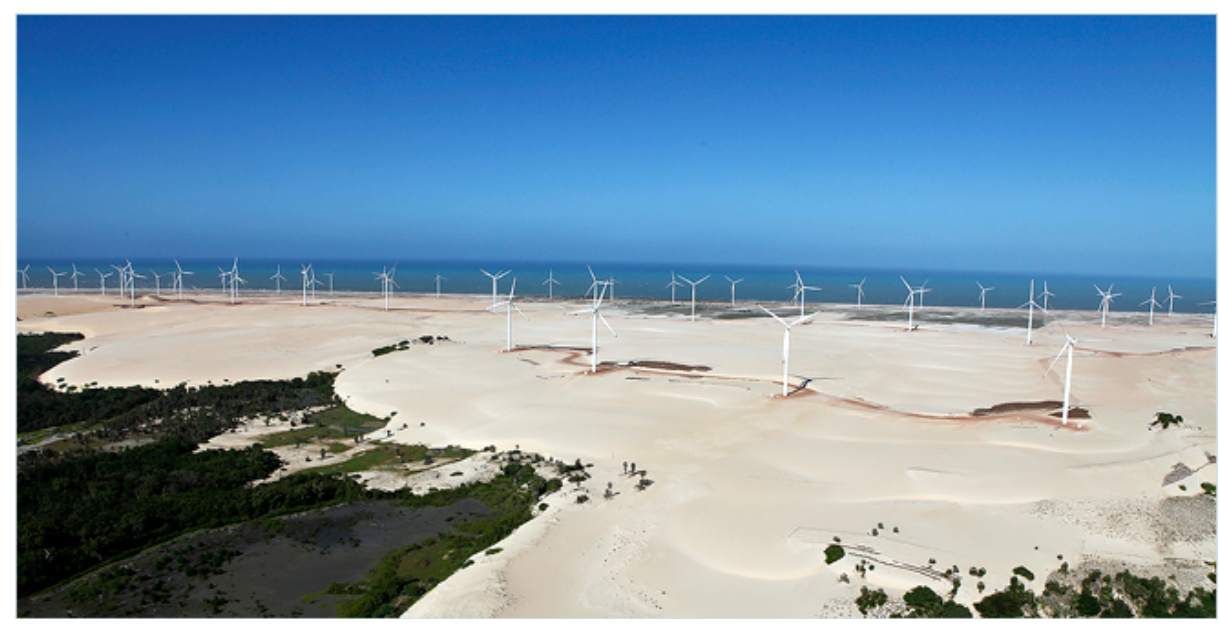

Figura 5-1: Parque Eólico de Aracati. Fonte: Bons Ventos (2010).

A Figura 5-1 apresenta uma fotografia do Parque Eólico de Aracati ao longo da região litorânea nordestina. Observa-se nela a distribuição regular das 67 turbinas, com suas torres fixadas em terreno arenoso.

Nas análises primárias utilizaram-se somente os dados referentes à fazenda eólica de Bons Ventos. Pelas Tabelas 5-1 e 5-2, têm-se as estatísticas descritivas das variáveis de cada banco de dados referente a esta fazenda eólica.

Tabela 5-1: Estatísticas descritivas das variáveis que compõem o banco de dados ERAI da fazenda eólica de Bons Ventos.

\begin{tabular}{lrrrr}
\hline & Pressão & Temperatura & Velocidade & Direção \\
N & 15336 & 15336 & 15336 & 15336 \\
NA & 0 & 0 & 0 & 0 \\
Mínimo & 99913,2 & 295,80 & 0,20 & 0,32 \\
Máximo & 101271 & 306,30 & 13,80 & 359,74 \\
$1^{\circ}$ Quartil & 100393 & 298,888 & 6,51293 & 85,3111 \\
$3^{\circ}$ Quartil & 100705 & 301,911 & 9,260108 & 121,871 \\
Média & 100553,3 & 300,4214 & 7,785479 & 104,2969 \\
Mediana & 100538 & 300,16 & 7,946445 & 103,6885 \\
Soma & 1542086000 & 4607263 & 119398,1 & 1599498 \\
Variância & 49199,72 & 3,87 & 4,47 & 988,03 \\
Desvio & & & & \\
Padrão & 221,81 & 1,97 & 2,11 & 31,43 \\
Assimetria & 0,23 & 0,30 & $-0,45$ & 2,30 \\
Curtose & $-0,42$ & $-0,74$ & 0,20 & 17,51 \\
\hline
\end{tabular}


Tabela 5-2: Estatísticas descritivas das variáveis que compõem o banco de dados NNRP da fazenda eólica de Bons Ventos.

\begin{tabular}{lcccc}
\hline N & Pressão & Temperatura & Velocidade & Direção \\
NA & 15336 & 15336 & 15336 & 15336 \\
Mínimo & 0 & 0 & 0 & 0 \\
Máximo & 100599 & 294,57 & 0,38 & 3,53 \\
$1^{\circ}$ Quartil & 101885 & 305,93 & 13,87 & 356,77 \\
$3^{\circ}$ Quartil & 101078 & 298,68 & 6,65 & 88,66 \\
Média & 101395 & 301,48 & 9,17 & 128,62 \\
Mediana & 101241,5 & 300,05 & 7,82 & 107,56 \\
Soma & 101228 & 299,79 & 8,03 & 104,51 \\
Variância & 1552639000 & 4601515 & 119900,01 & 1649489 \\
Desvio & 47620,32 & 3,52 & 3,94 & 752,34 \\
Padrão & 218,22 & 1,88 & 1,98 & 27,43 \\
Assimetria & 0,20 & & & \\
Curtose & $-0,48$ & 0,22 & $-0,52$ & 0,94 \\
\hline
\end{tabular}
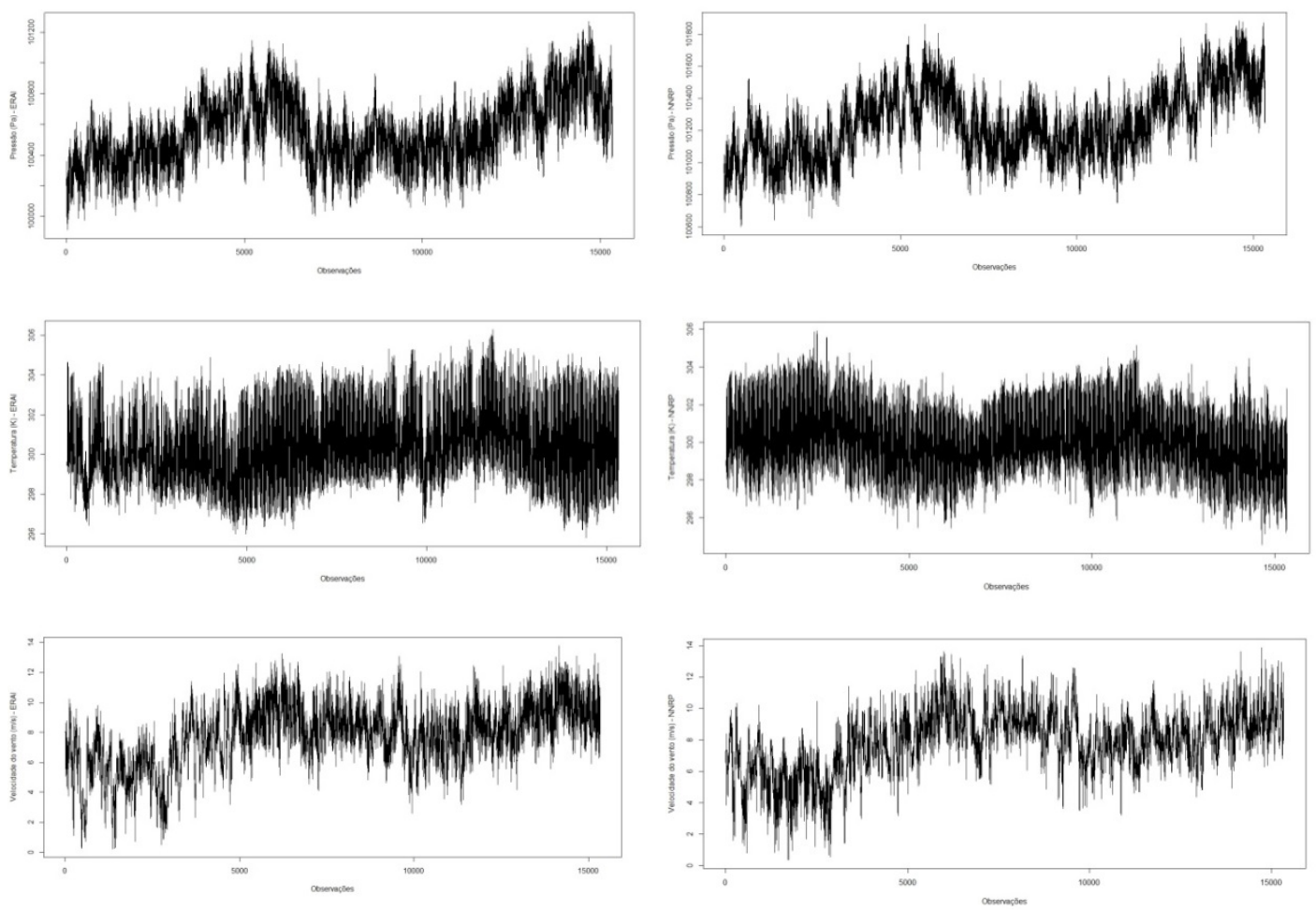

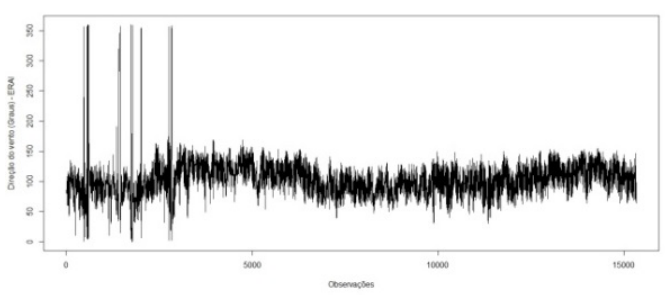

(a)

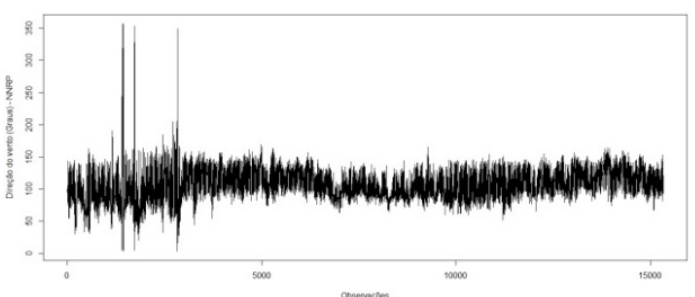

(b)

Figura 5-2: Séries históricas de pressão, temperatura, velocidade e direção do vento, respectivamente para o conjunto de dados ERAI (a) e NNRP (b). 

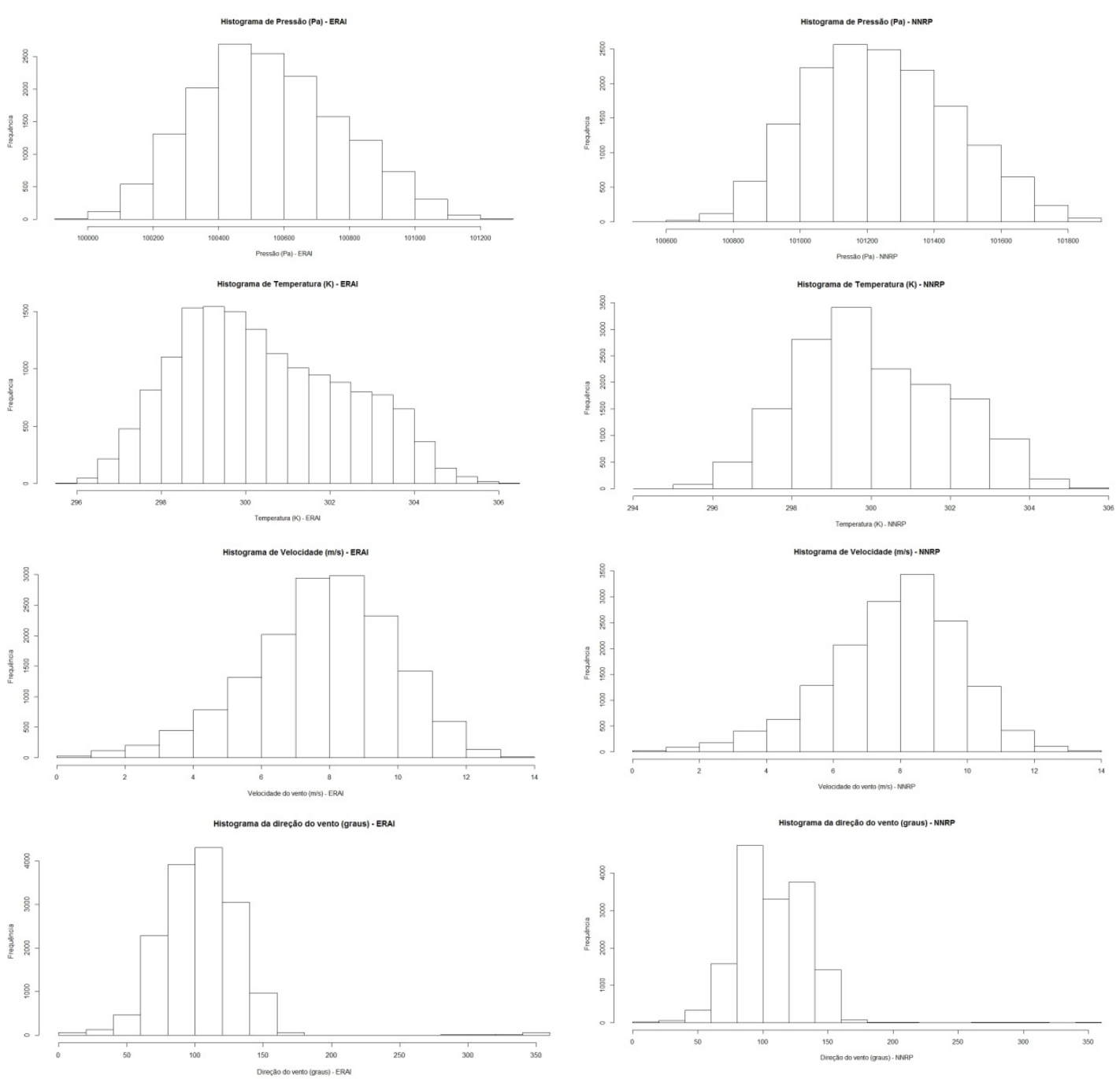

(a)

(b)

Figura 5-3: Histogramas das variáveis pressão, temperatura, velocidade e direção do vento, respectivamente para o conjunto de dados ERAI (a) e NNRP (b). 

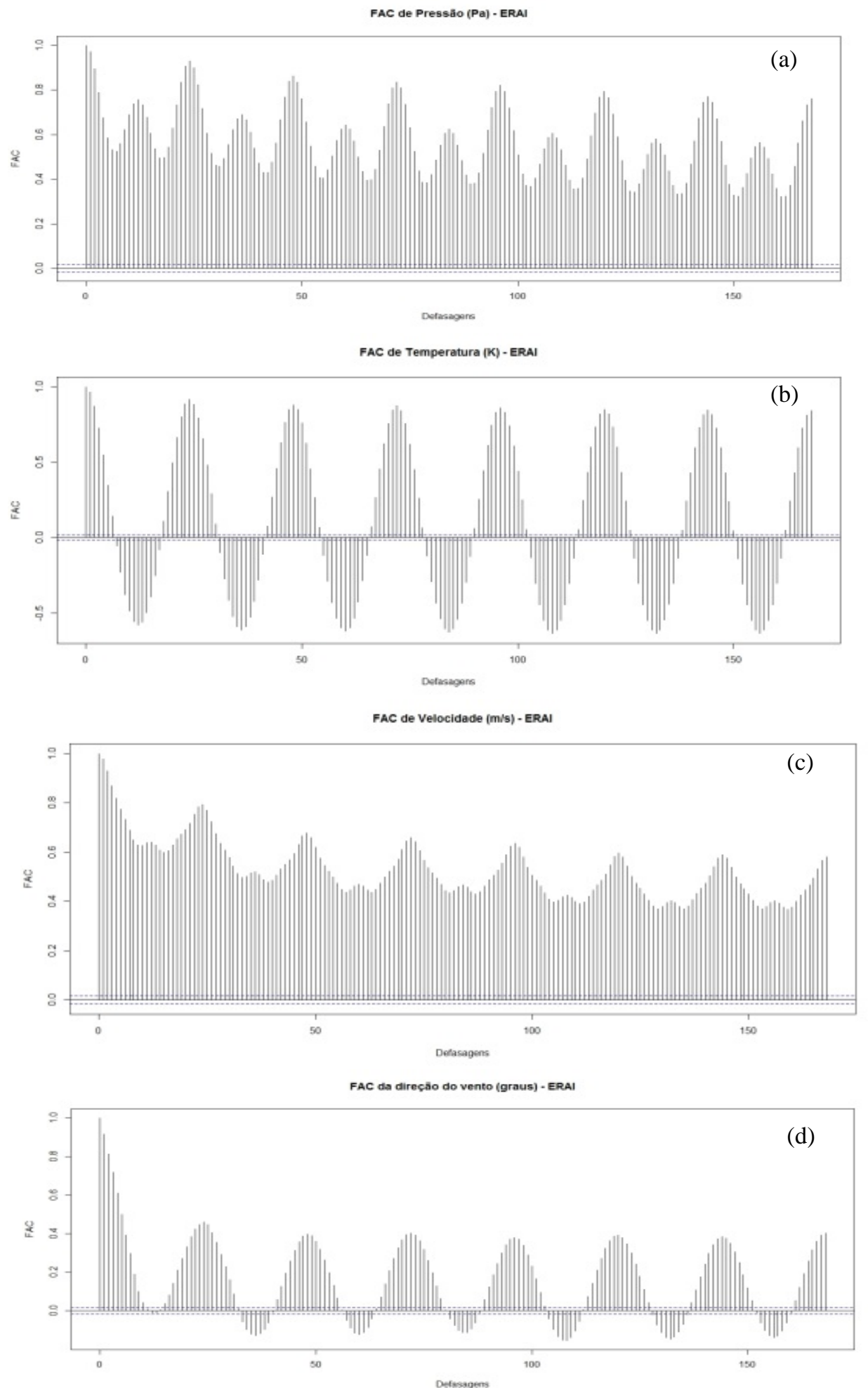

Figura 5-4: Autocorrelações simples das variáveis pressão (a), temperatura (b), velocidade (c) e direção (d) do vento, do conjunto de dados ERAI. 

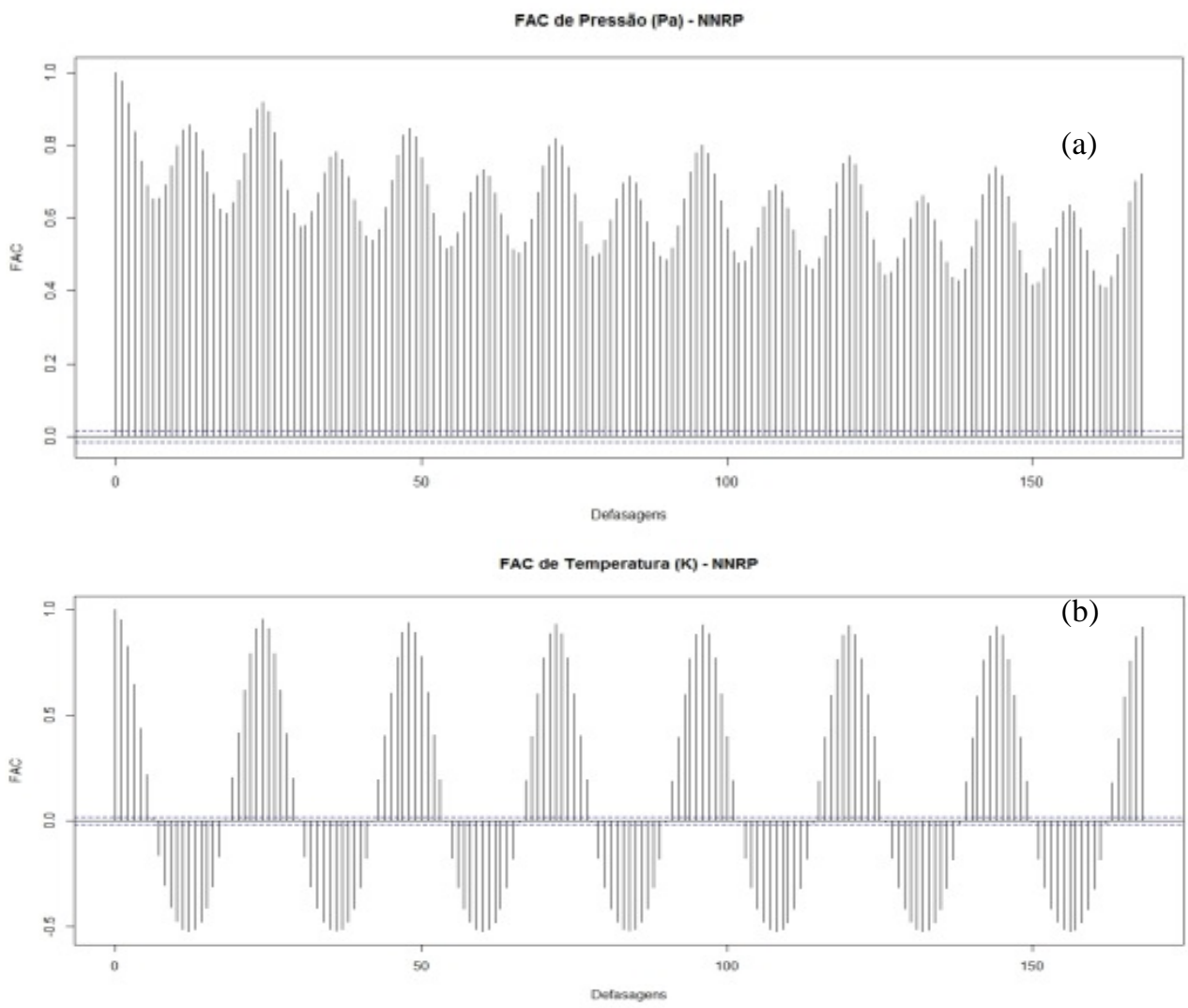

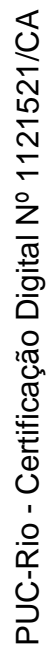
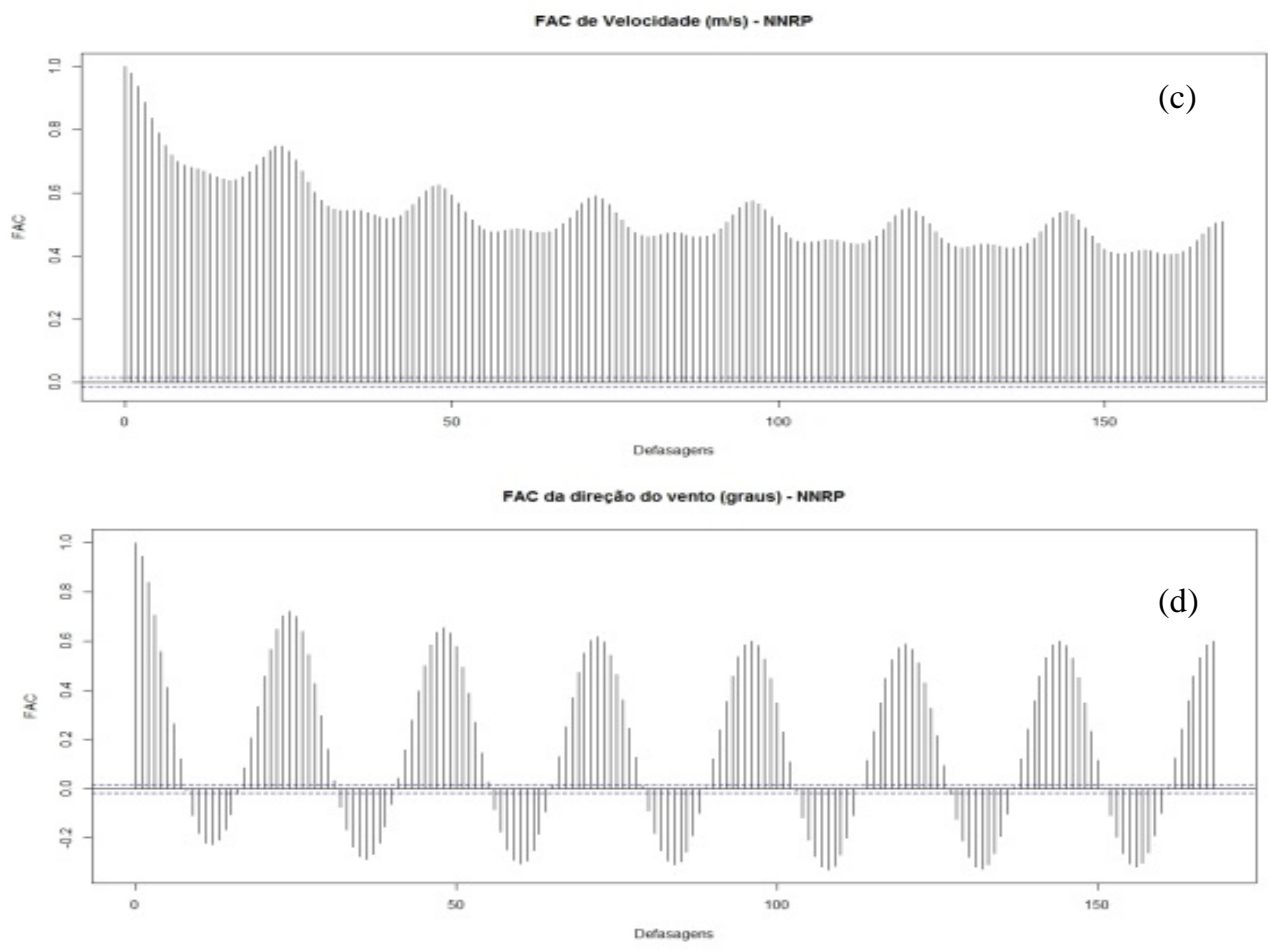

Figura 5-5: Autocorrelações simples das variáveis pressão (a), temperatura (b), velocidade (c) e direção (d) do vento, do conjunto de dados NNRP. 
As Figuras 5-2 a 5-5 apresentam as séries históricas, histogramas e autocorrelações simples das variáveis pressão, temperatura, direção e velocidade do vento de ambos os bancos de dados. Como se pode observar por estes gráficos e pelas Tabelas 5-1 e 5-2, os resultados obtidos com os dois bancos de dados apresentam comportamento muito similar. A elevada amplitude da direção do vento (359,4244 para ERAI e 353,2442 para NNRP) em ambos os conjuntos de dados pode estar relacionada a rajadas de vento, que influenciaria a direção destes. Algumas diferenças podem ser observadas ao se analisar o gráfico de autocorrelações das velocidades e direções do vento. Para o conjunto de dados ERAI, estas autocorrelações apresentam um comportamento mais suave em comparação ao banco de dados NNRP.

Outra forma de analisar o vento em uma determinada região é utilizando o gráfico rosa dos ventos. Este gráfico polar apresenta a intensidade da velocidade de acordo com a sua direção, o que torna possível a visualização da direção predominante do vento. Comparando as rosas dos ventos para os conjuntos de dados ERAI e NNRP, verificam-se algumas diferenças entre elas.

- A rosa dos ventos ERAI apresenta uma forma mais regular, enquanto que a rosa dos ventos NNRP possui uma forma irregular, com dois máximos de intensidade.

- A direção predominante na rosa dos ventos ERAI é em torno $110^{\circ}$, enquanto que na rosa dos ventos NNRP as duas direções predominantes são em torno de $90^{\circ}$ e $150^{\circ}$. 


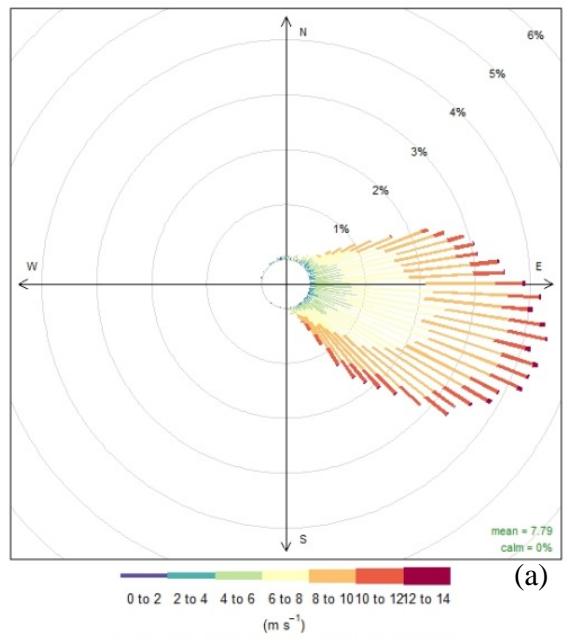

Frequency of counts by wind direction $(\%)$

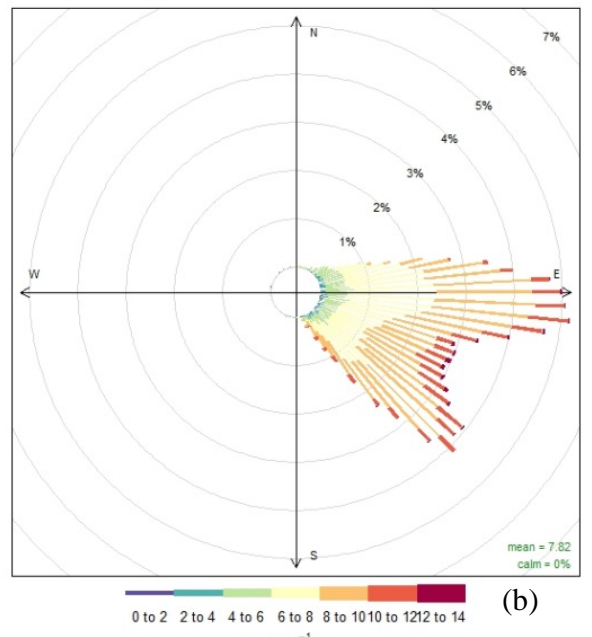

Frequency of counts by wind direction (\%)

Figura 5-6: Rosa dos ventos para os conjuntos de dados ERAI (a) e NNRP (b).

A densidade do ar não é fornecida nos bancos de dados. Sendo assim esta foi calculada a partir da relação (3.1) utilizando a fórmula proposta por Hughes [11]. 
Tabela 5-3: Estatísticas descritivas da densidade do ar calculada para os conjuntos de dados ERAI e NNRP.

\begin{tabular}{lcc}
\hline & ERAI & NNRP \\
$\mathrm{N}$ & 15336 & 15336 \\
$\mathrm{NA}$ & 0 & 0 \\
Mínimo & 1,14 & 1,15 \\
Máximo & 1,19 & 1,20 \\
$1^{\circ}$ Quartil & 1,16 & 1,17 \\
$3^{\text {o }}$ Quartil & 1,17 & 1,18 \\
Média & 1,17 & 1,18 \\
Mediana & 1,17 & 1,18 \\
Soma & 17886,11 & 18030,93 \\
Variância & 0,00 & 0,00 \\
Desvio & & \\
Padrão & 0,01 & 0,01 \\
Assimetria & $-0,25$ & $-0,11$ \\
Curtose & $-0,56$ & $-0,40$ \\
\hline
\end{tabular}

Pela Tabela 5-3, têm-se os resultados da densidade do ar em $\mathrm{kg} / \mathrm{m}^{3}$ calculada para os dois conjuntos de dados. Observa-se que em ambos, a densidade do ar apresenta um valor muito próximo. Isto também pode ser visualizado pelas estatísticas descritivas apresentadas na Tabela, onde se verifica que a amplitude destes dados é da ordem de 0,04656 e 0,053623, assim como seu coeficiente de variação possui o valor de 0,007404721 e 0,007048411, para os bancos ERAI e NNRP, respectivamente.

Sabe-se que a densidade do ar está intimamente ligada à pressão e à temperatura. Como os valores calculados para a densidade do ar com os dois conjuntos de dados são muitos próximos entre si e ao valor da densidade do ar ao nível do mar, pode-se atribuir a esta o valor constante de $1,225 \mathrm{~kg} / \mathrm{m}^{3}$. Optou-se por esse valor pela proximidade com o mar do local onde as informações foram obtidas. Considerando a altitude de apenas 80 metros das torres, pode-se também desprezar a influência da altitude sobre a densidade do ar [15].

Os dados utilizados foram medidos a uma altitude de 100 metros. Todavia, o modelo de turbina utilizada na fazenda eólica Bons Ventos possui uma altitude de 80 metros [4], [26]. Sendo assim, mesmo considerando esta pequena diferença de altitude, a velocidade do vento é transformada para uma altitude de 80 metros pela Lei Logarítmica e Lei da Potência. 
Nesta transformação tem de se definir a rugosidade superficial que será utilizada neste cálculo. Estando a fazenda de Bons Ventos a beira-mar, esta rugosidade deve ser de areia. No entanto, como se pode observar pela Tabela 3-1, esta não é fornecida. Sendo assim utilizou-se a rugosidade com o valor de 0,003 $\mathrm{m}$, correspondente a uma superfície de características semelhantes. O expoente $\alpha$ para a Lei de Potência, calculado utilizando esta rugosidade, assume um valor de 0,09964232, que pode ser muito bem aproximado para 0,1.
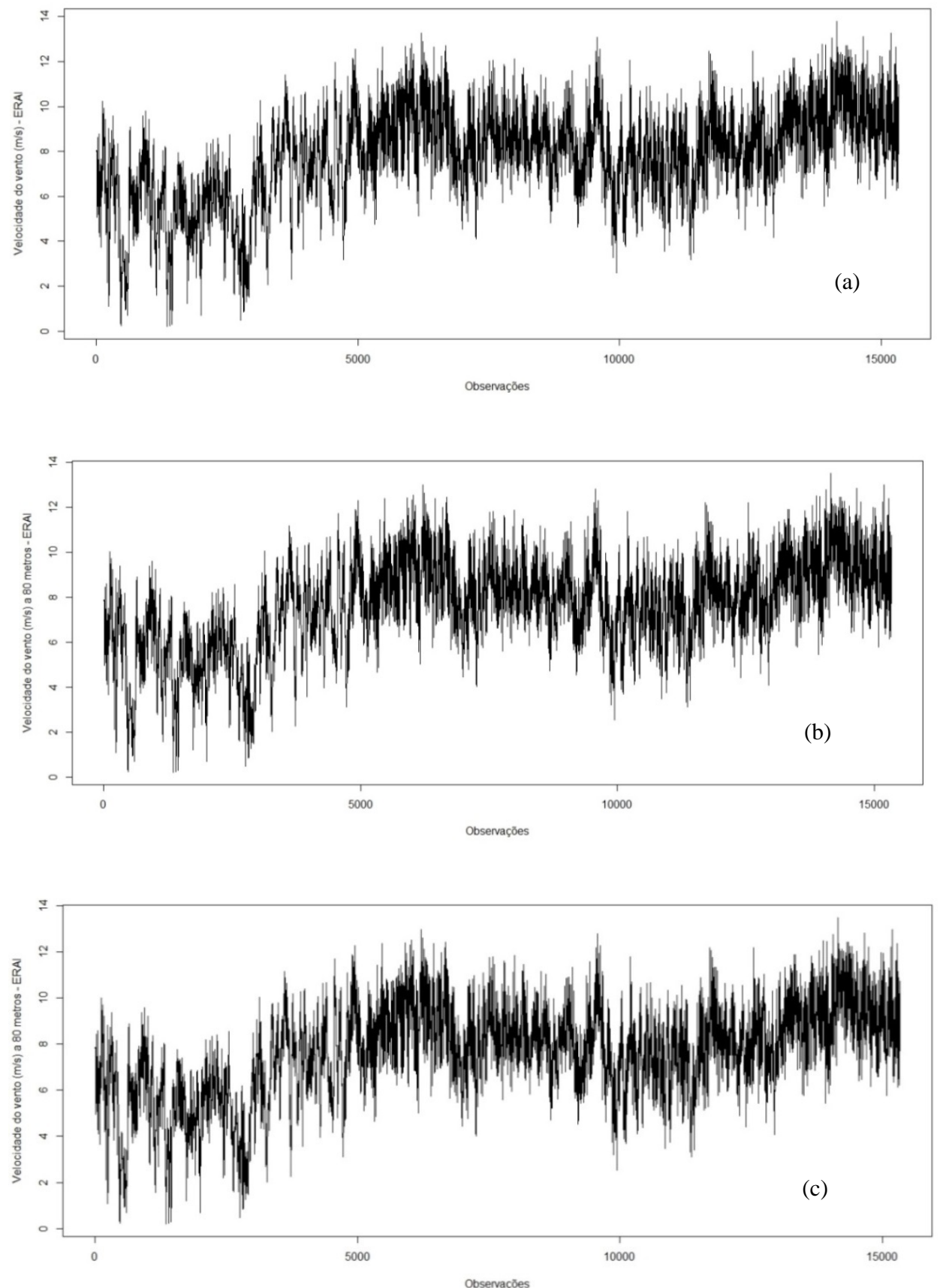

Figura 5-7: Série histórica da velocidade do vento (a), projetada pela Lei Logarítmica (b) e projetada pela Lei da Potência (c), para o conjunto de dados ERAI. 


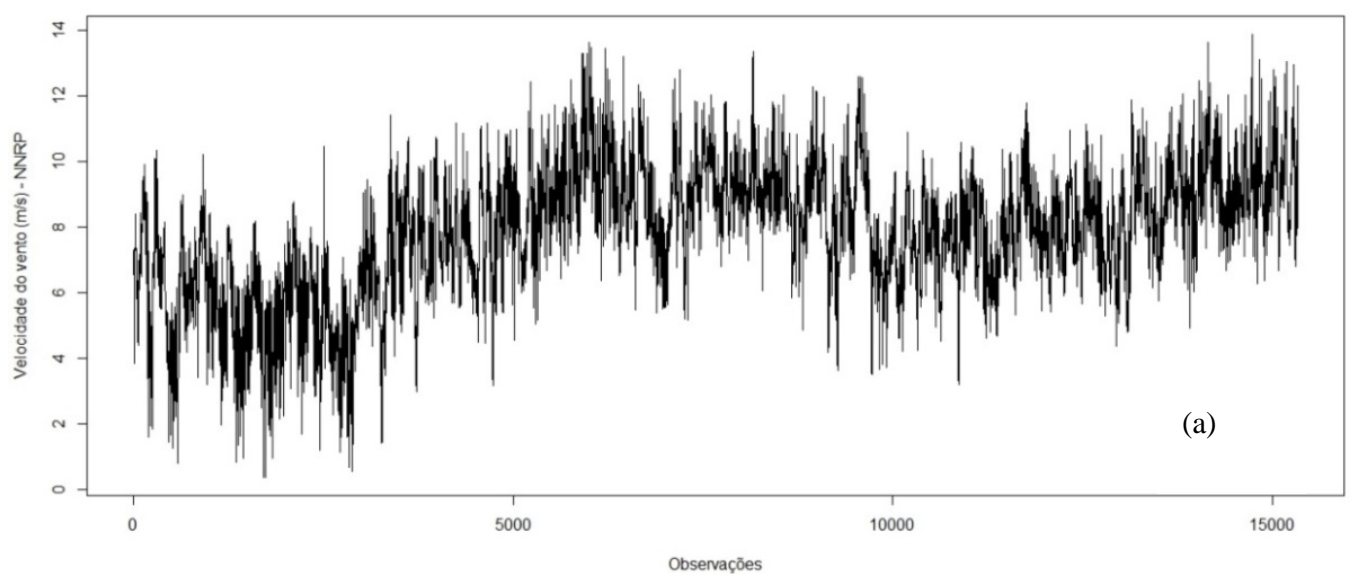

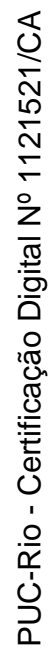
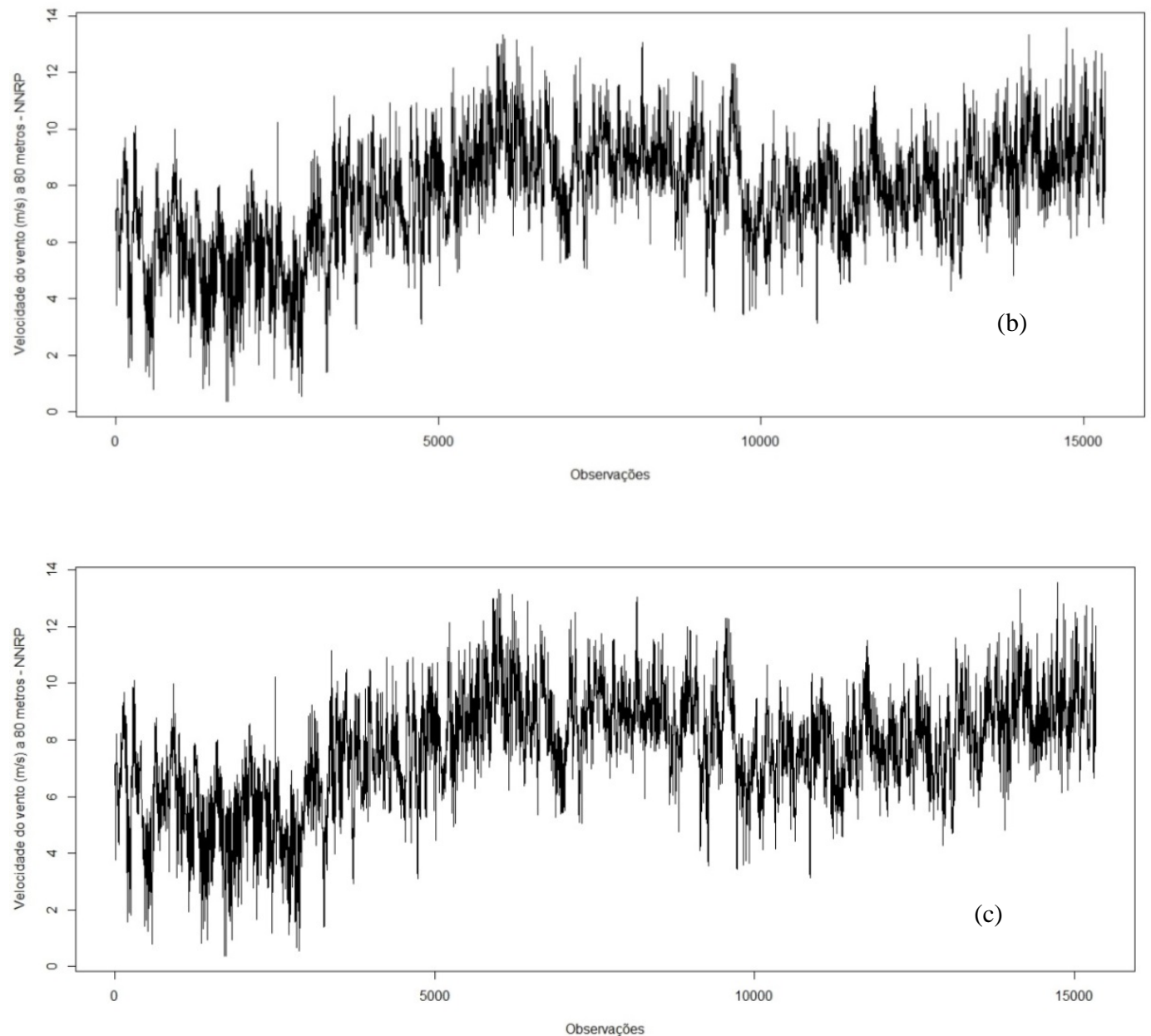

Figura 5-8: Série histórica da velocidade do vento (a), projetada pela Lei Logarítmica (b) e projetada pela Lei da Potência (c), para o conjunto de dados NNRP. 
Tabela 5-4: Estatísticas descritivas das velocidades a 100 metros e a 80 metros projetadas pela Lei da Potência e a Lei Logarítmica do banco de dados ERAl.

\begin{tabular}{lrrr}
\hline & $\begin{array}{l}\text { Velocidade a } \\
\text { Velocidade a }\end{array}$ & $\begin{array}{l}\text { Velocidade a } \\
\text { (Potência) }\end{array}$ & $\begin{array}{l}\text { 80 metros } \\
\text { (Logarítmica) }\end{array}$ \\
N & 15336 & 15336 & 15336 \\
NA & 0 & 0 & 0 \\
Mínimo & 0,20 & 0,20 & 0,20 \\
Máximo & 13,80 & 13,50 & 13,51 \\
$1^{\circ}$ Quartil & 6,51 & 6,37 & 6,37 \\
$3^{\circ}$ Quartil & 9,26 & 9,06 & 9,06 \\
Média & 7,76 & 7,61 & 7,62 \\
Mediana & 7,95 & 7,77 & 7,78 \\
Soma & 119398,1 & 116763,3 & 116839,8 \\
Variância & 4,45 & 4,25 & 4,26 \\
Desvio Padrão & 2,11 & 2,06 & 2,06 \\
Assimetria & $-0,45$ & $-0,45$ & $-0,45$ \\
Curtose & 0,20 & 0,20 & 0,20 \\
\hline
\end{tabular}

Tabela 5-5: Estatísticas descritivas das velocidades a 100 metros e a 80 metros projetadas pela Lei da Potência e a Lei Logarítmica do banco de dados NNRP.

\begin{tabular}{|c|c|c|c|}
\hline & $\begin{array}{l}\text { Velocidade a } \\
100 \text { metros }\end{array}$ & $\begin{array}{l}\text { Velocidade } \\
\text { a } 80 \text { metros } \\
\text { (Potência) }\end{array}$ & $\begin{array}{l}\text { Velocidade a } \\
80 \text { metros } \\
\text { (Logarítmica) }\end{array}$ \\
\hline $\mathrm{N}$ & 15336 & 15336 & 15336 \\
\hline NA & 0 & 0 & 0 \\
\hline Mínimo & 0,38 & 0,37 & 0,37 \\
\hline Máximo & 13,87 & 13,56 & 13,57 \\
\hline $1^{\circ}$ Quartil & 6,65 & 6,50 & 6,50 \\
\hline $3^{\circ}$ Quartil & 9,17 & 8,96 & 8,97 \\
\hline Média & 7,82 & 7,65 & 7,65 \\
\hline Mediana & 8,03 & 7,85 & 7,85 \\
\hline Soma & 119900 & 117254,1 & 117331 \\
\hline Variância & 3,94 & 3,76 & 3,77 \\
\hline Desvio & & & \\
\hline Padrão & 1,98 & 1,94 & 1,94 \\
\hline Assimetria & $-0,52$ & $-0,52$ & $-0,52$ \\
\hline Curtose & 0,46 & 0,46 & 0,46 \\
\hline
\end{tabular}

Pelas Figuras 5-7 e 5-8 e Tabelas 5-4 e 5-5, observa-se que a velocidade do vento não varia muito com a diferença de altitude de 20 metros, entre a torre e a estimativa dos dados. Obviamente, isto só é válido para terrenos planos, que é o 
caso da localidade desta fazenda eólica. Mesmo assim, por uma questão de rigor, foi considerada para as análises subsequentes a velocidade calculada a 80 metros pela Lei da Potência.

A etapa seguinte foi analisar o potencial eólico desta região da fazenda de Bons Ventos através dos dados dos dois conjuntos de variáveis e verificar se existe alguma diferença entre estes. O primeiro item a ser considerado na avaliação do potencial eólico de uma região são os parâmetros da distribuição Weibull. Tais parâmetros foram calculados a partir das relações apresentadas no Capítulo 3.

Tabela 5-6: Estimativas dos parâmetros da distribuição Weibull das duas fontes de dados.

\begin{tabular}{lll}
\hline Parâmetros & ERAI & NNRP \\
$k$ & 4,2 & 4,6 \\
$c$ & $8,38 \mathrm{~m} / \mathrm{s}$ & $8,38 \mathrm{~m} / \mathrm{s}$ \\
\hline
\end{tabular}

Verifica-se pela Tabela 5-6 que as estimativas destes parâmetros para os dois conjuntos de dados são próximos. Contudo, deve-se observar o valor alto estimado para o parâmetro $k$ em relação à faixa de 1,5 a 3, apresentado por Dalmaz [8]. Uma possível razão para estes valores pode ser a intensidade alta dos ventos estimados nestas duas fontes (vide Histogramas Figura 5-3).

O segundo item a ser considerado na avaliação do potencial eólico da região de Bons Ventos é a chamada Densidade de Energia Eólica (DEE), cuja formula já foi apresentada no Capítulo 3. Sendo assim, considerando o valor constante de $1,225 \mathrm{~kg} / \mathrm{m}^{3}$ para a densidade do ar, a expressão para o cálculo da densidade de energia eólica (DEE) será dada por

$$
D E E=0,6125 \frac{1}{n} \sum_{i=1}^{n} V_{j}^{3}
$$

onde $n$ é o número de observações de velocidades do vento e $V_{j}$ são as $j$-ésimas velocidades do vento.

Os valores obtidos para a DEE usando as duas fontes de dados, são de $327,3777 \mathrm{~W} / \mathrm{m}^{2}$ para ERAI e $324,3138 \mathrm{~W} / \mathrm{m}^{2}$ para $\mathrm{NNRP}$, que permitem classificar a região de Bons Ventos como pertencente à classe 3, ou seja, uma região propícia para a produção de energia eólica. 
Com os resultados obtidos até então, pode-se calcular a potência teórica do ar em cada turbina através da fórmula (3.16). Em Bons Ventos são utilizadas turbinas do modelo Suzlon S-88, e segundo Suzlon [26], a área varrida pelo rotor desta turbina seria $A=6,082 \mathrm{~m}^{2}$.

Segundo o site Portal Canoa Quebrada [22], o parque eólico de Bons Ventos possui 24 aerogeradores, de modo que a potencia total do parque é resultante da soma das potências teórica destas 24 turbinas, cuja dispersão espacial é visualizada na Figura 5-1.
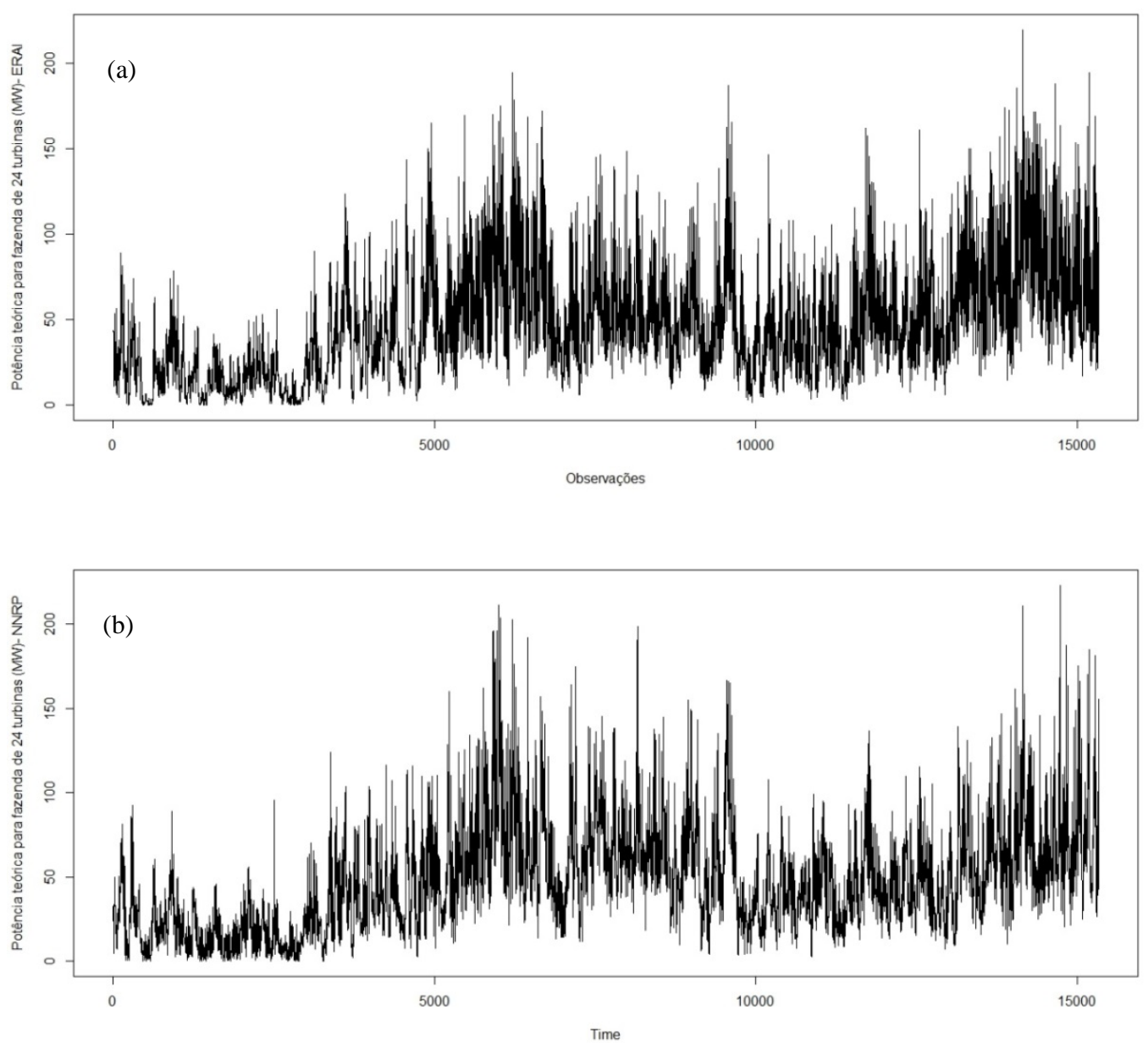

Figura 5-9: Potência teórica calculada para uma fazenda eólica (24 turbinas), utilizando as fontes ERAI e NNRP. 

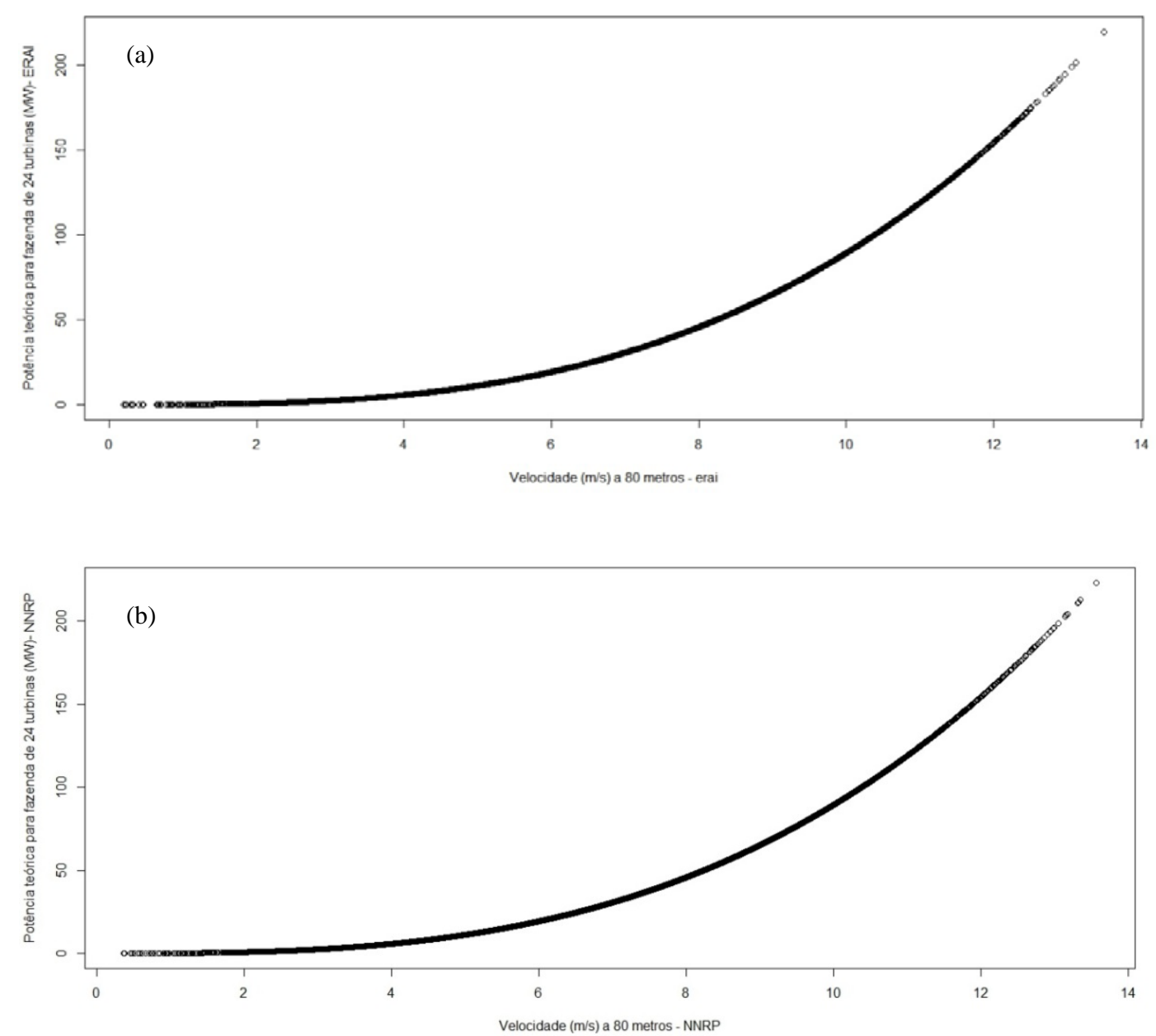

Figura 5-10: Gráfico de dispersão entre potência teórica calculada e a velocidade para a fazenda eólica (24 turbinas) de Bons Ventos, utilizando as fontes ERAI (a) e NNRP (b).

Tabela 5-7: Estatísticas descritivas das potências calculadas para a fazenda de 24 turbinas de Bons Ventos.

\begin{tabular}{lrr}
\hline & Potência & \multicolumn{1}{l}{ Potência } \\
& ERAI & \multicolumn{1}{l}{ NNRP } \\
N & 15336 & 15336 \\
NA & 0 & 0 \\
Mínimo & 0,00 & 0,00 \\
Máximo & 219,87 & 223,1 \\
$1^{\circ}$ Quartil & 23,10 & 24,56 \\
$3^{\circ}$ Quartil & 66,40 & 64,37 \\
Média & 47,79 & 47,34 \\
Mediana & 41,98 & 43,22 \\
Desvio & & \\
Padrão & 32,62 & 30,57 \\
Assimetria & 0,93 & 0,99 \\
Curtose & 0,79 & 1,50 \\
\hline
\end{tabular}


Observa-se do gráfico 5-10 que a potência teórica da fazenda de Bons Ventos possui um comportamento não linear com a velocidade dos ventos fornecidos pelas duas fontes de dados.

Resta ainda avaliar neste estudo os dados de geração observados, ou seja, o que foi efetivamente produzido pela fazenda eólica.

Tabela 5-8: Estatísticas descritivas da Geração Eólica.

\begin{tabular}{cc}
\hline & Geração \\
Eólica \\
NA & 15336 \\
Mínimo & 0 \\
Máximo & 50,97 \\
$1^{\circ}$ Quartil & 5,37 \\
$3^{\circ}$ Quartil & 29,57 \\
Média & 18,61 \\
Mediana & 15,58 \\
Soma & 285339,46 \\
Variância & 227,60 \\
Desvio Padrão & 15,09 \\
Assimetria & 0,54 \\
Curtose & $-0,87$ \\
\hline
\end{tabular}




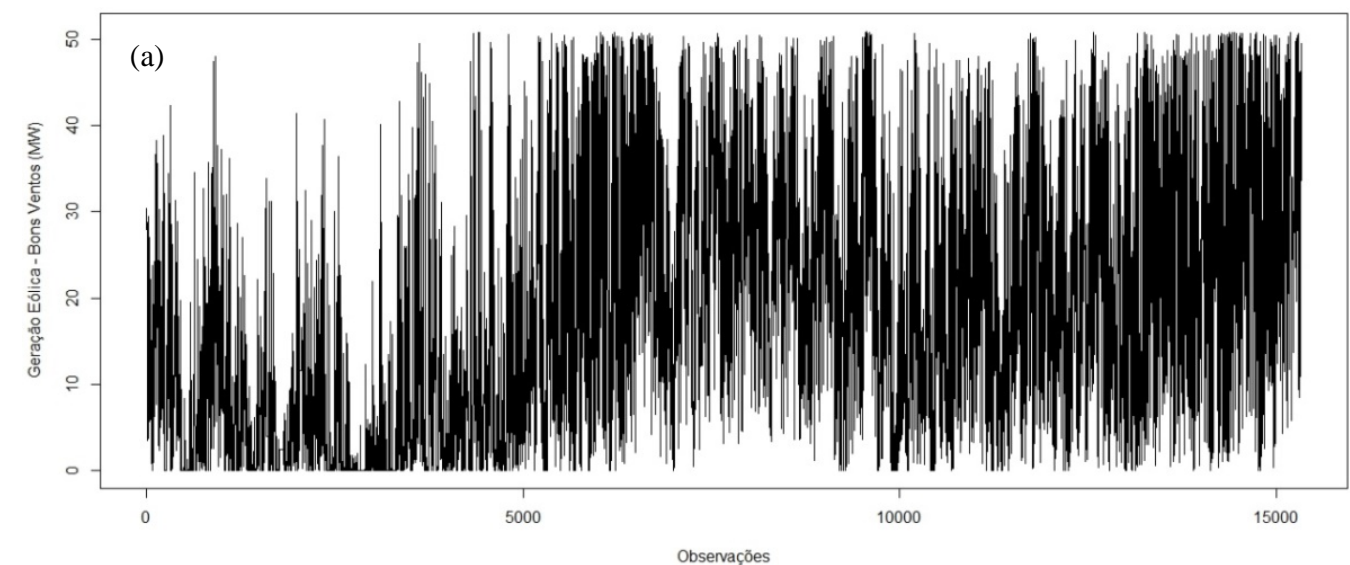

Histograma da Geração Eólica (MW) - Bons Ventos

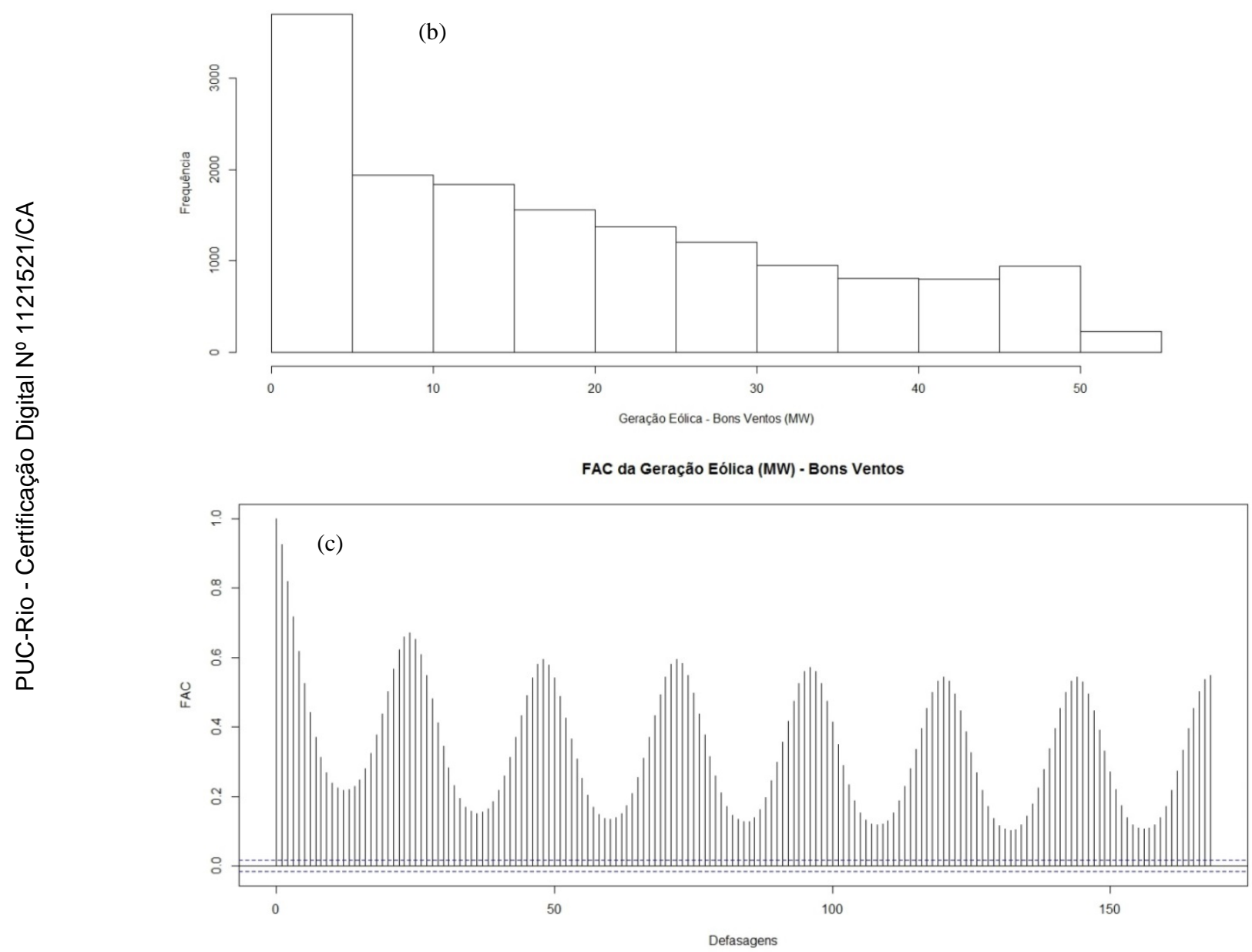

Figura 5-11: Série Histórica (a), Histograma (b) e Auto correlação simples (c) da geração eólica.

Pela Tabela 5-8 e Figura 5-11, constata-se uma alta incidência de instantes em que a produção da fazenda é igual à zero. Isto pode ser devido à manutenção das turbinas ou o simples fechamento destas. Verifica-se também o 
comportamento sazonal em relação a estes dados, referente ao período de 24 horas.
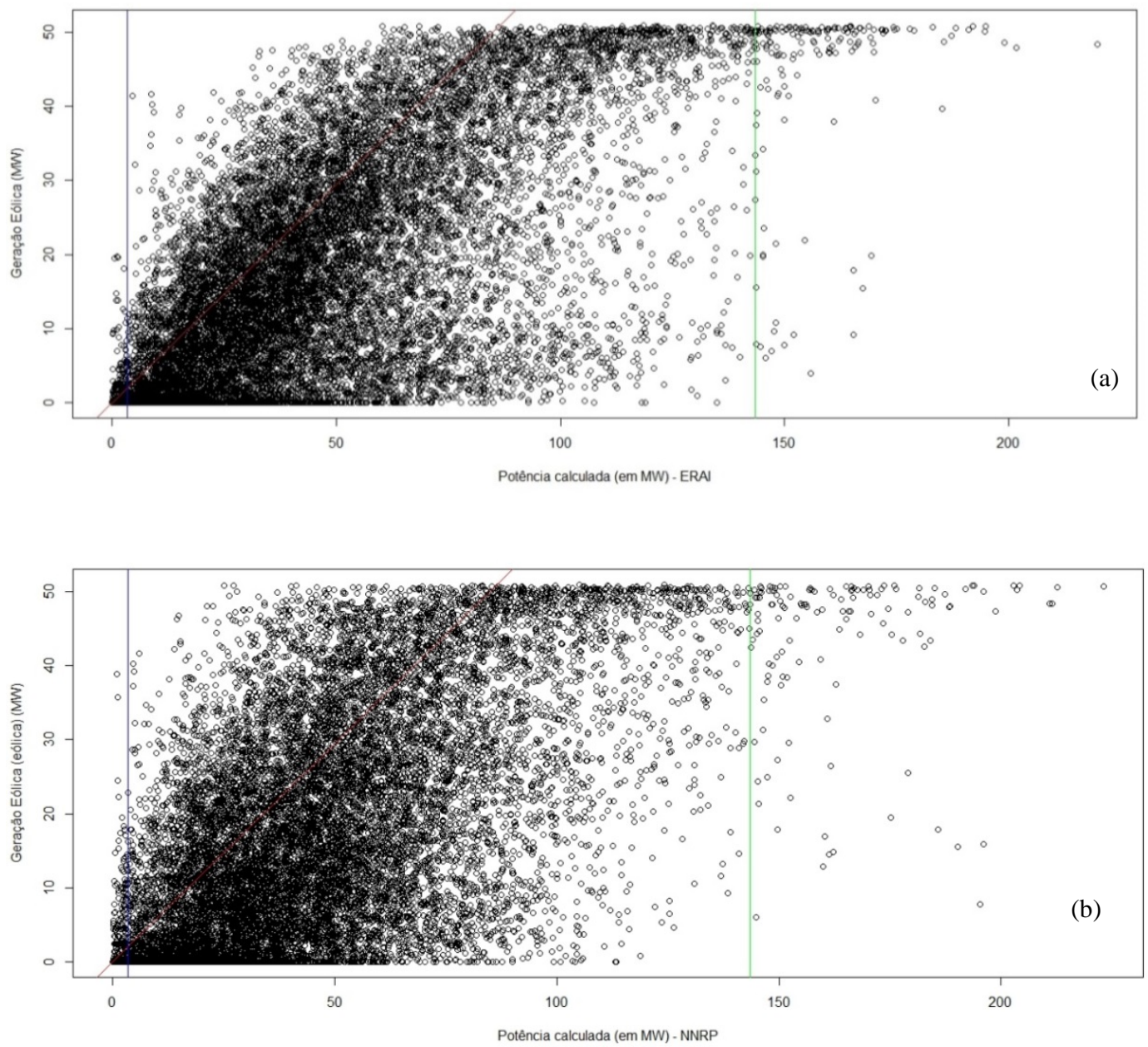

Figura 5-12: Gráfico de dispersão da potência calculada para a fazenda contra a Geração Eólica de Bons Ventos dos bancos de dados ERAI (a) e NNRP (b).

Pela Figura 5-12, observa-se que existe uma relação não linear entre a geração eólica e a potência teórica calculada. Esta também sugere que a potência gerada ultrapassa a potência calculada em um limite maior que 0,59, que corresponde ao limite de Betz. Tais dados podem ser visualizados acima da reta de cor vermelha na Figura. As retas de cores azul e verde representam a potência calculada para as velocidades de cut-in (4 m/s) e cut-out $(25 \mathrm{~m} / \mathrm{s})$. 


\section{6 \\ Modelagem e previsão}

\section{1}

\section{Modelagem dos dados}

Nesta seção serão apresentados os diversos procedimentos usados na modelagem dos dados que foram descritos até então. O objetivo deste estudo é ajustar um modelo que consiga explicar a geração eólica através da velocidade do vento para que, com isto, se consiga construir um histórico de geração eólica dos 30 anos anteriores.

Inicialmente a modelagem destes dados considerou a velocidade do vento elevada ao cubo, espelhada pela fórmula da potência teórica do vento. Este também considerou inicialmente apenas uma fonte de dados, a NNRP, para verificar se esta bastaria para a obtenção de resultados satisfatórios. Assim foi proposto o modelo inicial (6.1), em que

$$
y_{t}=\beta_{0}+\beta_{1} x_{1 t}+\beta_{2} x_{2 t}+\varepsilon_{t}
$$

onde $y_{t}$ é a geração eólica, $x_{1 t}$ e $x_{2 t}$ são as componentes da velocidade decomposta e $\varepsilon_{t} \sim N\left(0, \sigma^{2}\right)$. No caso da velocidade foi considerada a sua decomposição em uma direção específica. Assim sendo as variáveis independentes do modelo (6.1) foram calculadas da seguinte forma:

$$
\begin{aligned}
& x_{1 t}=\left(v_{t} \cos \left(D-d_{t}\right)\right)^{3} \\
& x_{2 t}=\left(v_{t} \operatorname{sen}\left(D-d_{t}\right)\right)^{3}
\end{aligned}
$$

onde $D$ é a direção considerada para a decomposição do vento, $v_{t}$ e $d_{t}$ são a velocidade e direção do vento do banco de dados no instante $t$. No ajuste dos modelos, foram consideradas as direções para a decomposição de $90^{\circ}, 100^{\circ}, 110^{\circ}$ e $115^{\circ}$. Como a diferença entre estes ângulos é pequena, os resultados do ajuste para cada modelo são similares para as quatro direções. 
As Figuras 6-1 e 6-2 apresentam os resultados considerando o caso da decomposição a $90^{\circ}$. Contudo o mesmo padrão se repete para outras direções. A assimetria nos resíduos (Figura 6-1) e a sua elevada sazonalidade observada no gráfico de autocorrelação simples (Figura 6-2) indicam que eles não aparentam possuir uma distribuição normal. Isto sugere que este modelo não é adequado para explicar a geração eólica de forma plausível e aceitável.

Em vista destes resultados, pensou-se em outras formas de modelagem que conseguissem fornecer resultados satisfatórios.

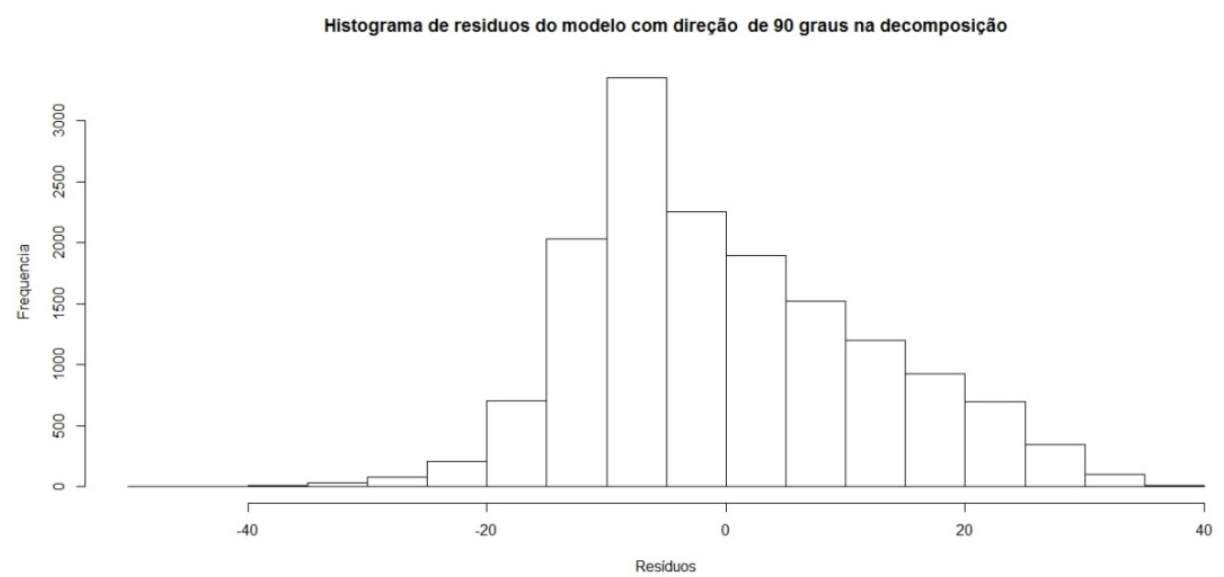

Figura 6-1: Histograma dos resíduos do modelo (6.1), considerando $D=\mathbf{9 0}^{\circ}$.

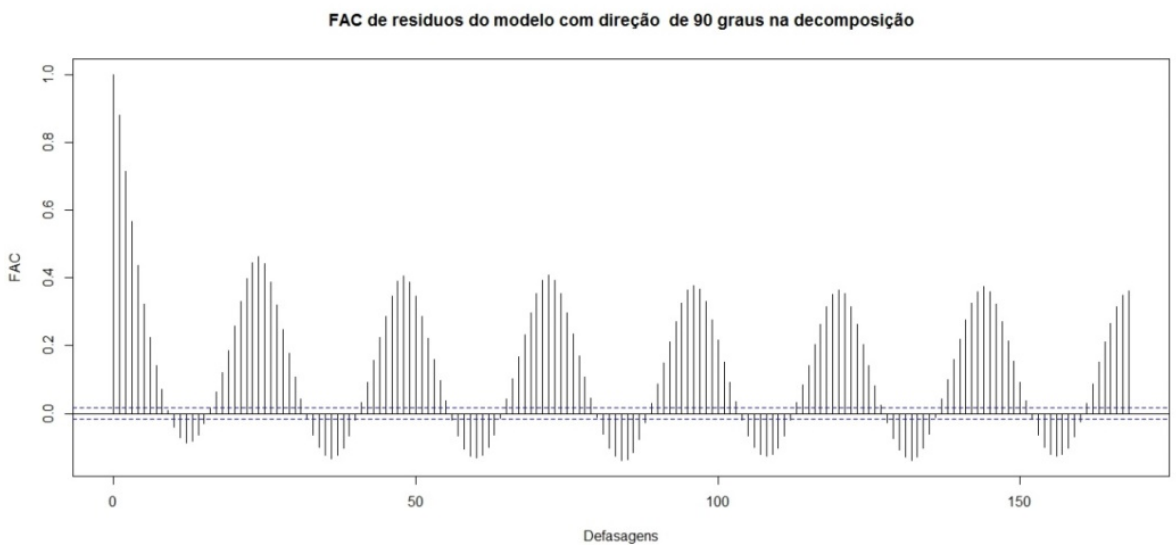

Figura 6-2: Autocorrelação simples dos resíduos do modelo (6.1), considerando $D=\mathbf{9 0}^{\circ}$.

Com base no comportamento altamente sazonal dos resíduos, resolveu-se incluir algumas defasagens da própria produção eólica no modelo. Sendo assim, como uma primeira tentativa, foram incluídas as defasagens da produção eólica em 12 e 24 horas. Nestas condições utilizou-se o modelo (6.2) em que 
$y_{t}=\beta_{0}+\beta_{1} x_{1 t}+\beta_{2} x_{2 t}+\beta_{3} y_{t+12}+\beta_{4} y_{t+24}+\varepsilon_{t}$,

onde $\varepsilon_{t} \sim N\left(0, \sigma^{2}\right), x_{1 t}=\left(v_{t} \cos \left(D-d_{t}\right)\right)^{3}$ e $x_{2 t}=\left(v_{t} \operatorname{sen}\left(D-d_{t}\right)\right)^{3}$.

Novamente foi considerada a decomposição do vento nas direções de $90^{\circ}, 100^{\circ}, 110^{\circ}$ e $115^{\circ}$. Um dos casos estudados com este modelo não considerou a decomposição da velocidade, visando avaliar a relevância e necessidade desta decomposição no ajuste do modelo.

Tabela 6-1: $R^{2}, R^{2}$ ajustado, AIC, BIC e p-valores dos testes de White e Jarque-Bera do modelo (6.2), de acordo com a direção de decomposição e sem decomposição.

\begin{tabular}{lllllll}
\hline Modelos & $\mathrm{R}^{2}$ & $\mathrm{R}^{2}$ aj. & AIC & BIC & White & J.B. \\
Decomp. a $90^{\circ}$ & 0,54 & 0,54 & 114622,6 & 114668,4 & 0,00 & 0,00 \\
Decomp. a $100^{\circ}$ & 0,55 & 0,55 & 114211 & 114256,8 & 0,00 & 0,00 \\
Decomp. a $110^{\circ}$ & 0,56 & 0,56 & 114050,5 & 114096,3 & 0,00 & 0,00 \\
Decomp. a $115^{\circ}$ & 0,56 & 0,56 & 114144,2 & 114190 & 0,00 & 0,00 \\
Sem decomposição & 0,53 & 0,53 & 114890,6 & 114928,8 & 0,00 & 0,00 \\
\hline
\end{tabular}

(a)

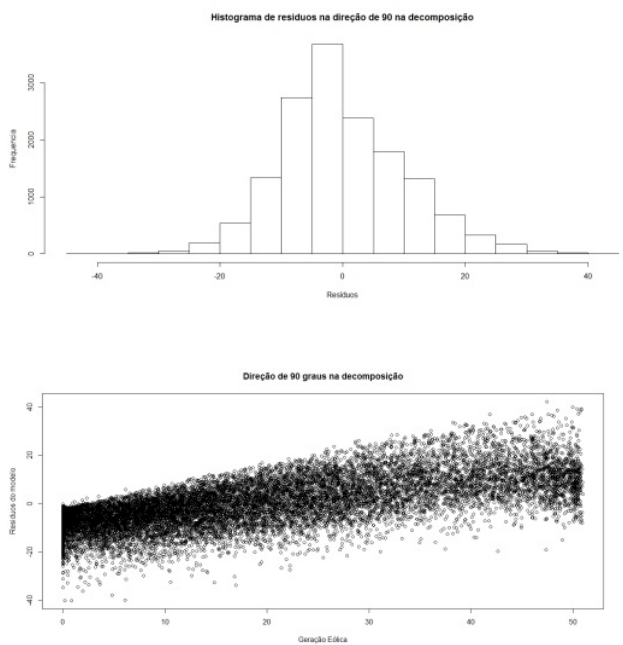

(c) (b)

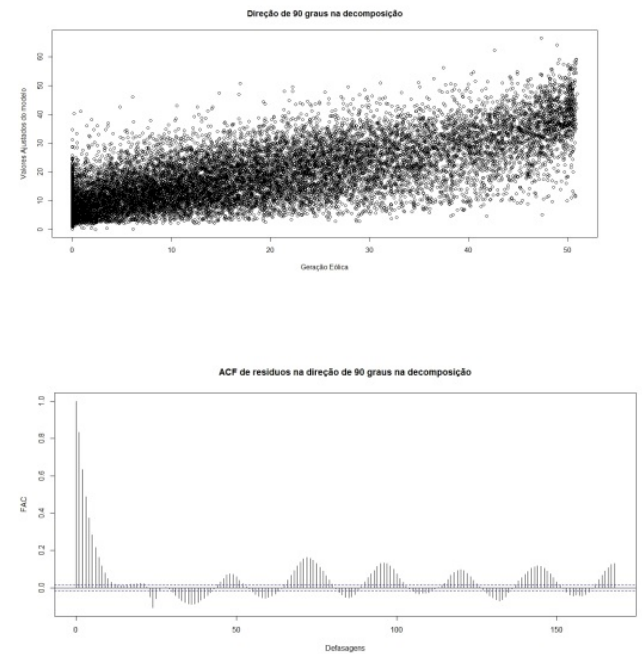

(d)

Figura 6-3: Histogramas dos resíduos (a), gráfico de dispersão da geração eólica com os valores ajustados pelo modelo (b) e com os resíduos do modelo (c) e autocorrelação simples dos resíduos (d) do modelo (6.2) considerando $\mathrm{D}=\mathbf{9 0}^{\circ}$.

Como se pode observar pela Figura 6-3, os resultados ainda não foram completamente satisfatórios, com os histogramas apresentando uma elevada assimetria e sua autocorrelação ainda sendo significativa. Além disso, os $\mathrm{R}^{2}$ e $\mathrm{R}^{2}$ ajustados do modelo em relação à direção de decomposição da velocidade não 
foram muito elevados. Os resultados para as outras direções foram de aparência similar a estes, uma vez que o intervalo entre esses ângulos é muito pequeno.

Também se observa pela Tabela 6-1 que os p-valores dos testes estatísticos aplicados aos resíduos deste modelo são nulos, rejeitando com isso a hipótese de homoscedasticidade e normalidade dos resíduos para um nível de significância de 5\%. Esta constatação pode ser atribuída ao fato de que os modelos foram ajustados com cada variável possuindo em torno de 15 mil observações. Estes valores elevados acarretam em valores nulos dos p-valores destes testes.

Com o objetivo de melhorar o ajuste foram consideradas algumas alternativas. Uma forma encontrada foi a inclusão de mais defasagens da própria produção eólica no modelo. Assumindo que a produção eólica gerada em um determinado instante possa estar relacionada a produção gerada em instantes anteriores e próximos, adicionou-se as defasagens de 1 a 11 no modelo.

Outro item também levado em consideração na modelagem foi a variável indicadora da hora de produção eólica. A definição desta indicadora basicamente atribui o valor 1 para aquela determinada hora e 0 para as outras horas. Devido à multicolinearidade, só foi possível incluir no modelo 23 variáveis indicadoras. Estas variáveis podem indicar se em alguma faixa de horas no decorrer do dia os ventos são mais frequentes, atribuindo assim uma maior geração de energia eólica. Considerando estes dois novos aprimoramentos, tem-se o modelo (6.3) em que,

$y_{t}=\beta_{0}+\beta_{1} h_{0}+\beta_{2} h_{1}+\beta_{3} h_{2}+\beta_{4} h_{3}+\beta_{5} h_{4}+\beta_{6} h_{5}+\beta_{7} h_{6}+\beta_{8} h_{7}+\beta_{9} h_{8}+$ $\beta_{10} h_{9}+\beta_{11} h_{10}+\beta_{12} h_{11}+\beta_{13} h_{12}+\beta_{14} h_{13}+\beta_{15} h_{14}+\beta_{16} h_{15}+\beta_{17} h_{16}+$ $\beta_{18} h_{17}+\beta_{19} h_{18}+\beta_{20} h_{19}+\beta_{21} h_{20}+\beta_{22} h_{21}+\beta_{23} h_{22}+\beta_{24} x_{1 t}+\beta_{25} x_{2 t}+$ $\beta_{26} y_{t+1}+\beta_{27} y_{t+2}+\beta_{28} y_{t+3}+\beta_{29} y_{t+4}+\beta_{30} y_{t+5}+\beta_{31} y_{t+6}+\beta_{32} y_{t+7}+$ $\beta_{33} y_{t+8}+\beta_{34} y_{t+9}+\beta_{35} y_{t+10}+\beta_{36} y_{t+11}+\beta_{37} y_{t+12}+\beta_{38} y_{t+24}+\varepsilon_{t}$,

onde $\varepsilon_{t} \sim N\left(0, \sigma^{2}\right), x_{1 t}=\left(v_{t} \cos \left(D-d_{t}\right)\right)^{3}$ e $x_{2 t}=\left(v_{t} \operatorname{sen}\left(D-d_{t}\right)\right)^{3}$.

Tabela 6-2: $\mathrm{R}^{2}, \mathrm{R}^{2}$ ajustado, AIC, BIC e p-valores dos testes de White e Jarque-Bera do modelo (6.3), de acordo com a direção de decomposição e sem decomposição.

\begin{tabular}{lllllll}
\hline Modelos & $\mathrm{R}^{2}$ & $\mathrm{R}^{2}$ aj. & AIC & BIC & White & J.B. \\
Decomp. a $90^{\circ}$ & 0,89 & 0,89 & 93016,83 & 93322,29 & 0,00 & 0,00 \\
Decomp. a $100^{\circ}$ & 0,89 & 0,89 & 92979,74 & 93285,2 & 0,00 & 0,00 \\
Decomp. a $110^{\circ}$ & 0,89 & 0,89 & 93034,35 & 93339,81 & 0,00 & 0,00 \\
Decomp. a $115^{\circ}$ & 0,89 & 0,89 & 93092,9 & 93398,36 & 0,00 & 0,00 \\
Sem decomposição & 0,89 & 0,89 & 93214,38 & 93512,2 & 0,00 & 0,00 \\
\hline
\end{tabular}




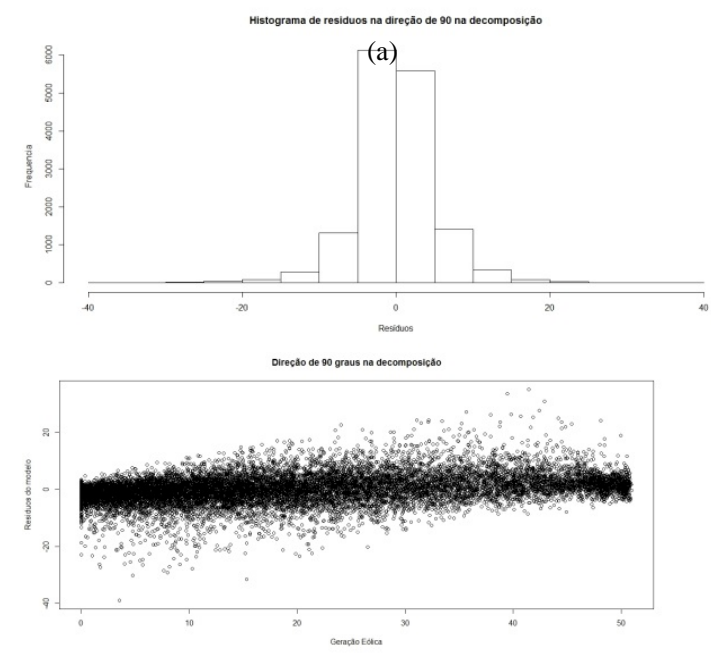

(c)

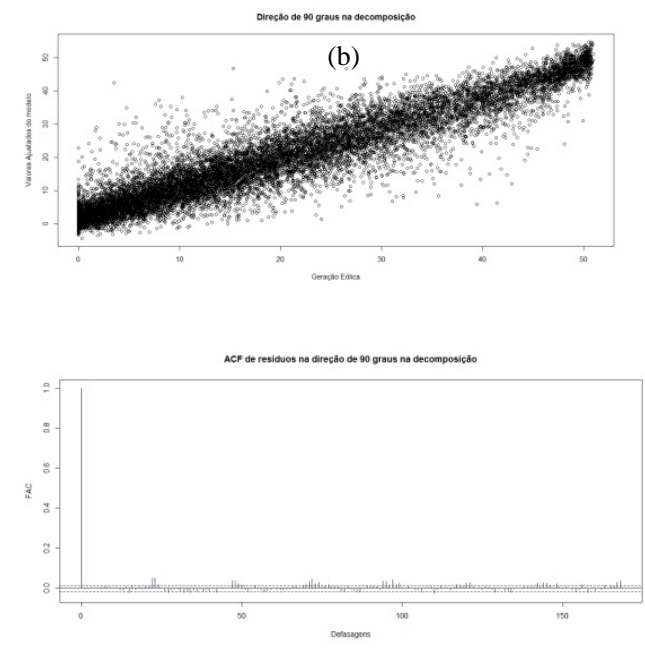

(d)

Figura 6-4: Histogramas dos resíduos, gráfico de dispersão da geração eólica com os valores ajustados pelo modelo (b) e com os resíduos do modelo (c) e autocorrelação simples dos resíduos (d) do modelo (6.3), considerando $\mathrm{D}=\mathbf{9 0}^{\circ}$.

A inclusão destas novas variáveis foi definitiva para a obtenção de um resultado mais satisfatório para o modelo. Os valores do $\mathrm{R}^{2}$ e $\mathrm{R}^{2}$ ajustado tenderam a subir atingindo o patamar de 0,89, assim como as análises gráficas feitas com a Figura 6-4. Como pode se observar por estes resultados, os valores ajustados foram bem adequados ao modelo, e os resíduos não apresentam mais uma sazonalidade marcante, indicando ausência de autocorrelação serial e presença de uma distribuição normal.

Mais uma vez observa-se que os p-valores dos testes White e Jarque-Bera aplicados aos resíduos deste modelo foram nulos, em vista do elevado número de observações em cada variável. Todavia, pode-se chegar a conclusão de que esta informação não é conclusiva, uma vez que pelo histograma e gráfico de autocorrelação simples dos resíduos mostrados pela Figura 6-4, a hipótese de normalidade e de homoscedasticidade não seria rejeitada.

Apesar dos bons resultados alcançados nesta etapa, consideraram-se alternativas com o objetivo de melhorar o ajuste. A decomposição da velocidade defasada em 12 e em 24 horas foi incluída no modelo, assim como a utilização de dois bancos de dados de velocidade. Até então somente um banco de dados de velocidade (NNRP) para a fazenda eólica de Bons Ventos havia sido utilizado nestes cálculos. Agora o modelo será ajustado utilizando ambas as fontes de dados (ERAI e NNRP), usando a expressão (6.4) em que 
$y_{t}=\beta_{0}+\beta_{1} h_{0}+\beta_{2} h_{1}+\beta_{3} h_{2}+\beta_{4} h_{3}+\beta_{5} h_{4}+\beta_{6} h_{5}+\beta_{7} h_{6}+\beta_{8} h_{7}+\beta_{9} h_{8}+$ $\beta_{10} h_{9}+\beta_{11} h_{10}+\beta_{12} h_{11}+\beta_{13} h_{12}+\beta_{14} h_{13}+\beta_{15} h_{14}+\beta_{16} h_{15}+\beta_{17} h_{16}+$ $\beta_{18} h_{17}+\beta_{19} h_{18}+\beta_{20} h_{19}+\beta_{21} h_{20}+\beta_{22} h_{21}+\beta_{23} h_{22}+\beta_{24} x_{1 t}+\beta_{25} x_{2 t}+$ $\beta_{26} x_{3 t}+\beta_{27} x_{4 t}+\beta_{28} x_{5 t}+\beta_{29} x_{6 t}+\beta_{30} z_{1 t}+\beta_{31} z_{2 t}+\beta_{32} z_{3 t}+\beta_{33} z_{4 t}+$ $\beta_{34} z_{5 t}+\beta_{35} z_{6 t}+\beta_{36} y_{t+1}+\beta_{37} y_{t+2}+\beta_{38} y_{t+3}+\beta_{39} y_{t+4}+\beta_{40} y_{t+5}+$ $\beta_{41} y_{t+6}+\beta_{42} y_{t+7}+\beta_{43} y_{t+8}+\beta_{44} y_{t+9}+\beta_{45} y_{t+10}+\beta_{46} y_{t+11}+\beta_{47} y_{t+12}+$ $\beta_{48} y_{t+24}+\varepsilon_{t}$

onde $\varepsilon_{t} \sim N\left(0, \sigma^{2}\right)$,

$x_{1 t}=\left(v_{t} \cos \left(D-d_{t}\right)\right)^{3}, x_{2 t}=\left(v_{t} \operatorname{sen}\left(D-d_{t}\right)\right)^{3}$,

$x_{3 t}=\left(v_{t+12} \cos \left(D-d_{t+12}\right)\right)^{3}, x_{4 t}=\left(v_{t+12} \operatorname{sen}\left(D-d_{t+12}\right)\right)^{3}, x_{5 t}=$ $\left(v_{t+24} \cos \left(D-d_{t+24}\right)\right)^{3}$ e $x_{6 t}=\left(v_{t+24} \operatorname{sen}\left(D-d_{t+24}\right)\right)^{3}$

são as decomposições em relação ao banco de dados ERAI e $z_{1 t}=\left(v_{t} \cos (D-\right.$ $\left.\left.d_{t}\right)\right)^{3}, \quad z_{2 t}=\left(v_{t} \operatorname{sen}\left(D-d_{t}\right)\right)^{3}, \quad z_{3 t}=\left(v_{t+12} \cos \left(D-d_{t+12}\right)\right)^{3}, \quad z_{4 t}=$ $\left(v_{t+12} \operatorname{sen}\left(D-d_{t+12}\right)\right)^{3}, \quad z_{5 t}=\left(v_{t+24} \cos \left(D-d_{t+24}\right)\right)^{3} \quad \mathrm{e}$ $z_{6 t}=\left(v_{t+24} \operatorname{sen}\left(D-d_{t+24}\right)\right)^{3}$ decomposições da velocidade em relação ao banco de dados NNRP.

Tabela 6-3: $R^{2}, R^{2}$ ajustado, AIC, BIC e p-valores dos testes de White e Jarque-Bera do modelo (6.4), de acordo com a direção de decomposição e sem decomposição.

\begin{tabular}{lllllll}
\hline Modelos & $\mathrm{R}^{2}$ & $\mathrm{R}^{2}$ aj. & AIC & BIC & White & J.B. \\
Decomp. a 90 & 0,89 & 0,89 & 92364,26 & 92746,08 & 0,00 & 0,00 \\
Decomp. a $100^{\circ}$ & 0,89 & 0,89 & 92527,89 & 92909,7 & 0,00 & 0,00 \\
Decomp. a $110^{\circ}$ & 0,89 & 0,89 & 92755,42 & 93137,24 & 0,00 & 0,00 \\
Decomp. a 115 & 0,89 & 0,89 & 92856,59 & 93238,41 & 0,00 & 0,00 \\
Sem decomposição & 0,89 & 0,89 & 93056,31 & 93392,31 & 0,00 & 0,00 \\
\hline
\end{tabular}

(a)

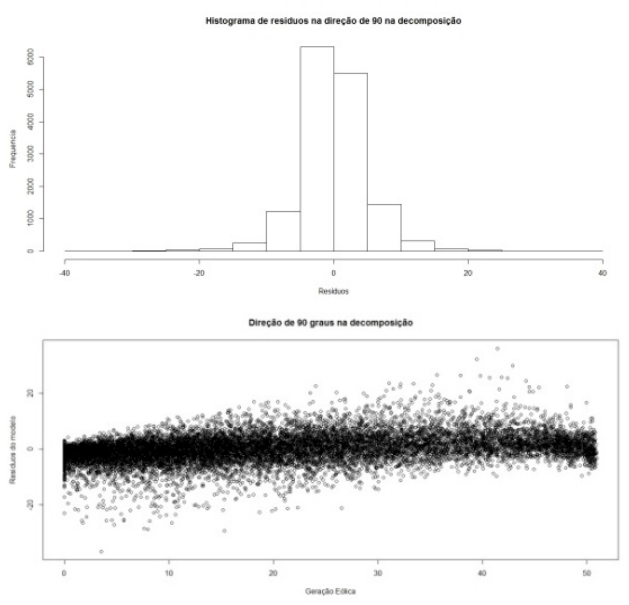

(c) (b)

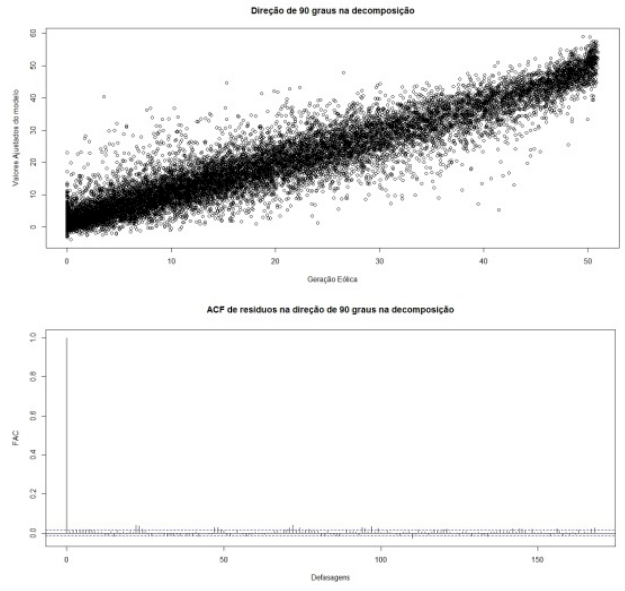

(d)

Figura 6-5: Histogramas dos resíduos, gráfico de dispersão da geração eólica com os valores ajustados pelo modelo (b) e com os resíduos do modelo (c) e autocorrelação simples dos resíduos (d) do modelo (6.4), considerando $\mathrm{D}=\mathbf{9 0}^{\circ}$. 
Os resultados alcançados pelo ajuste deste modelo aprimorado foram levemente melhores que os alcançados com o modelo (6.3), onde se observa um aumento do valor do $\mathrm{R}^{2}$ e $\mathrm{R}^{2}$ ajustado e uma redução do valor do AIC e BIC. As observações obtidas graficamente em relação aos resíduos e um bom comportamento em relação aos valores ajustados com este modelo aprimorado são similares aquelas apresentadas pelo modelo (6.3). Tendo isso em mente, escolheuse o modelo (6.4) com decomposição a $90^{\circ}$ como sendo o modelo responsável pela previsão out-of-sample, já que este possui o menor AIC.

Pode-se observar que, assim como nos modelos anteriores, os p-valores dos testes de White e Jarque-Bera foram nulos. Contudo, isto não implica na rejeição das hipóteses de homescedasticidade e normalidade dos resíduos, tendo em vista o comportamento gráfico mostrado na Figura 6-5.

No sentido de explorar o resultado final obtido, ajustou-se o modelo (6.4) utilizando somente uma das fontes de velocidade do vento com um modelo só tendo a fonte de velocidade ERAI e outro modelo somente a fonte de velocidade NNRP.

Tabela 6-4: $\mathrm{R}^{2}, \mathrm{R}^{2}$ ajustado, AIC, BIC e p-valores dos testes de White e Jarque-Bera do modelo (6.4) somente com os dados ERAl, de acordo com a direção de decomposição e sem decomposição.

\begin{tabular}{lllllcl}
\hline Modelos & $\mathrm{R}^{2}$ & $\mathrm{R}^{2}$ aj. & AIC & BIC & White & J.B. \\
Decomp. a $90^{\circ}$ & 0,89 & 0,89 & 92397,89 & 92733,9 & 0,00 & 0,00 \\
Decomp. a $100^{\circ}$ & 0,89 & 0,89 & 92603,82 & 92939,82 & 0,00 & 0,00 \\
Decomp. a $110^{\circ}$ & 0,89 & 0,89 & 92875 & 93211 & 0,00 & 0,00 \\
Decomp. a $115^{\circ}$ & 0,89 & 0,89 & 92991,07 & 93327,07 & 0,00 & 0,00 \\
Sem decomposição & 0,89 & 0,89 & 93120,04 & 93433,13 & 0,00 & 0,00 \\
\hline
\end{tabular}

Tabela 6-5: $\mathrm{R}^{2}, \mathrm{R}^{2}$ ajustado, AIC, BIC e p-valores dos testes de White e Jarque-Bera do modelo (6.4) somente com os dados NNRP, de acordo com a direção de decomposição e sem decomposição.

\begin{tabular}{lllllcl}
\hline Modelos & $\mathrm{R}^{2}$ & $\mathrm{R}^{2}$ aj. & AIC & BIC & White & J.B. \\
Decomp. a $90^{\circ}$ & 0,89 & 0,89 & 92957,64 & 93293,64 & 0,00 & 0,00 \\
Decomp. a $100^{\circ}$ & 0,89 & 0,89 & 92963,09 & 93299,09 & 0,00 & 0,00 \\
Decomp. a $110^{\circ}$ & 0,89 & 0,89 & 93039,4 & 93375,4 & 0,00 & 0,00 \\
Decomp. a $115^{\circ}$ & 0,89 & 0,89 & 93089,78 & 93425,78 & 0,00 & 0,00 \\
Sem decomposição & 0,89 & 0,89 & 93193,02 & 93506,12 & 0,00 & 0,00 \\
\hline
\end{tabular}


Pode-se observar que ambos os resultados apresentados pelas Tabelas 6-4 e 6-5 são próximos aos da Tabela 6-3. No entanto, os modelos contando com somente uma fonte de velocidade apresentaram AIC levemente maiores que aquele que conta com as duas fontes de velocidade. Sendo assim, ainda preferiuse escolher o modelo contando com as duas fontes de velocidade.

\section{2}

\section{Previsão out-of-sample}

O objetivo deste estudo é construir um modelo com o qual seja possível explicar o histórico da produção eólica de forma adequada em certo período em que os dados são conhecidos, e a partir deste, construir o período inexistente dos dados de geração eólica. Sendo assim, primeiramente deve ser avaliada a sua capacidade de previsão para o período com dados conhecidos.

Levando em conta este propósito, este modelo foi reajustado sem uma parte dos dados assumida como período de teste, no qual foi avaliada a sua capacidade de previsão para os dados retirados e para os dados restantes, tomados como período de treinamento do modelo.

O período de teste é definido pelas primeiras 4320 observações, correspondentes aos primeiros 180 dias, enquanto que o restante das observações incorporam o período de treinamento. Vale ressaltar que estas 4320 observações foram retiradas de todas as variáveis na análise.

Esta análise foi ampliada para outras fazendas tais como Canoa Quebrada (C.Q.), Enacel (E.) e Icaraizinho (I.). Estas fazendas eólicas possuem o mesmo tipo de turbina e estão situadas em regiões próximas a Bons Ventos, o que implica na expectativa de que os resultados obtidos nelas sejam bem parecidos aos de Bons Ventos [4], [19] e [22]. A capacidade das fazendas Canoa Quebrada, Enacel e Icaraizinho são 57, 31,5 e 54,6 MW, respectivamente. Uma análise exploratória das variáveis velocidade e direção do vento e da geração eólica destas três fazendas pode ser visualizada pelos Apêndices A e B.

Como se observou, o número de variáveis no modelo escolhido (48) foi elevado. Com isso, foram aplicadas as técnicas de stepwise e LASSO. No entanto, 
devido ao grande número de dados utilizados, a técnica LASSO mostrou-se inadequada, apontando com isso para o uso do modelo completo.

Tabela 6-6: $\mathrm{R}^{2}, \mathrm{R}^{2}$ ajustado, AIC, BIC, MAE e RMSE in-sample para os modelos (6.4) completos e stepwise de Bons Ventos, Canoa Quebrada, Enacel e Icaraizinho.

\begin{tabular}{ccccccc}
\hline Modelos & $\mathrm{R}^{2}$ & $\mathrm{R}^{2}$ aj. & AIC & BIC & MAE & RSME \\
B.V. & 0,88 & 0,88 & 67353,9 & 67719,15 & 3,78 & 5,16 \\
B.V.S. & 0,88 & 0,88 & 67335,11 & 67598,08 & 3,76 & 5,16 \\
C.Q. & 0,87 & 0,87 & 71003,86 & 71369,1 & 4,46 & 6,09 \\
C.Q. S. & 0,87 & 0,87 & 70985,77 & 71226,83 & 4,46 & 6,09 \\
E. & 0,87 & 0,87 & 57091,99 & 57457,24 & 2,44 & 3,23 \\
E. S. & 0,87 & 0,87 & 57069,65 & 57332,63 & 2,44 & 3,23 \\
I. & 0,89 & 0,89 & 66088,82 & 66454,07 & 3,50 & 4,87 \\
I.S. & 0,89 & 0,89 & 66058,71 & 66285,16 & 3,51 & 4,87 \\
\hline
\end{tabular}

Na Tabela 6-6, têm-se os resultados de cada modelagem, onde B.V. indica o resultado obtido para o modelo completo de Bons Ventos, enquanto B.V.S. indica o resultado para o modelo stepwise de Bons Ventos. Esta mesma nomenclatura foi feita para Canoa Quebrada (C.Q.), Enacel (E.) e Icaraizinho (I.). Como previsto, a Tabela 6-6 mostra que realmente os resultados para as fazendas Canoa Quebrada, Enacel e Icaraizinho foram muito parecidos com aqueles obtidos para Bons Ventos. O Apêndice C apresenta os coeficientes estimados no ajuste dos modelos para estas quatro fazendas. O ajuste do modelo (6.4) é bem adequado para as quatro fazendas consideradas, uma vez que todos os $\mathrm{R}^{2}$ e $\mathrm{R}^{2}$ ajustados são maiores que 0,85 , sendo os maiores valores obtidos para a fazenda Icaraizinho. A qualidade do ajuste deste modelo também pode ser observada pelos valores pequenos das estatísticas in-sample MAE e RMSE, com os menores valores destas pertencendo a Enacel. 
Tabela 6-7: Porcentagem de incidência de previsões menores que zero, para cada os modelos completo e stepwise das fazendas estudadas.

\begin{tabular}{ll}
\hline B.V. & $1,23 \%$ \\
B.V.S. & $1,37 \%$ \\
C.Q. & $0,63 \%$ \\
C.Q.S. & $0,69 \%$ \\
E. & $7,64 \%$ \\
E.S. & $8,01 \%$ \\
I. & $0,00 \%$ \\
I.S. & $0,00 \%$ \\
\hline
\end{tabular}

Tabela 6-8: Estatísticas MAE, RMSE e Pseudo $\mathrm{R}^{2}$ out-of-sample para os modelos completos e stepwise de Bons Ventos, Canoa Quebrada, Enacel e Icaraizinho.

\begin{tabular}{cccc}
\hline & MAE & RMSE & Pseudo R ${ }^{2}$ \\
B.V. & 8,20 & 10,30 & 0,68 \\
B.V.S. & 8,16 & 10,25 & 0,68 \\
C.Q. & 10,68 & 13,12 & 0,63 \\
C.Q.S. & 10,52 & 12,93 & 0,64 \\
E. & 6,149 & 7,43 & 0,55 \\
E.S. & 6,131 & 7,41 & 0,55 \\
I. & 10,83 & 13,04 & 0,71 \\
I.S. & 10,94 & 13,14 & 0,70 \\
\hline
\end{tabular}

Na questão da previsão out-of-sample, algumas das fazendas eólicas apresentaram valores menores que zero. Neste caso, foi assumida como zero a previsão destes valores. Pela Tabela 6-7, verifica-se que a incidência de tais dados tende a variar de fazenda para fazenda eólica, sendo maior para Enacel e menor para Icaraizinho.

Após este procedimento, foram calculadas as estatísticas de aderência para os modelos considerando as previsões out-of-sample. De uma forma geral, observa-se que os valores dos MAE tenderam a ser altos, com os menores valores pertencendo à fazenda Enacel. Já os valores de Pseudo $\mathrm{R}^{2}$ foram todos positivos, indicando um bom ajuste do modelo em relação a sua capacidade de previsão, vide Tabela 6-8. 
Tabela 6-9: Estatísticas MAE, RMSE e Pseudo $\mathrm{R}^{2}$ out-of-sample para os modelos completos e stepwise de Bons Ventos, Canoa Quebrada, Enacel e Icaraizinho sem as defasagens da geração eólica.

\begin{tabular}{lcll}
\hline & MAE & \multicolumn{1}{c}{ RMSE } & Pseudo ${ }^{2}$ \\
B.V. & 7,60 & 9,57 & 0,72 \\
B.V.S. & 7,14 & 8,92 & 0,76 \\
C.Q. & 9,14 & 11,05 & 0,74 \\
C.Q.S. & 9,11 & 11,01 & 0,74 \\
E.C. & 4,72 & 5,74 & 0,73 \\
E.S. & 4,71 & 5,73 & 0,73 \\
I.C. & 8,78 & 10,60 & 0,81 \\
I.S. & 8,79 & 10,61 & 0,81 \\
\hline
\end{tabular}

Como parte de um procedimento investigativo, foram calculadas as medidas out-of-sample, considerando o modelo sem nenhuma defasagem da geração eólica, cujos resultados são mostrados na Tabela 6-9. Embora os valores sejam menores, indicando um erro menor por parte do modelo, ainda escolheu-se os modelos com as defasagens para análises subsequentes, pois observando a Tabela no Apêndice C, estas mostraram-se ser significativas em sua maioria, tanto para o modelo completo quanto para o stepwise.

Também foram calculados os valores da estatística MAE, considerando as periocidades horária, diária, semanal e mensal. De certa forma, observa-se que, conforme a periodicidade aumenta, os erros tendem a valores menores, como se observa pela Figura 6-6.

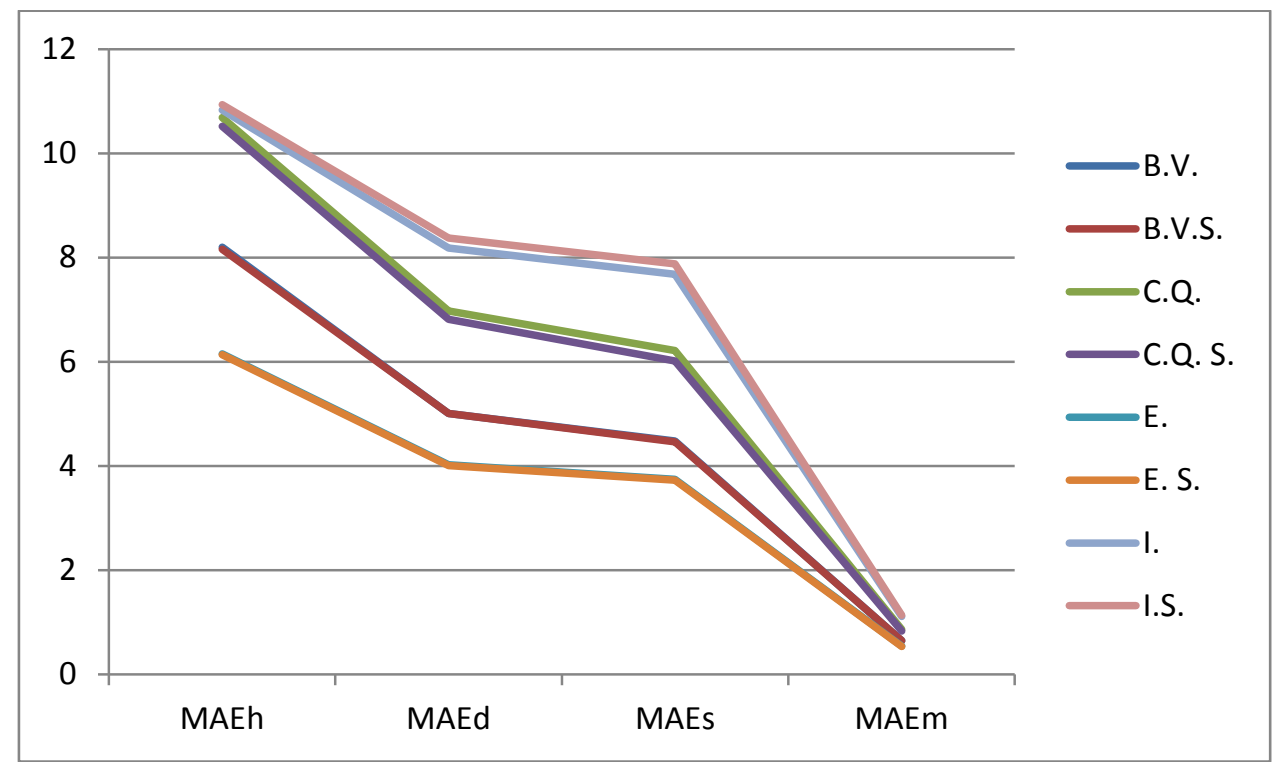

Figura 6-6: MAE out-of-sample horário, diário, semanal e mensal para os modelos completo e stepwise das fazendas estudadas. 


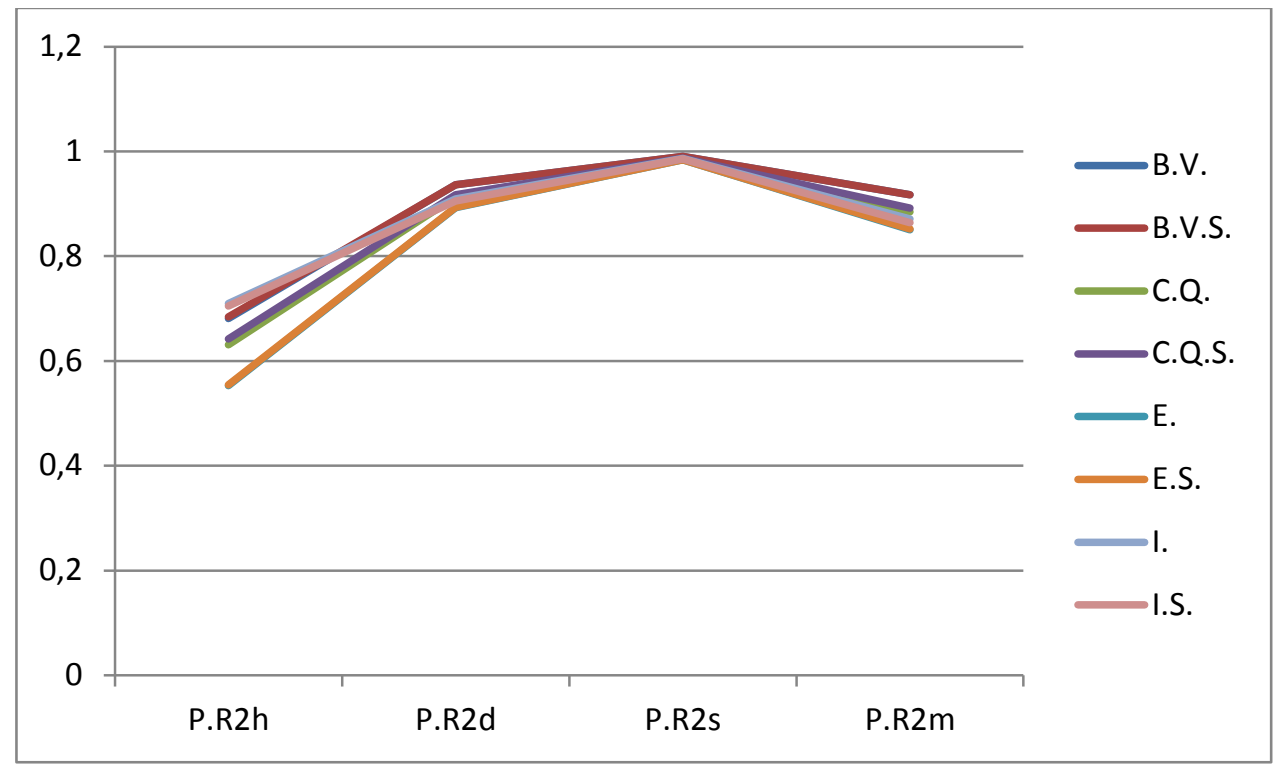

Figura 6-7: Pseudo $\mathrm{R}^{2}$ out-of-sample horário, diário, semanal e mensal para os modelos completo e stepwise das fazendas estudadas.

Em relação aos Pseudo $\mathrm{R}^{2}$, estes tenderam a aumentar com a periodicidade, alcançando o seu valor máximo para a periodicidade semanal. Por outro lado, os valores de Pseudo $\mathrm{R}^{2}$ diminuem sensivelmente para a periodicidade mensal. Vale ressaltar que todos os valores obtidos foram positivos.

Além disso, foi também estudado como tais medidas se comportam por tipo e patamar de carga. Este é definido pela similaridade de carga que é produzida em determinados períodos do dia, que pode ser dividida em, definida por [13]:

- Tipo 1: Segunda a sábado. Leve (0 às 6:59), Médio (7 às 17:59 e 21:00 às 23:59) e Pesado (18:00 as 20:59);

- Tipo 2: Domingo e feriados. Leve (0 às 16:59 e 22:00 às 23:59) Médio (17:00 às 21:59).

Esta análise pode ser visualizada pelas Figuras do Apêndice D, as quais apresentam um comportamento semelhante as dos casos anteriores em que não foram consideradas as divisões. Como no caso anterior, observa-se que os valores de MAE para a periodicidade horária foram maiores do que os valores para a periodicidade mensal, e, por conseguinte, fornecendo erros menores.

Em relação aos valores de Pseudo $\mathrm{R}^{2}$ apresentados no Apêndice D considerando estas divisões, observa-se que, dependendo do tipo e do patamar de 
carga, um modelo tende a ser melhor que outro. Como um exemplo, pode-se citar o caso do modelo stepwise da fazenda Icaraizinho, no qual para o Tipo 1 Pesado foi melhor do que os outros, enquanto que para o Tipo 2 Leve, este já ficou abaixo dos demais.

No entanto, como se observou em Bons Ventos, os dados de geração para as outras fazendas eólicas possuem uma incidência de zeros em períodos grandes consecutivos. Suspeita-se com isso, que estes estejam de alguma forma influenciando no cálculo das medidas MAE e Pseudo $\mathrm{R}^{2}$ out of sample. Sendo assim, foram recalculadas estas medidas considerando apenas os instantes onde a geração eólica de cada fazenda observada foi diferente de zero. Com este procedimento, observa-se uma redução muita pequena no valor do MAE out-ofsample, como pode ser observado pela Figura 6-8. Em relação aos valores de Pseudo $\mathrm{R}^{2}$ out-of-sample, pode ser observada uma mudança bem pequena quando comparados aos valores deste calculados anteriormente. Um exemplo que pode ser citado a respeito destas mudanças é a diminuição no caso da periodicidade horária, como pode ser visualizado na Figura 6-9.

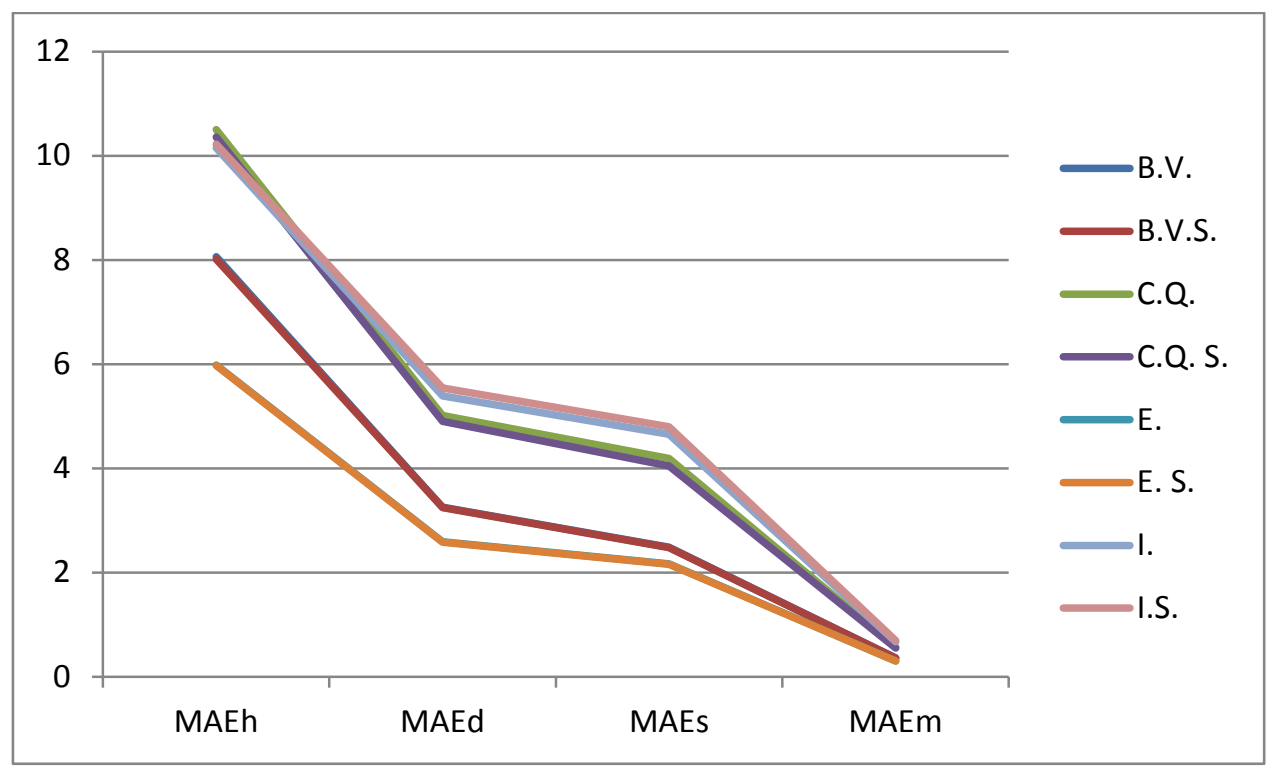

Figura 6-8: MAE out-of-sample horário, diário, semanal e mensal para os modelos completo e stepwise das fazendas estudadas, considerando os instantes onde a geração foi maior que 0 . 


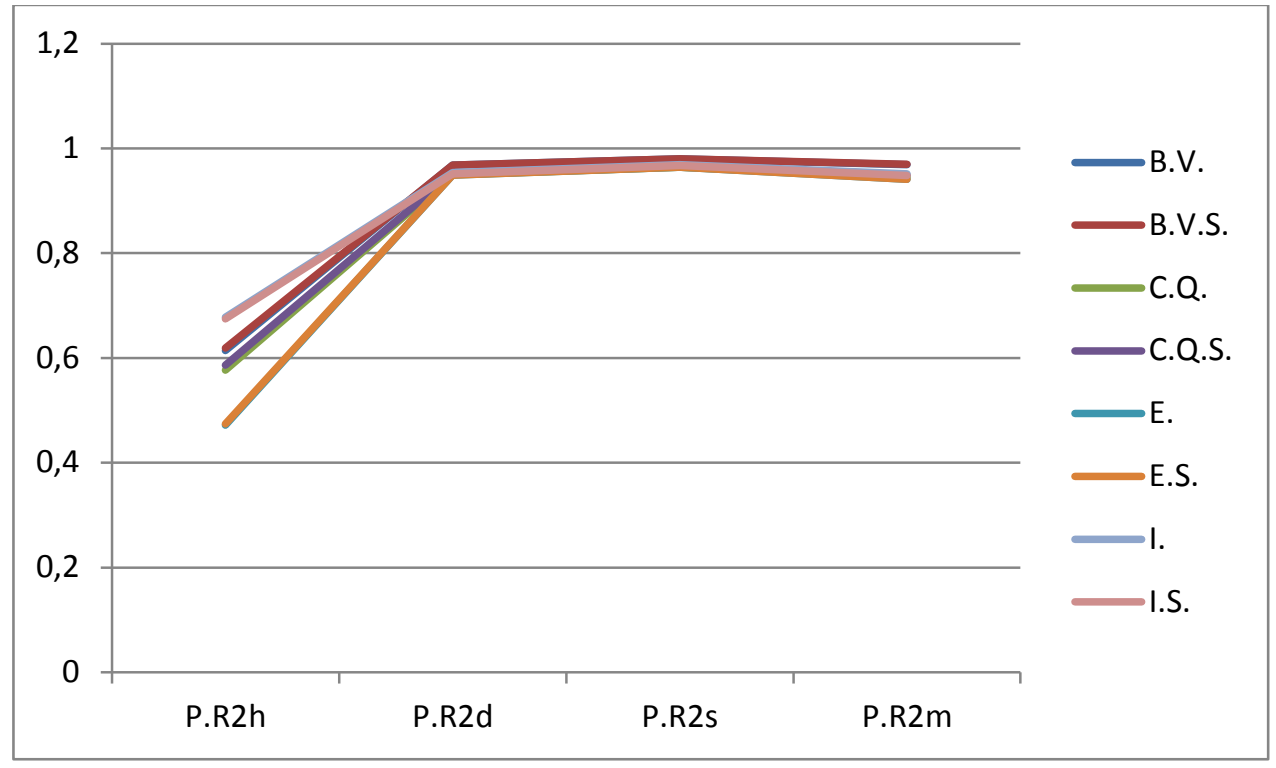

Figura 6-9: Pseudo $\mathrm{R}^{2}$ out-of-sample horário, diário, semanal e mensal para os modelos completo e stepwise das fazendas estudadas, considerando os instantes onde a geração foi maior que 0 .

Esse mesmo estudo foi aplicado para os dois tipos e patamares citados anteriormente, e os resultados obtidos podem ser visualizados graficamente pelas Figuras do Apêndice E, que mostram que os valores de MAE e Pseudo $\mathrm{R}^{2}$ out-ofsample tendem a se modificar muito pouco. Usando o mesmo procedimento do caso anterior de retirada dos instantes de produção eólica zero, observa-se uma redução de MAE out-of-sample que ficou abaixo da expectativa. Já no caso do Pseudo $\mathrm{R}^{2}$ out-of-sample, pode ser observado que estes sofreram uma leve modificação em seus valores.

\section{3}

\section{Reconstrução do Histórico}

Após esta avaliação, foi feita então a reconstrução do histórico da produção eólica para o período de 30 anos não incluso na modelagem, no qual não se tinha observações da geração eólica, mas tinha dados de velocidade. Com isso, foi feita a previsão para estes 262944 dados restantes considerando os modelos completos e stepwise das quatro fazendas eólicas estudadas, compreendendo o período de 02/01/1981 a 30/12/2010, que pode ser visualizada no Apêndice F e os histogramas comparativos do histórico estendido e dos dados observados para 
cada fazenda, está disponível no Apêndice G, onde se observa certa tendência similar entre os dois.

Pelos resultados obtidos, pode-se concluir que esta extensão foi, de certa forma satisfatória, conseguindo incorporar as características de cada localidade. No entanto, este procedimento produziu em alguns poucos instantes valores menores que zero e maiores do que a capacidade de cada fazenda, como se pode observar pela Tabela 6-10.

Quando as previsões foram menores que zero, estas foram assumidas como sendo zero. Já no caso em que as previsões apresentaram valores maiores que a capacidade da fazenda em questão, a mesma foi assumida como tendo o seu valor máximo de produção eólica.

Tabela 6-10: Incidência de previsões menores que zero e maiores que a capacidade da fazenda na reconstrução do histórico de cada fazenda pelo modelo completo e stepwise.

\begin{tabular}{ccc}
\hline & G.E. $<0$ & G.E. $>$ Cap. \\
B.V. & $1,53 \%$ & $1,39 \%$ \\
B.V.S. & $1,46 \%$ & $1,35 \%$ \\
C.Q. & $1,27 \%$ & $1,49 \%$ \\
C.Q.S. & $1,22 \%$ & $1,51 \%$ \\
E. & $4,66 \%$ & $0,59 \%$ \\
E.S. & $4,70 \%$ & $0,59 \%$ \\
I. & $2,18 \%$ & $0,71 \%$ \\
I.S. & $1,84 \%$ & $0,70 \%$ \\
\hline
\end{tabular}




\section{Considerações finais}

\section{1}

\section{Conclusões}

A energia eólica tem-se mostrado cada vez mais presente no âmbito da produção de energia elétrica, uma vez que esta é considerada limpa, não produzindo resíduos tóxicos. O histórico de produção da energia eólica disponibilizada para esta dissertação é pequeno quando comparado com a extensão do histórico das características do vento (velocidade e direção, por exemplo). Sendo assim, o objetivo desta dissertação foi, através do ajuste de um modelo, conseguir de forma adequada explicar esta produção para que fosse feita a reconstrução deste histórico.

Antes deste ajuste, tomaram-se os dados disponibilizados pela empresa 3tier dos bancos provenientes de duas fontes, ERAI e NNRP, e mediram-se as características do vento da fazenda eólica Bons Ventos. Verificou-se que a velocidade neste local tende a se concentrar mais na direção de $90^{\circ}$. Já em relação aos dados de produção eólica desta fazenda, observou-se uma extensão muito grande de períodos onde a produção eólica registrada foi igual a zero.

Após esta análise inicial dos dados, foi feita uma sequência de ajustes de modelos estatísticos. Através de várias tentativas verificou-se que colocando as informações dos dois bancos de dados, ERAI e NNRP, obtinha-se um resultado melhor. Também havia melhora quando se considerava a decomposição da velocidade do vento a $90^{\circ}$. Além destes procedimentos, foram consideradas as variáveis indicadoras das horas e as defasagens da própria produção, assumindo que esta em um determinado instante pudesse estar relacionada à produção em instantes próximos.

Com o ajuste de um modelo adequado, foi avaliada a sua capacidade de previsão, aplicando o modelo ajustado em um subconjunto de dados retirados anteriormente. Este procedimento foi estendido para as fazendas Canoa Quebrada, Enacel e Icairaizinho, uma vez que estas possuem características geográficas 
semelhantes às de Bons Ventos. O ajuste do modelo para estas fazendas mostrou ser adequado, com elevado $\mathrm{R}^{2}$, inclusive o do modelo stepwise.

Os valores da medida MAE out of sample apresentaram valores grandes, quando se considerou o caso horário. Todavia, estes tenderam a diminuir e convergir para zero. Para o caso do Pseudo $\mathrm{R}^{2}$, este tende a aumentar conforme os dados são agrupados em periodicidade diária, semanal e mensal, sofrendo uma pequena queda na mensal. Assumindo-se que a origem destes valores altos pudesse estar relacionada ao alto índice de zeros no período de avaliação para a previsão da produção eólica, as medidas foram recalculadas considerando apenas os instantes nos quais a geração eólica observada fosse diferente de zero. Com isto, os valores MAE e Pseudo $\mathrm{R}^{2}$ out of sample apresentaram uma pequena alteração. Esta análise também foi feita para cada patamar de carga, já que a avaliação econômica pode ser feita em cima destes patamares, onde se observaram resultados semelhantes.

Para a reconstrução do histórico de 30 anos de cada fazenda, foram considerados todos os dados históricos do vento. Esta reconstrução mostrou resultados bem adequados uma vez que os valores previstos para cada fazenda estavam dentro do limite de sua capacidade, com uma baixa incidência de valores preditos menores que zero ou maiores que a capacidade da fazenda em questão.

\section{2}

\section{Trabalhos futuros}

Com os resultados obtidos neste estudo abrem um leque de possibilidades de novos desdobramentos para trabalhos futuros, tais como:

1) A extensão da metodologia para as outras fazendas eólicas do Nordeste, uma vez que esta região é a maior detentora de usinas destinadas a produção de energia eólica do Brasil;

2) Uma investigação mais aprofundada dos instantes onde a produção eólica foi igual a zero, investigando os efeitos que esta pode estar causando;

3) Uma análise maior referente aos métodos de transformação da altitude nos dados (Lei da Potência e Lei Logarítmica). 


\section{Referências Bibliográficas}

[1] ABRÃO, M.S. Ventos: Tipos de vento, massas de ar, frentes frias e brisa marítima. 2005. Disponível em: <http://educacao.uol.com.br / disciplinas / ciencias / ventos-tipos-de-vento-massas-de-ar-frentes-frias-e-brisa-maritima.htm>. Acesso em 15 de fevereiro de 2013.

[2] AMARAL, B.M. Modelos varx para geração de cenários de vento e vazão aliados à comercialização de energia. Dissertação (Mestrado em Engenharia Elétrica), Pontifícia Universidade Católica do Rio de Janeiro, Rio de Janeiro - RJ, 2011.

[3] ANEEL. Atlas da energia eólica - Energia Eólica. 2006. Disponível em: <http://www.aneel.gov.br / aplicacoes / atlas /pdf / 06-energia_eolica(3).pdf.>. Acesso em 07 de agosto de 2013.

[4] BONS VENTOS. Bons Ventos - Parque Eólico Aracati. 2010. Disponível em: < http://www.bonsventos.eng.br/ sis.interna.asp?pasta=1\&pagina=125>. Acesso em 22 de junho de 2013.

[5] CAMELO, H.N.; MARIA, P.H.S.; CARAVALHO, P.C.M.; PEREIRA, T.B.P. Métodos de Extrapolação de Velocidade do Vento para Regiões Litorâneas do Nordeste Brasileiro. 2010. In: Congresso Brasileiro de Meteorologia, 16, 2010. Anais do Congresso Brasileiro de Meteorologia. Belém - PA.

[6] CRESESB. Tutorial de Energia Eólica - 1. História da Energia Eólica e suas utilizações. 2008a. Disponível em: < http://www.cresesb.cepel.br/ content.php?cid=201>. Acesso em 15 de fevereiro de 2013.

[7] CRESESB. Tutorial de Energia Eólica - 2. O Recurso Eólico. 2008b. Disponível em: < http://www.cresesb.cepel.br/ content.php?cid=211>. Acesso em 15 de fevereiro de 2013.

[8] DALMAZ, A. Estudo do Potencial Eólico e Previsão de Ventos para Geração de Eletricidade em Santa Catarina, 2007. Dissertação (Mestrado em Engenharia Mecânica) - Programa de Pós Graduação em Engenharia Mecânica, Universidade Federal de Santa Catarina, Santa Catarina - RS.

[9] HÜBNER, N. Brazil's Wind Power Auction Spurs More Clean Energy Development. 2009. Disponível em <http://www.renewableenergyworld.com/ rea / news / article / 2009 / 12 / brazils-wind-power-auction-spurs-more-clean-energydevelopment.> Acesso em 06 de agosto de 2013.

[10] HUGHES, T. Lesson Number 1. in an Oklahoma Wind Power Tutorial Series. 2000a. Environmental Verification and Analysis Center. University of Oklahoma. 
[11] HUGHES, T. Lesson Number 2. in an Oklahoma Wind Power Tutorial Series. 2000b. Environmental Verification and Analysis Center. University of Oklahoma.

[12] HUGHES, T. Lesson Number 3. in an Oklahoma Wind Power Tutorial Series. 2000c. Environmental Verification and Analysis Center. University of Oklahoma.

[13] INSTITUTO ABRADEE DE ENERGIA. Repensar as tarifas de energia. 2010. Disponível em: $<$ http://www.abradee01.org / uploader /Sinaishorosazonaisnatarifadeenergia_9997.pdf>Acesso em 27 de outubro de 2013.

[14] JENKINS, N.; ANAYA-LARA, O.; EKANAYAKE, J.; CARTWRIGHT, P.; HUGHES, M. Wind Energy Generation - Modeling and Control. England: Ed. John Wiley \&Sons Ltd, 2009.

[15] JHA, A.R. Wind Turbine Techonolgy. Ed. Taylor \& Francis Group. Florida. 2011.

[16] KUBIK, M.L.; COKER, P.J.; BARLOW, J. F.; HUNT, C. A study into the accuracy of using meteorological wind data to estimate turbine generation output. Renewable Energy. V. 51, 2013, 153-158.

[17] KUSIAK, A.; ZHENG, H.; SONG, Z. Models for monitoring wind farm power. Renewable Energy. V. 34, 2009a, 583-590.

[18] KUSIAK, A.; ZHENG, H.; SONG, Z. On-line monitoring of power curves. Renewable Energy. V. 34, 2009b, 1487-1493.

[19] MERCURIUS ENGENHARIA Parque Eólico Icaraizinho. Disponivel em: $<$ http://www.mercurius.com.br/ portifolio/ energias-alternativas/ parque-eolicoicaraizinho> Acesso em 25 de nomvembro de 2013.

[20] NEMITZ, E. De vento em popa. 2009. Disponível em: $<$ http://cienciahoje.uol.com.br/ especiais/ meio-ambiente-em-foco/ de-vento-empopa $>$. Acesso em 15 de fevereiro de 2013.

[21] N $\phi$ RGATT, P; HOLTTINEN, H. A Multi-turbine power approach. In: Nordic Wind Power Conference. 2004. Chalmers. University of Tecnology, Gothenburg, Sweden.

[22] PORTAL CANOA QUEBRADA. Energia eólica no Ceará. 2013. Disponível em $\quad<$ http://www.portalcanoaquebrada.com.br/ canoa_quebrada_arquiteto/ energia_eolica_em_canoa_quebrada.html> Acesso em 02 de junho de 2013.

[23] R7 NOTICIAS. Geração de energia eólica deve crescer até 600\% no Brasil até 2014. 2011. Disponível em : <http://noticias.r7.com/ economia/ noticias/ geracao-de-energia-eolica-deve-crescer-ate-600-no-brasil-ate2014-20110822.html>. Acesso em 06 de agosto de 2013. 
[24] SHEPHERD, D.G. 1994. Historical Development of the Windmill. In Wind Turbine Technology - Fundamental Concepts of Wind Turbine Engineering, SPERA, S.A, (ed), 1 ed. New York, ASME Press, pp 1-46.

[25] SOENS, J.; DRIESEN, J.; BELMANS, R. Estimation of Fluctuation of Wind Power Generation in Belgium. Fifth International Workshop on Large-scale Integration of Wind Power and Transmission Networks for Offshore Wind Farms, 7-8 abril 2005, Glasgow.

[26] SUZLON. S-88 2.1 MW Technical Overview.

[27] WWEA, 2011. World Wind Energy Report 2010. Disponível em: < Erro! A referência de hiperlink não é válida.> Acesso em 19 de maio de 2013.

[28] WWEA 2012. Half year report 2012. Disponível em: < Erro! A referência de hiperlink não é válida.> Acesso em 19 de maio de 2013.

[29] ZHANG, J.; CHOWDHURY, S.; MESSAC, A.; CASTILLO, L. A Multivariate and Multimodal Wind Distribution model. Renewable Energy. V. 51. 2013. 436-447. 


\section{Apêndice A - Análise Exploratória dos dados de geração eólica para as fazendas Canoa Quebrada, Enacel e Icaraizinho}

Tabela A-1: Estatísticas descritivas da geração eólica pertencentes a s usinas Canoa Quebrada, Enacel e Icaraizinho.

\begin{tabular}{|c|c|c|c|}
\hline & $\begin{array}{l}\text { Canoa } \\
\text { Quebrada }\end{array}$ & Enacel & Icaraizinho \\
\hline $\mathrm{N}$ & 15336 & 15336 & 15336 \\
\hline NA & 0 & 0 & 0 \\
\hline Mínimo & 0 & 0 & 0 \\
\hline Máximo & 58,57 & 31,96 & 53,54 \\
\hline $1^{\circ}$ Quartil & 6,9 & 2,91 & 7,75 \\
\hline $3^{\circ}$ Quartil & 35,3 & 18,15 & 39,72 \\
\hline Média & 22,10 & 11,22 & 24,19 \\
\hline Mediana & 18,7 & 9,49 & 24,83 \\
\hline Soma & 338989,8 & 171999,7 & 370973,6 \\
\hline Variância & 305,00 & 85,29 & 285,80 \\
\hline Desvio & & & \\
\hline Padrão & 17,46 & 9,24 & 16,91 \\
\hline Assimetria & 0,48 & 0,51 & 0,01 \\
\hline Curtose & $-0,94$ & $-0,90$ & $-1,37$ \\
\hline
\end{tabular}

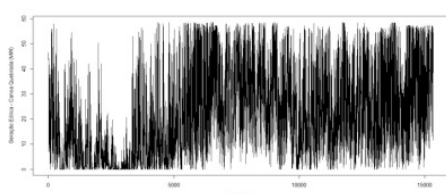

(a)

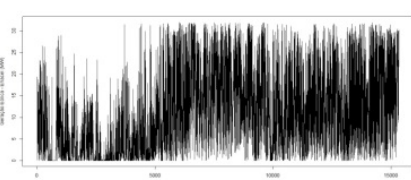

(b)

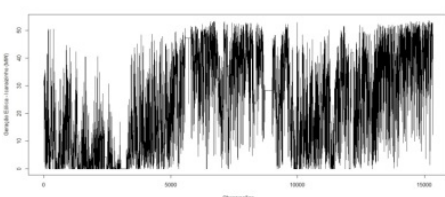

(c)

Figura A-1: Série histórica das gerações eólicas das fazendas Canoa Quebrada (a), Enacel (b) e Icaraizinho (c). 
Apêndice B - Análise Exploratória dos dados das fazendas eólicas Canoa Quebrada, Enacel e Icaraizinho
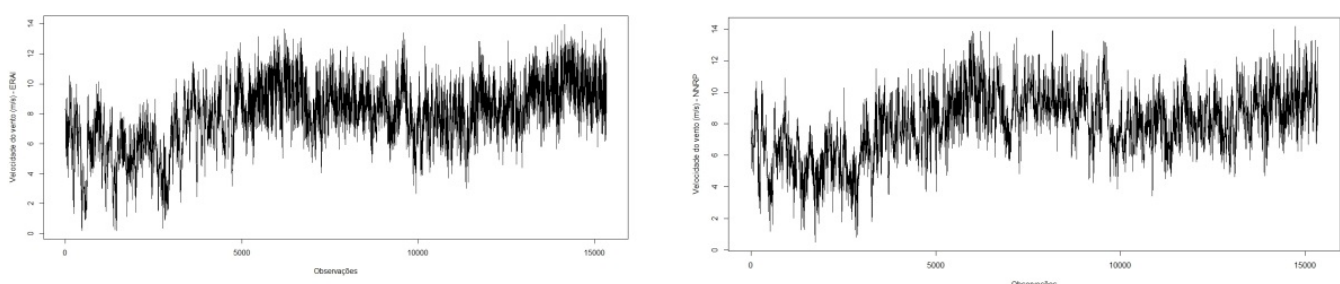

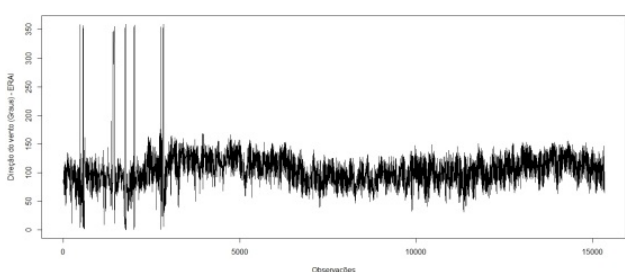

(a)

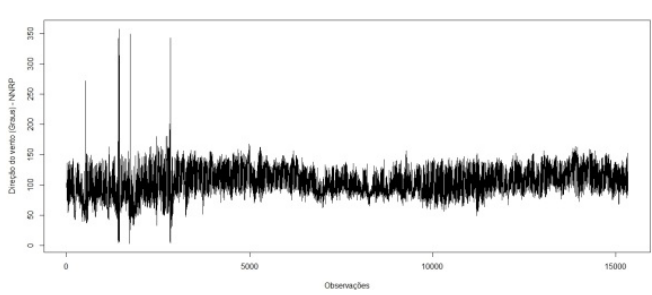

(b)

Figura B-1: Série Histórica para as velocidade e direção do vento, respectivamente para bancos ERAI (a) e NNRP (b) da fazenda Canoa Quebrada.

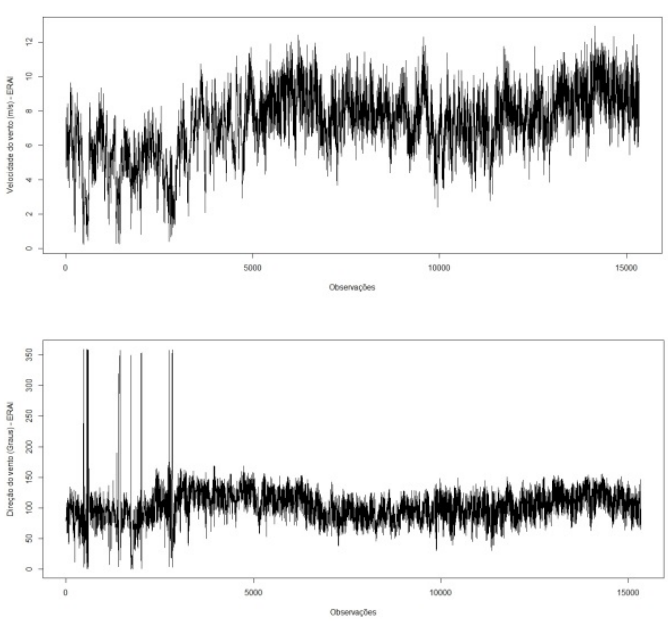

(a)
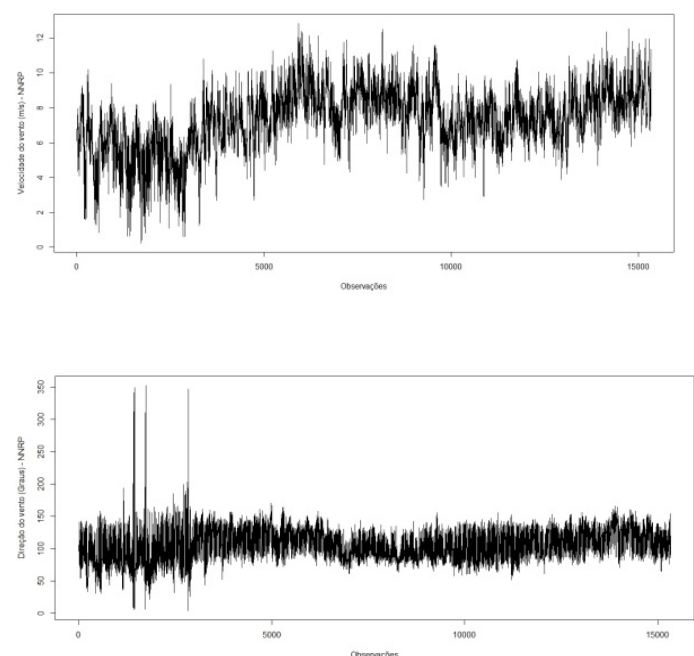

(b)

Figura B-2: Série Histórica para as velocidade e direção do vento, respectivamente para bancos ERAI (a) e NNRP (b) da fazenda Enacel. 

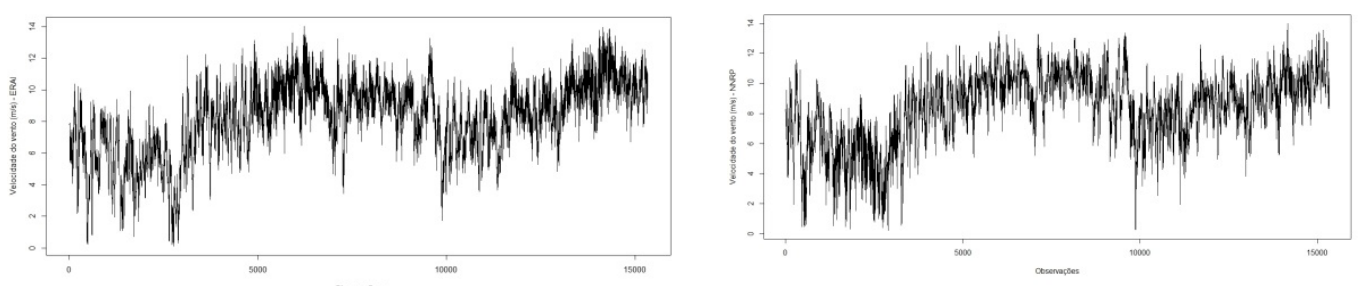

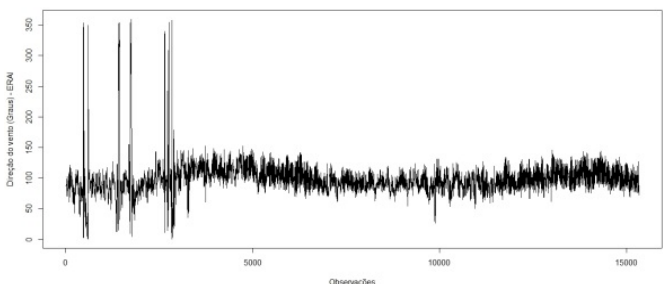

(a)

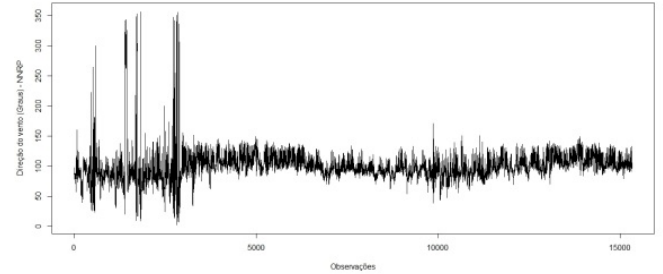

(b)

Figura B-3: Série Histórica para as velocidade e direção do vento, respectivamente para bancos ERAI (a) e NNRP (b) da fazenda Icaraizinho. 


\section{Apêndice C - Coeficientes dos modelos completos stepwise para as fazendas eólicas estudadas}

Tabela C-1: Estimativas dos coeficientes para os modelos completo e stepwise das quatro fazendas estudadas.

\begin{tabular}{|c|c|c|c|c|c|c|c|c|}
\hline & $\begin{array}{l}\text { B.V. } \\
\text { Completo }\end{array}$ & $\begin{array}{l}\text { B.V. } \\
\text { Stepwise }\end{array}$ & $\begin{array}{l}\text { C.Q. } \\
\text { Completo }\end{array}$ & $\begin{array}{l}\text { C.Q. } \\
\text { stepwise }\end{array}$ & $\begin{array}{l}\text { E. } \\
\text { completo }\end{array}$ & $\begin{array}{l}\text { E. } \\
\text { stepwise }\end{array}$ & $\begin{array}{l}\text { I. } \\
\text { completo }\end{array}$ & I. step. \\
\hline (Int.) & $\begin{array}{r}2,30613 \\
(* * *)\end{array}$ & $\begin{array}{r}2,084853 \\
(* * *)\end{array}$ & $\begin{array}{r}2,61013 \\
(* * *)\end{array}$ & $\begin{array}{r}2,078885 \\
(* * *)\end{array}$ & $\begin{array}{r}1,107764 \\
(* * *)\end{array}$ & $\begin{array}{r}1,196185 \\
(* * *)\end{array}$ & 0,099215 & 0,048461 \\
\hline h0 & $-0,50859$ & 0 & $-0,4238$ & 0 & $\begin{array}{r}-0,786 \\
(* * *)\end{array}$ & $\begin{array}{r}-0,8526 \\
(* * *)\end{array}$ & 0,068549 & 0 \\
\hline h1 & $-0,49653$ & 0 & $-0,51505$ & 0 & $\begin{array}{r}-1,44151 \\
(* * *)\end{array}$ & $\begin{array}{r}-1,51079 \\
(* * *)\end{array}$ & 0,015581 & 0 \\
\hline h2 & $\begin{array}{r}-1,16652 \\
(* *)\end{array}$ & $\begin{array}{r}-0,8597 \\
(* *)\end{array}$ & $\begin{array}{r}-1,51533 \\
(* * *)\end{array}$ & $\begin{array}{r}-1,11355 \\
(* * *)\end{array}$ & $\begin{array}{r}-1,75446 \\
(* * *)\end{array}$ & $\begin{array}{r}-1,83633 \\
(* * *)\end{array}$ & $\begin{array}{r}-0,88424 \\
(* *)\end{array}$ & $\begin{array}{r}-0,85528 \\
(* * *)\end{array}$ \\
\hline h3 & $\begin{array}{r}-1,99998 \\
(* * *)\end{array}$ & $\begin{array}{r}-1,71313 \\
(* * *)\end{array}$ & $\begin{array}{r}-2,452 \\
(* * *)\end{array}$ & $\begin{array}{r}-2,04041 \\
(* * *)\end{array}$ & $\begin{array}{r}-2,11375 \\
(* * *)\end{array}$ & $\begin{array}{r}-2,20599 \\
(* * *)\end{array}$ & $\begin{array}{r}-1,15878 \\
(* * *)\end{array}$ & $\begin{array}{r}-1,13278 \\
(* * *)\end{array}$ \\
\hline h4 & $\begin{array}{r}-2,676 \\
(* * *)\end{array}$ & $\begin{array}{r}-2,42454 \\
(* * *)\end{array}$ & $\begin{array}{r}-3,08563 \\
(* * *)\end{array}$ & $\begin{array}{r}-2,66512 \\
(* *)\end{array}$ & $\begin{array}{r}-2,53548 \\
(* * *)\end{array}$ & $\begin{array}{r}-2,63219 \\
(* * *)\end{array}$ & $\begin{array}{r}-1,50337 \\
(* * *)\end{array}$ & $\begin{array}{r}-1,47594 \\
(* * *)\end{array}$ \\
\hline h5 & $\begin{array}{r}-2,96709 \\
(* * *)\end{array}$ & $\begin{array}{r}-2,74321 \\
(* * *)\end{array}$ & $\begin{array}{r}-3,93113 \\
(* * *)\end{array}$ & $\begin{array}{r}-3,46517 \\
(* * *)\end{array}$ & $\begin{array}{r}-1,7221 \\
(* * *)\end{array}$ & $\begin{array}{r}-1,83818 \\
(* * *)\end{array}$ & $\begin{array}{r}-1,67318 \\
(* * *)\end{array}$ & $\begin{array}{r}-1,65229 \\
(* * *)\end{array}$ \\
\hline h6 & $\begin{array}{r}-3,23192 \\
(* * *)\end{array}$ & $\begin{array}{r}-3,01734 \\
(* * *)\end{array}$ & $\begin{array}{r}-3,62439 \\
(* * *)\end{array}$ & $\begin{array}{r}-3,09517 \\
(* * *)\end{array}$ & $\begin{array}{r}-1,70378 \\
(* * *)\end{array}$ & $\begin{array}{r}-1,83205 \\
(* * *)\end{array}$ & $\begin{array}{r}-1,66337 \\
(* * *)\end{array}$ & $\begin{array}{r}-1,63432 \\
(* * *)\end{array}$ \\
\hline h7 & $\begin{array}{r}-2,3439 \\
(* * *)\end{array}$ & $\begin{array}{r}-2,14679 \\
(* * *)\end{array}$ & $\begin{array}{r}-2,58081 \\
(* * *)\end{array}$ & $\begin{array}{r}-2,02301 \\
(* *)\end{array}$ & $\begin{array}{r}-1,16844 \\
(* * *)\end{array}$ & $\begin{array}{r}-1,31415 \\
(* * *)\end{array}$ & 0,150904 & 0 \\
\hline h8 & $-0,14387$ & 0 & 0,624368 & $\begin{array}{r}1,195146 \\
(* *)\end{array}$ & $\begin{array}{r}1,225575 \\
(* *)\end{array}$ & $\begin{array}{r}1,069357 \\
(* * *)\end{array}$ & $\begin{array}{r}3,085852 \\
(* * *)\end{array}$ & $\begin{array}{r}3,117443 \\
(* * *)\end{array}$ \\
\hline h9 & $\begin{array}{r}-1,51062 \\
(* * *)\end{array}$ & $\begin{array}{r}-1,32728 \\
(* * *)\end{array}$ & $\begin{array}{r}-1,79053 \\
(* * *)\end{array}$ & $\begin{array}{r}-1,22394 \\
(* *)\end{array}$ & $\begin{array}{r}0,510309 \\
(.)\end{array}$ & $\begin{array}{r}0,350746 \\
(.)\end{array}$ & $\begin{array}{r}3,019633 \\
(* * *)\end{array}$ & $\begin{array}{r}3,046054 \\
(* * *)\end{array}$ \\
\hline h10 & $\begin{array}{r}-2,1389 \\
(* * *)\end{array}$ & $\begin{array}{r}-1,96809 \\
(* * *)\end{array}$ & $\begin{array}{r}-2,46644 \\
(* * *)\end{array}$ & $\begin{array}{r}-1,89773 \\
(* * *)\end{array}$ & 0,284405 & 0 & $\begin{array}{r}2,628024 \\
(* * *)\end{array}$ & $\begin{array}{r}2,677878 \\
(* * *)\end{array}$ \\
\hline h11 & $\begin{array}{r}-2,09902 \\
(* * *)\end{array}$ & $\begin{array}{r}-1,93899 \\
(* * *)\end{array}$ & $\begin{array}{r}-2,12883 \\
(* * *)\end{array}$ & $\begin{array}{r}-1,55664 \\
(* * *)\end{array}$ & 0,062697 & 0 & $\begin{array}{r}3,096391 \\
(* * *)\end{array}$ & $\begin{array}{r}3,178412 \\
(* * *)\end{array}$ \\
\hline h12 & $\begin{array}{r}-2,5498 \\
(* * *)\end{array}$ & $\begin{array}{r}-2,37025 \\
(* * *)\end{array}$ & $\begin{array}{r}-2,36609 \\
(* *)\end{array}$ & $\begin{array}{r}-1,78092 \\
(* * *)\end{array}$ & $-0,25991$ & $\begin{array}{r}-0,344 \\
(*)\end{array}$ & $\begin{array}{r}2,770054 \\
(* * *)\end{array}$ & $\begin{array}{r}2,848028 \\
(* * *)\end{array}$ \\
\hline h13 & $\begin{array}{r}-2,34278 \\
(* * *)\end{array}$ & $\begin{array}{r}-2,15739 \\
(* * *)\end{array}$ & $\begin{array}{r}-2,20709 \\
(* * *)\end{array}$ & $\begin{array}{r}-1,60645 \\
(* * *)\end{array}$ & $-0,29159$ & $\begin{array}{r}-0,34611 \\
(*)\end{array}$ & $\begin{array}{r}2,346983 \\
(* * *)\end{array}$ & $\begin{array}{r}2,435631 \\
(* * *)\end{array}$ \\
\hline h14 & $\begin{array}{r}-2,03448 \\
(* * *)\end{array}$ & $\begin{array}{r}-1,87027 \\
(* * *)\end{array}$ & $\begin{array}{r}-1,90089 \\
(* * *)\end{array}$ & $\begin{array}{r}-1,39475 \\
(* * *)\end{array}$ & $-0,33094$ & $\begin{array}{r}-0,37024 \\
(*)\end{array}$ & $\begin{array}{r}2,453894 \\
(* * *)\end{array}$ & $\begin{array}{r}2,531366 \\
(* * *)\end{array}$ \\
\hline h15 & $\begin{array}{r}-1,45152 \\
(* * *)\end{array}$ & $\begin{array}{r}-1,29767 \\
(* * *)\end{array}$ & $\begin{array}{r}-1,17684 \\
(*)\end{array}$ & $\begin{array}{r}-0,69539 \\
(*)\end{array}$ & 0,02053 & 0 & $\begin{array}{r}2,272693 \\
(* * *)\end{array}$ & $\begin{array}{r}2,338026 \\
(* * *)\end{array}$ \\
\hline h16 & $\begin{array}{r}-1,0141 \\
(* *)\end{array}$ & $\begin{array}{r}-0,88836 \\
(* *)\end{array}$ & $-0,59125$ & 0 & $-0,11888$ & 0 & $\begin{array}{r}1,626078 \\
(* * *)\end{array}$ & $\begin{array}{r}1,697131 \\
(* * *)\end{array}$ \\
\hline h17 & $\begin{array}{r}-1,00119 \\
(* *)\end{array}$ & $\begin{array}{r}-0,88548 \\
(* *)\end{array}$ & $-0,73099$ & 0 & 0,153413 & 0 & $\begin{array}{r}1,088316 \\
(* *)\end{array}$ & $\begin{array}{r}1,1885 \\
(* * *)\end{array}$ \\
\hline h18 & 0,424576 & $\begin{array}{r}0,534369 \\
(.)\end{array}$ & $\begin{array}{r}865989 \\
(.)\end{array}$ & $\begin{array}{r}1,226548 \\
(* *)\end{array}$ & $\begin{array}{r}1,278766 \\
(* * *)\end{array}$ & $\begin{array}{r}1,242127 \\
(* * *)\end{array}$ & 0,50378 & $\begin{array}{r}0,629869 \\
(*)\end{array}$ \\
\hline h19 & $\begin{array}{r}0,730641 \\
(*)\end{array}$ & $\begin{array}{r}0,847603 \\
(* *)\end{array}$ & $\begin{array}{r}1,339284 \\
(* *)\end{array}$ & $\begin{array}{r}1,665908 \\
(* * *)\end{array}$ & $\begin{array}{r}1,284657 \\
(* * *)\end{array}$ & $\begin{array}{r}1,215348 \\
(* * *)\end{array}$ & 0,322219 & $\begin{array}{r}0,426991 \\
(.)\end{array}$ \\
\hline h20 & $\begin{array}{r}0,846689 \\
(*)\end{array}$ & $\begin{array}{r}0,990778 \\
(* * *)\end{array}$ & $\begin{array}{r}1,369125 \\
(* *)\end{array}$ & $\begin{array}{r}1,632698 \\
(* *)\end{array}$ & $\begin{array}{r}1,571715 \\
(* * *)\end{array}$ & $\begin{array}{r}1,499061 \\
(* * *)\end{array}$ & $-0,21061$ & 0 \\
\hline h21 & 0,434499 & $\begin{array}{r}0,600382 \\
(*)\end{array}$ & $\begin{array}{r}0,901001 \\
(*)\end{array}$ & $\begin{array}{r}1,106503 \\
(* * *)\end{array}$ & $\begin{array}{r}1,097734 \\
(* * *)\end{array}$ & $\begin{array}{r}1,031853 \\
(* * *)\end{array}$ & $-0,17416$ & 0 \\
\hline h22 & $-0,15376$ & 0 & 0,076279 & 0 & $\begin{array}{r}0,479942 \\
\left.{ }^{*}\right)\end{array}$ & $\begin{array}{r}0,412041 \\
(*)\end{array}$ & $-0,11676$ & 0 \\
\hline x1_era & $\begin{array}{r}0,006588 \\
(* * *)\end{array}$ & $\begin{array}{r}0,006621 \\
(* * *)\end{array}$ & $\begin{array}{r}0,00675 \\
(* * *)\end{array}$ & $\begin{array}{r}0,006876 \\
(* *)\end{array}$ & $\begin{array}{r}0,003913 \\
(* * *)\end{array}$ & $\begin{array}{r}0,003897 \\
(* * *)\end{array}$ & $\begin{array}{r}0,0033 \\
(* * *)\end{array}$ & $\begin{array}{r}0,003245 \\
(* * *)\end{array}$ \\
\hline x2_erai_t & $\begin{array}{r}0,002749 \\
(* *)\end{array}$ & $\begin{array}{r}0,002226 \\
(* * *)\end{array}$ & $\begin{array}{r}0,00247 \\
(* *)\end{array}$ & $\begin{array}{r}0,002022 \\
(* *)\end{array}$ & $\begin{array}{r}0,001026 \\
(.)\end{array}$ & $\begin{array}{r}0,001341 \\
(* * *)\end{array}$ & $-0,00038$ & $-0,00082$ \\
\hline x1_erai_12 & $\begin{array}{r}0,000833 \\
(*)\end{array}$ & $\begin{array}{r}0,000881 \\
(* *)\end{array}$ & $\begin{array}{r}0,000805 \\
(*)\end{array}$ & $\begin{array}{r}0,000984 \\
(* *)\end{array}$ & $\begin{array}{r}0,000886 \\
(* * *)\end{array}$ & $\begin{array}{r}0,000952 \\
(* * *)\end{array}$ & $\begin{array}{r}0,000895 \\
(* * *)\end{array}$ & $\begin{array}{r}0,000897 \\
(* * *)\end{array}$ \\
\hline x2_erai_12 & 0,000724 & 0 & 0,000991 & 0 & $-5,07 \mathrm{E}-05$ & 0 & 0,00053 & 0 \\
\hline x1_erai_ & $\begin{array}{r}-0,00088 \\
(*)\end{array}$ & $\begin{array}{r}-0,00101 \\
(* *)\end{array}$ & $\begin{array}{r}-0,00143 \\
(* * *)\end{array}$ & $\begin{array}{r}-0,00142 \\
(* *)\end{array}$ & $\begin{array}{r}-0,00124 \\
(* * *)\end{array}$ & $\begin{array}{r}-0,00119 \\
(* * *)\end{array}$ & $\begin{array}{r}-0,00173 \\
(* * *)\end{array}$ & $\begin{array}{r}-0,00173 \\
(* * *)\end{array}$ \\
\hline x2_erai_24 & 0,00111 & $\begin{array}{r}0,00138 \\
(.)\end{array}$ & $\begin{array}{r}0,001489 \\
(.)\end{array}$ & $\begin{array}{r}0,002014 \\
(* *)\end{array}$ & 0,000153 & 0 & $-8,46 \mathrm{E}-05$ & 0 \\
\hline $\mathrm{x} 1{ }_{-}$ & $\begin{array}{r}0,000813 \\
(* *)\end{array}$ & $\begin{array}{r}0,000732 \\
(* *)\end{array}$ & $\begin{array}{r}0,000777 \\
(*)\end{array}$ & $\begin{array}{r}0,000811 \\
(* *)\end{array}$ & $\begin{array}{r}0,001049 \\
(* * *)\end{array}$ & $\begin{array}{r}0,001099 \\
(* * *)\end{array}$ & $\begin{array}{r}0,00038 \\
\text { (.) }\end{array}$ & $\begin{array}{r}0,000372 \\
(*)\end{array}$ \\
\hline x2_nnrp_t & $-0,00099$ & 0 & $-0,0008$ & 0 & 0,000454 & 0 & $-0,00026$ & 0 \\
\hline x1_nnrp_12 & $\begin{array}{r}0,000592 \\
(*)\end{array}$ & $\begin{array}{r}0,00047 \\
(.)\end{array}$ & 0,00044 & 0 & $\begin{array}{r}0,000592 \\
(* *)\end{array}$ & $\begin{array}{r}0,000636 \\
(* *)\end{array}$ & 0,000203 & 0,000302 \\
\hline P_12 & $\begin{array}{r}-0,00227 \\
(* *)\end{array}$ & $\begin{array}{r}-0,00198 \\
(* * *)\end{array}$ & $\begin{array}{r}-0,00245 \\
(* *)\end{array}$ & $\begin{array}{r}-0,00121 \\
(*)\end{array}$ & 0,000767 & $\begin{array}{r}0,00083 \\
(*)\end{array}$ & $-0,00056$ & 0 \\
\hline
\end{tabular}




\begin{tabular}{|c|c|c|c|c|c|c|c|c|}
\hline x1_nnrp_24 & $-0,00021$ & 0 & $-0,00016$ & 0 & 0,000134 & 0 & $9,68 \mathrm{E}-05$ & 0 \\
\hline x2_nnrp_24 & $\begin{array}{r}0,001383 \\
(.)\end{array}$ & 0,000997 & 0,001069 & 0 & 0,000914 & $\begin{array}{r}0,001116 \\
(* *)\end{array}$ & $-0,00021$ & 0 \\
\hline ge_1 & $\begin{array}{r}0,975784 \\
(* * *)\end{array}$ & $\begin{array}{r}0,976222 \\
(* * *)\end{array}$ & $\begin{array}{r}0,961124 \\
(* * *)\end{array}$ & $\begin{array}{r}0,962368 \\
(* * *)\end{array}$ & $\begin{array}{r}1,016578 \\
(* * *)\end{array}$ & $\begin{array}{r}1,016252 \\
(* * *)\end{array}$ & $\begin{array}{r}1,010133 \\
(* * *)\end{array}$ & $\begin{array}{r}1,009113 \\
(* * *)\end{array}$ \\
\hline ge_2 & $\begin{array}{r}-0,26554 \\
(* * *)\end{array}$ & $\begin{array}{r}-0,26621 \\
(* * *)\end{array}$ & $\begin{array}{r}-0,24999 \\
(* * *)\end{array}$ & $\begin{array}{r}-0,24918 \\
(* * *)\end{array}$ & $\begin{array}{r}-0,31879 \\
(* * *)\end{array}$ & $\begin{array}{r}-0,31757 \\
(* * *)\end{array}$ & $\begin{array}{r}-0,25125 \\
(* * *)\end{array}$ & $\begin{array}{r}-0,24779 \\
(* * *)\end{array}$ \\
\hline ge_3 & $\begin{array}{r}0,074069 \\
(* * *)\end{array}$ & $\begin{array}{r}0,074599 \\
(* * *)\end{array}$ & $\begin{array}{r}0,076468 \\
(* * *)\end{array}$ & $\begin{array}{r}0,075716 \\
(* * *)\end{array}$ & $\begin{array}{r}0,078421 \\
(* * *)\end{array}$ & $\begin{array}{r}0,074455 \\
(* * *)\end{array}$ & $\begin{array}{r}0,067707 \\
(* * *)\end{array}$ & $\begin{array}{r}0,05381 \\
(* * *)\end{array}$ \\
\hline ge_4 & $-0,02026$ & $\begin{array}{r}-0,02664 \\
(* *)\end{array}$ & $\begin{array}{r}-0,02346 \\
(.)\end{array}$ & $\begin{array}{r}-0,02317 \\
(*)\end{array}$ & $\begin{array}{r}-0,04314 \\
(* *)\end{array}$ & $\begin{array}{r}-0,03675 \\
(* * *)\end{array}$ & $-0,02018$ & 0 \\
\hline ge_5 & 0,001243 & 0 & 0,012112 & 0 & 0,00803 & 0 & 0,017577 & 0 \\
\hline ge_6 & $-0,00957$ & 0 & $-0,02$ & 0 & $-0,00216$ & 0 & $-0,01826$ & 0 \\
\hline ge_7 & 0,00695 & 0 & 0,013434 & 0 & $\begin{array}{r}0,023148 \\
(.)\end{array}$ & $\begin{array}{r}0,022591 \\
(* *)\end{array}$ & 0,010936 & 0 \\
\hline ge_8 & $-0,01209$ & 0 & $-0,01293$ & 0 & $-0,00221$ & 0 & 0,015074 & $\begin{array}{r}0,022476 \\
(* * *)\end{array}$ \\
\hline ge_9 & 0,007197 & 0 & 0,01039 & 0 & $\begin{array}{r}-0,03444 \\
(*)\end{array}$ & $\begin{array}{r}-0,03299 \\
(* *)\end{array}$ & 0,008741 & 0 \\
\hline ge_10 & $-0,00784$ & 0 & $-0,01455$ & 0 & $\begin{array}{r}0,026414 \\
\text {. }\end{array}$ & $\begin{array}{r}0,020302 \\
(*)\end{array}$ & 0,003824 & 0 \\
\hline ge_11 & 0,007524 & 0 & 0,019887 & 0 & $-0,01303$ & 0 & $-0,01152$ & 0 \\
\hline ge_12 & $\begin{array}{r}0,01585 \\
(.)\end{array}$ & $\begin{array}{r}0,01839 \\
(* * *)\end{array}$ & 0,009736 & $\begin{array}{r}0,018162 \\
(* *)\end{array}$ & 0,00957 & 0 & 0,013245 & $\begin{array}{r}0,010214 \\
\text { (.) }\end{array}$ \\
\hline ge_24 & $\begin{array}{r}0,027924 \\
(* * *)\end{array}$ & $\begin{array}{r}0,027217 \\
(* * *)\end{array}$ & $\begin{array}{r}0,039281 \\
(* * *)\end{array}$ & $\begin{array}{r}0,04014 \\
(* * *)\end{array}$ & $\begin{array}{r}0,059219 \\
(* * *)\end{array}$ & $\begin{array}{r}0,059051 \\
(* * *)\end{array}$ & $\begin{array}{r}0,055588 \\
(* * *)\end{array}$ & $\begin{array}{r}0,055384 \\
(* * *)\end{array}$ \\
\hline
\end{tabular}

Legenda de significância das variáveis: Significante a $0,1 \%\left(^{* * *}\right)$, a $1 \%\left(^{* *}\right)$, a $5 \%\left({ }^{*}\right)$, a $10 \%($.$) .$ 


\section{Apêndice D - MAE e Pseudo $\mathrm{R}^{2}$ out of sample por tipo e patamar das fazendas eólicas estudadas}

Neste apêndice, se tem o estudo do MAE e Pseudo $\mathrm{R}^{2}$ out of sample paracada patamar e tipo de carga. Nestes resultados, tem-se a seguinte nomenclatura: B.V. (modelo completo de Bons Ventos), B.V.S. (modelo stepwise de Bons Ventos), C.Q. (modelo completo de Canoa Quebrada), C.Q.S. (modelo stepwise de Canoa Quebrada), E. (modelo completo de Enacel), E.S. (modelo stepwise de Enacel), I. (modelo completo de Icaraizinho) e I.S. (modelo stepwise de Icaraizinho).
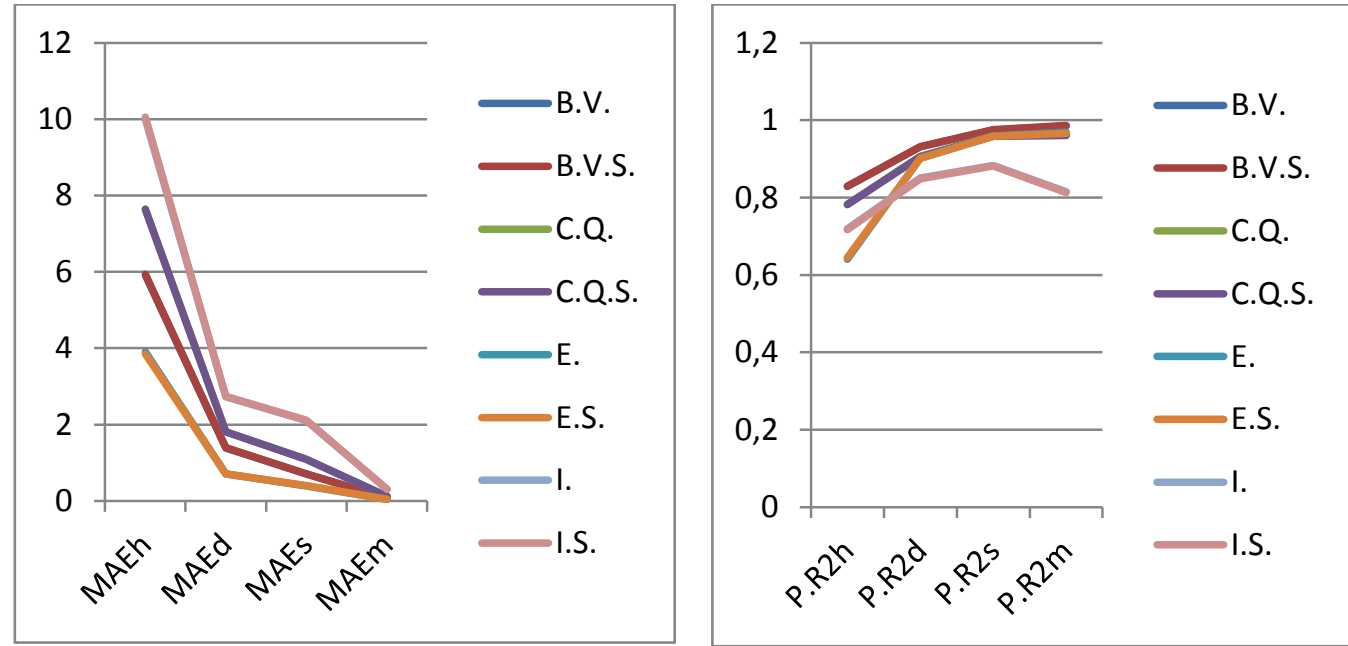

Figura D-1: MAE e Pseudo $\mathrm{R}^{2}$ out of sample do Tipo 1 Leve.
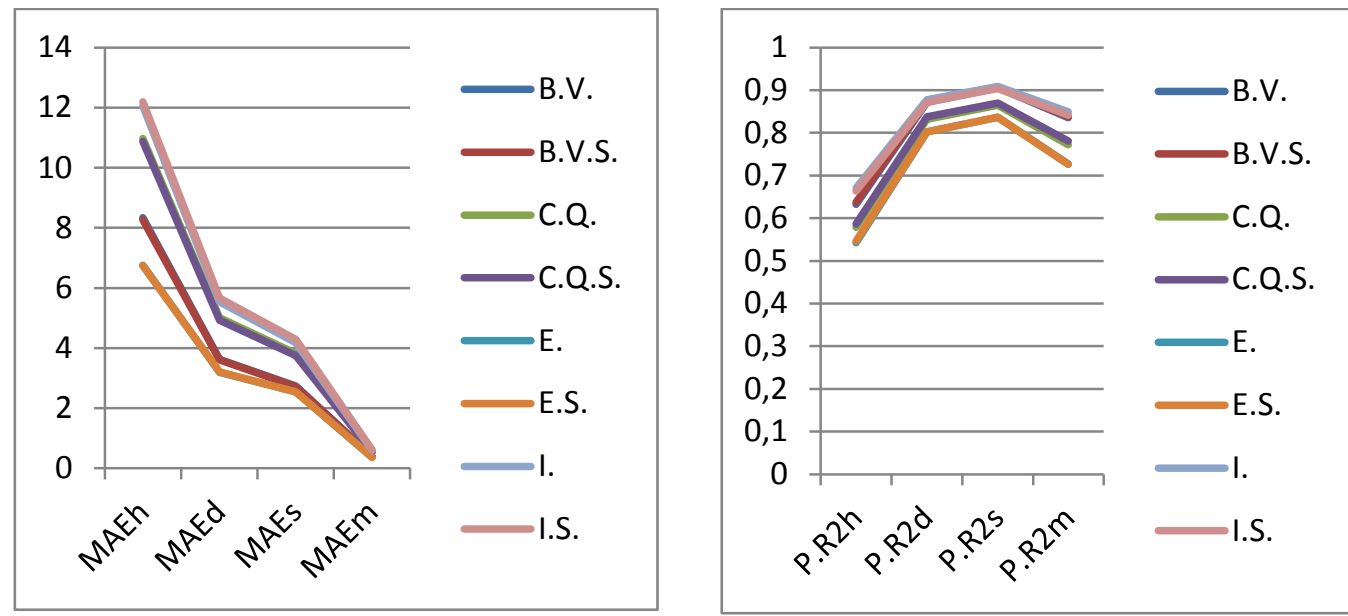

Figura D-2: MAE e Pseudo $\mathrm{R}^{2}$ out of sample do Tipo 1 Médio. 

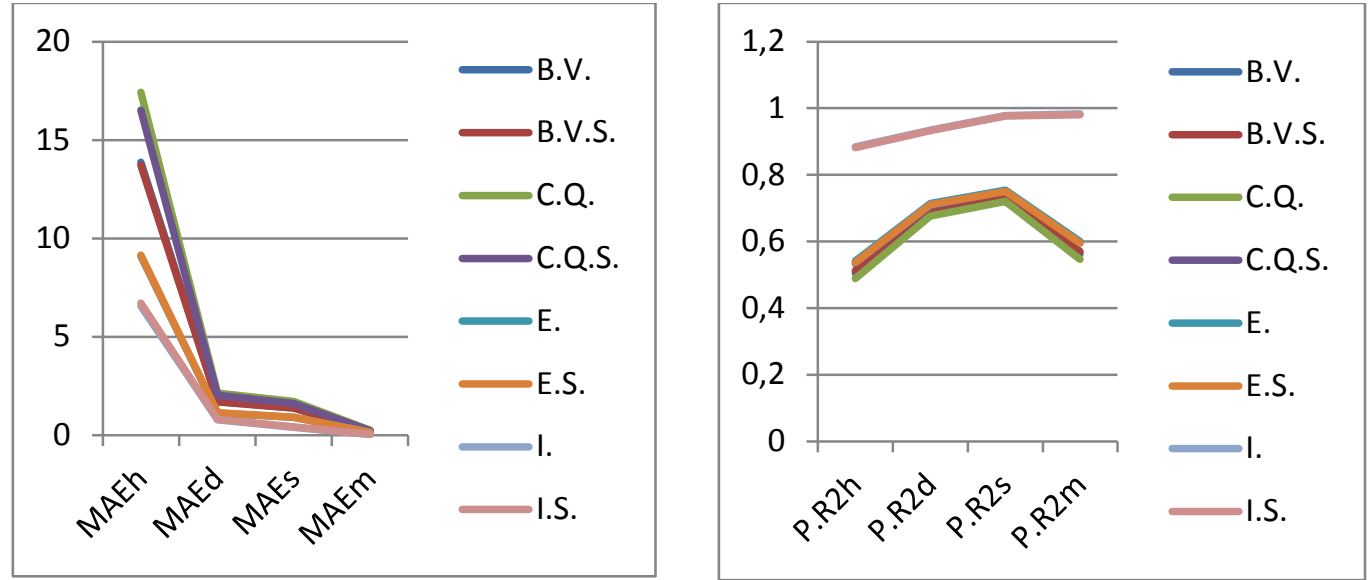

Figura D-3: MAE e Pseudo $\mathrm{R}^{2}$ out of sample do Tipo 1 Pesado.
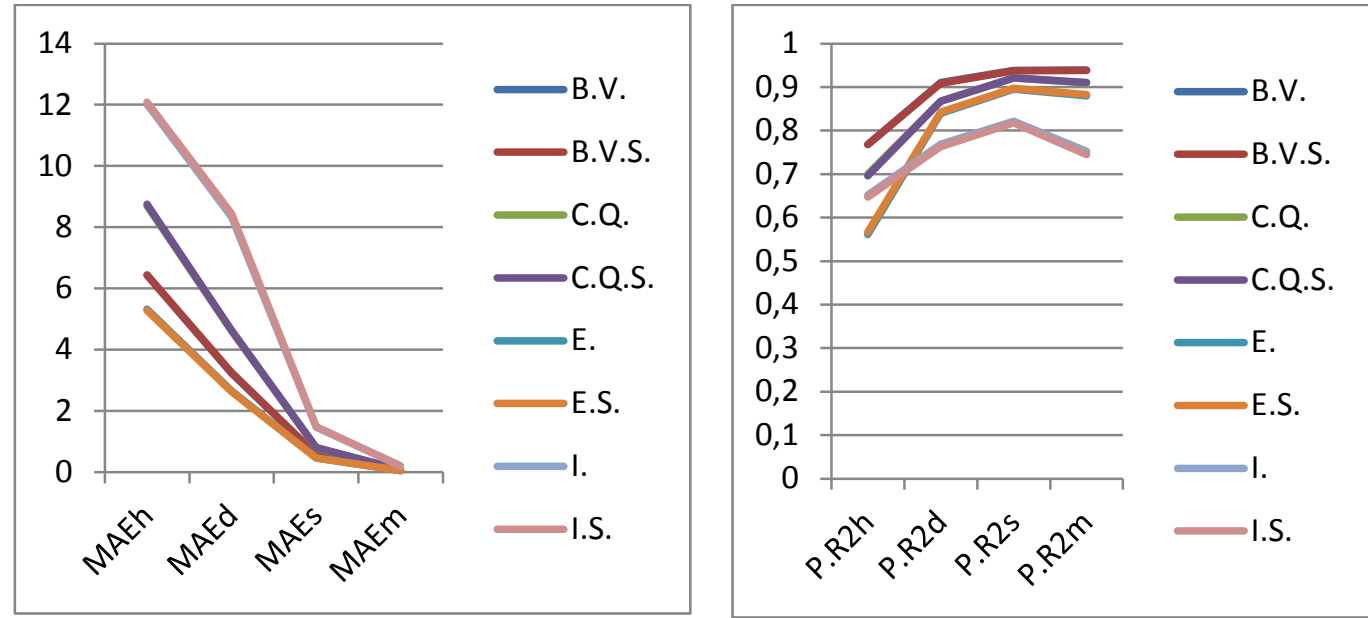

Figura D-4: MAE e Pseudo $\mathrm{R}^{2}$ out of sample do Tipo 2 Leve.
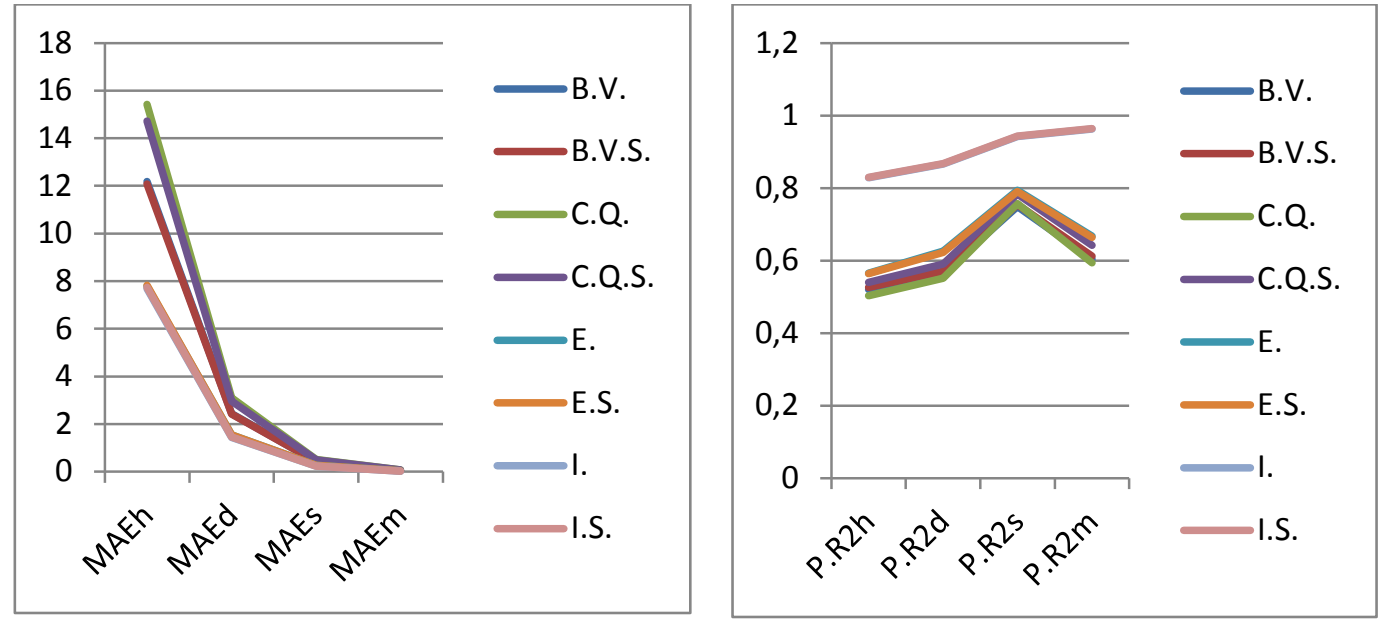

Figura D-5: MAE e Pseudo $\mathrm{R}^{2}$ out of sample do Tipo 2 Médio. 


\section{Apêndice E - MAE e Pseudo $\mathrm{R}^{2}$ out of sample por tipo e patamar das fazendas eólicas estudadas, retirando os zeros da geração eólica observada}

Neste apêndice, se tem o estudo do MAE e Pseudo $\mathrm{R}^{2}$ out of sample paracada patamar e tipo de carga, retirando os instantes onde a geração eólica observada de cada fazenda foi zero. Nestes resultados, tem-se a seguinte nomenclatura: B.V. (modelo completo de Bons Ventos), B.V.S. (modelo stepwise de Bons Ventos), C.Q. (modelo completo de Canoa Quebrada), C.Q.S. (modelo stepwise de Canoa Quebrada), E. (modelo completo de Enacel), E.S. (modelo stepwise de Enacel), I. (modelo completo de Icaraizinho) e I.S. (modelo stepwise de Icaraizinho).
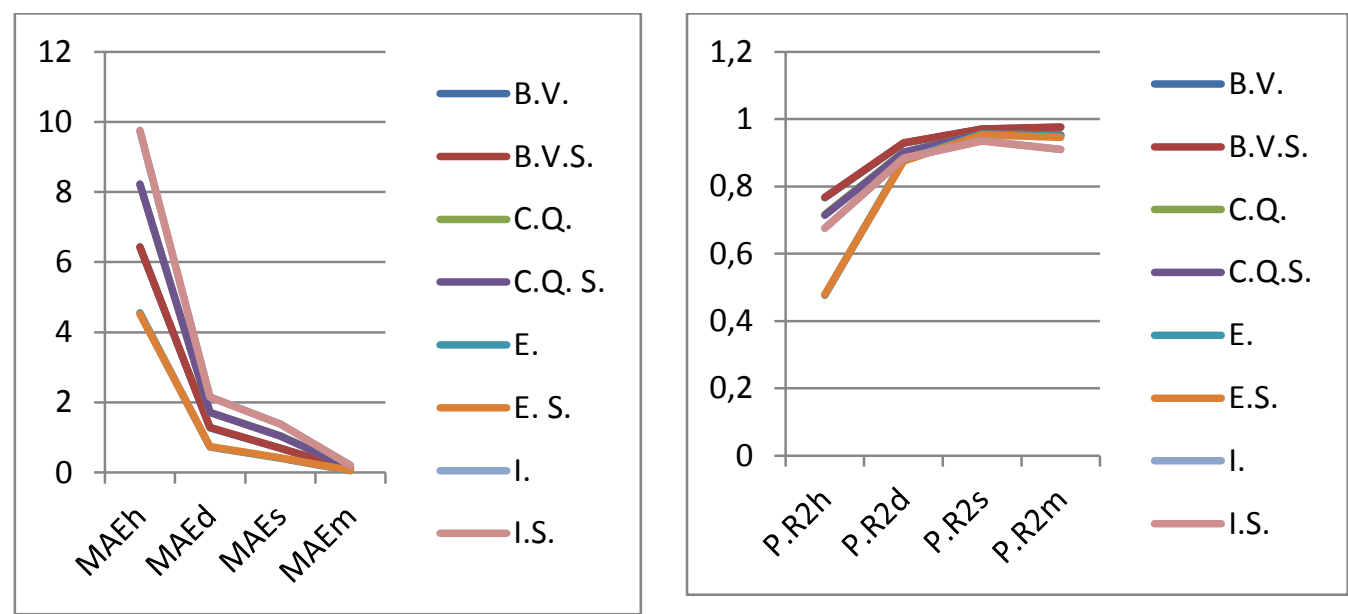

Figura E-1: MAE e Pseudo $\mathrm{R}^{2}$ out of sample do Tipo 1 Leve, retirando os zeros da geração eólica observada.
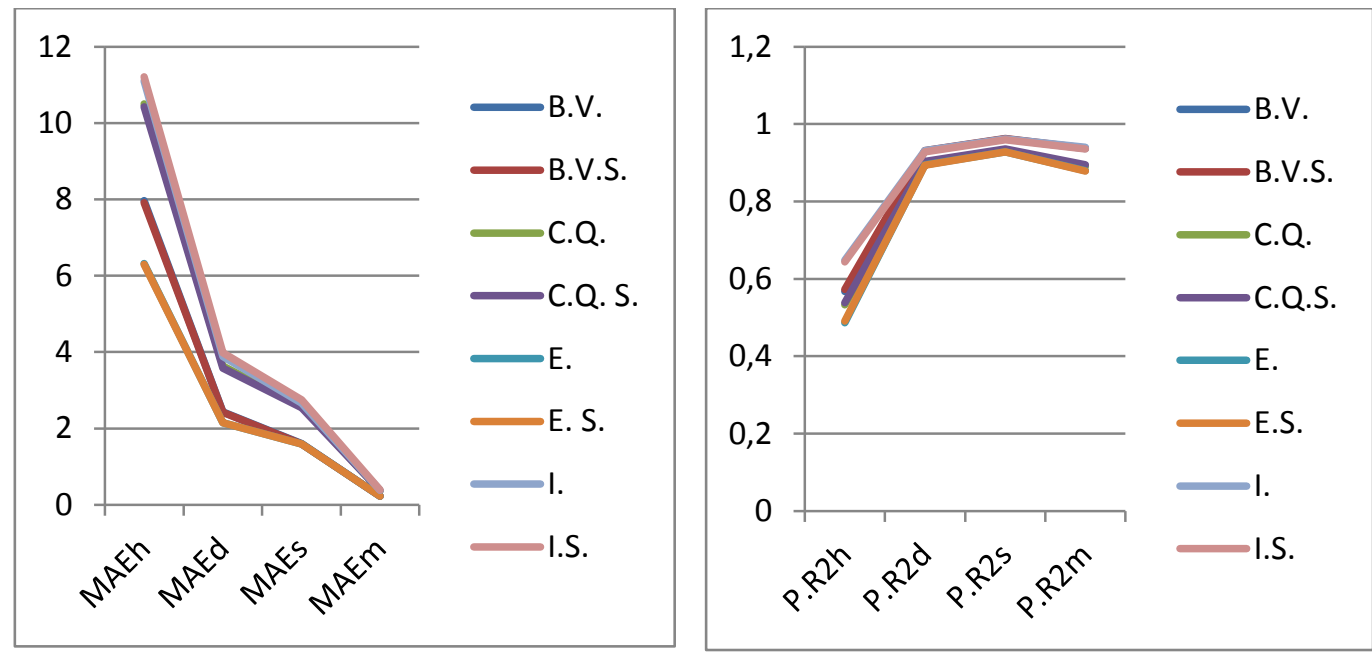

Figura E-2: MAE e Pseudo $\mathrm{R}^{2}$ out of sample do Tipo 1 Médio, retirando os zeros da geração eólica observada. 

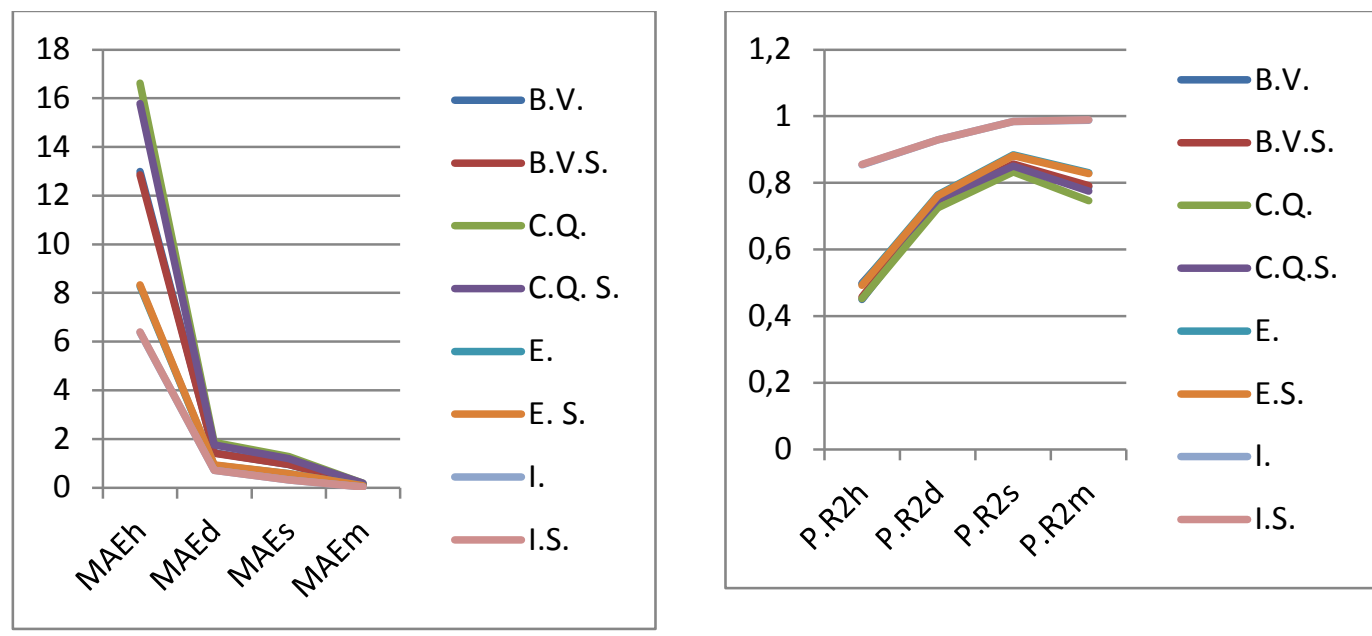

Figura E-3: MAE e Pseudo $\mathrm{R}^{2}$ out of sample do Tipo 1 Pesado, retirando os zeros da geração eólica observada.
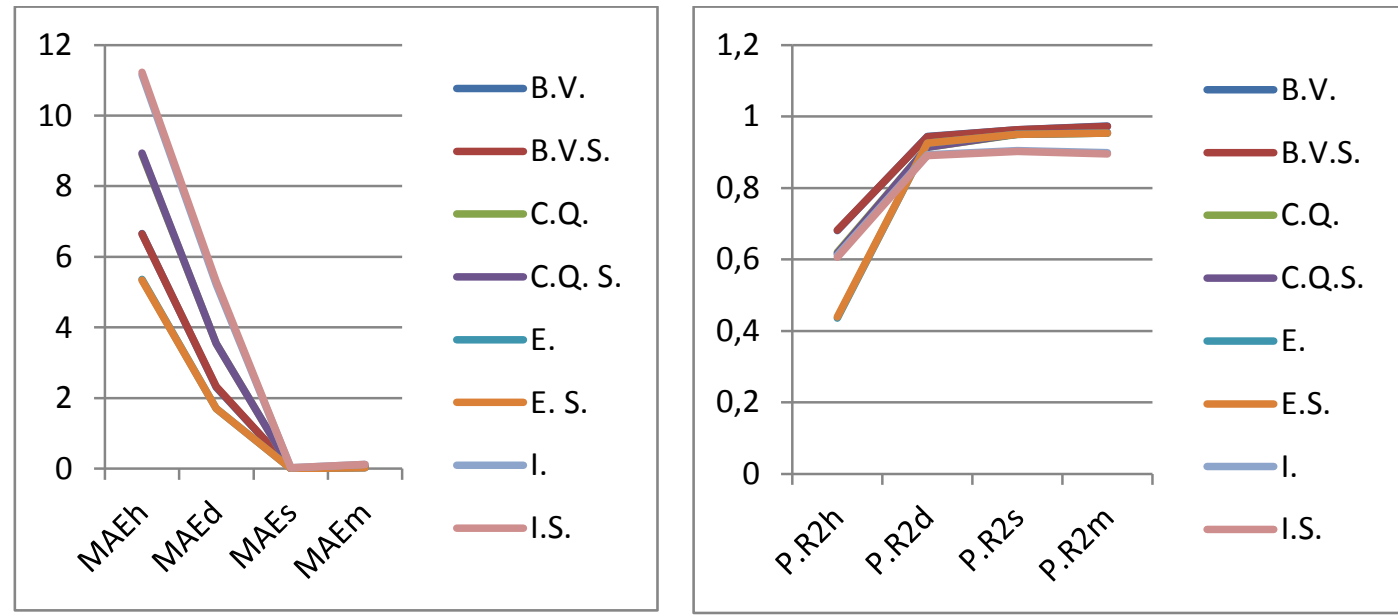

Figura E-4: MAE e Pseudo $\mathrm{R}^{2}$ out of sample do Tipo 2 Leve, retirando os zeros da geração eólica observada.
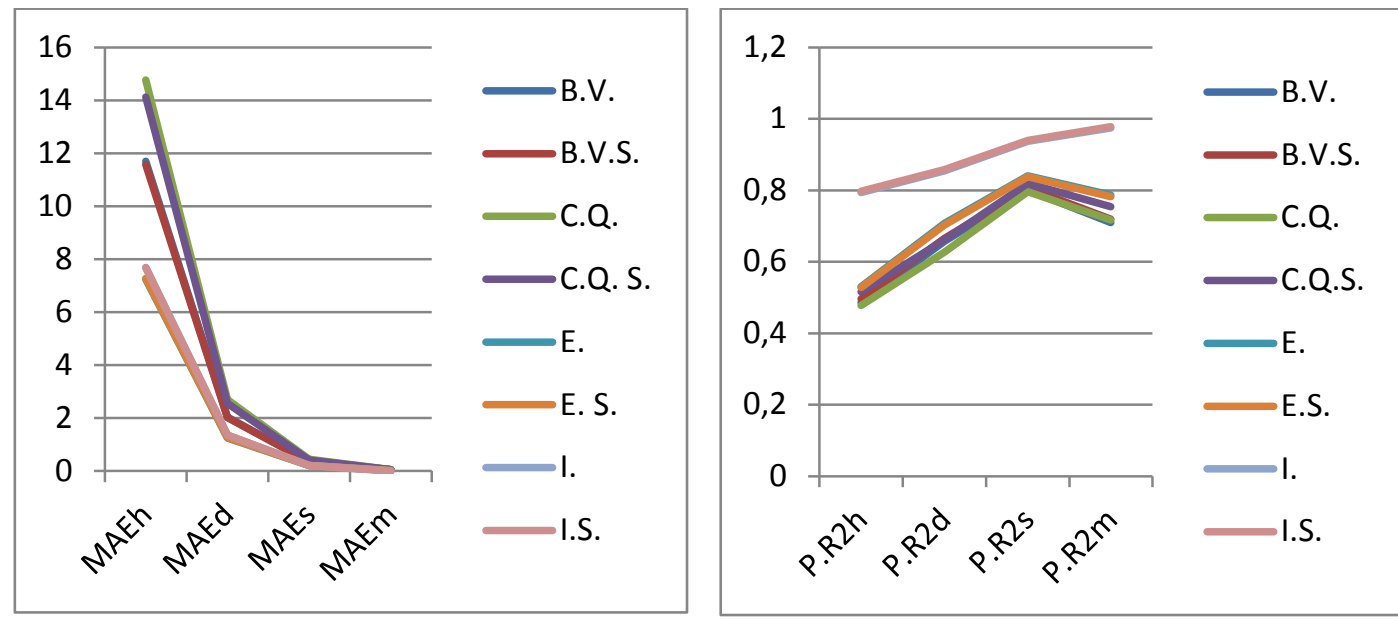

Figura E-5: MAE e Pseudo $\mathrm{R}^{2}$ out of sample do Tipo 2 Médio, retirando os zeros da geração eólica observada. 
Apêndice F - Extensão do histórico de geração eólica para as fazendas estudadas pelos modelos completo e stepwise

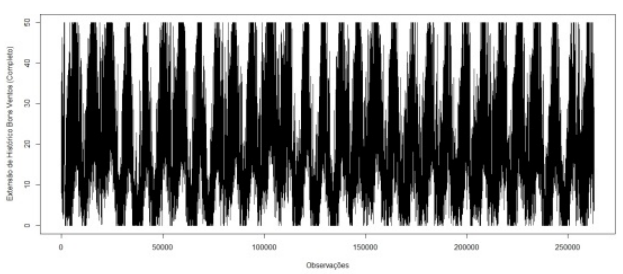

(a)

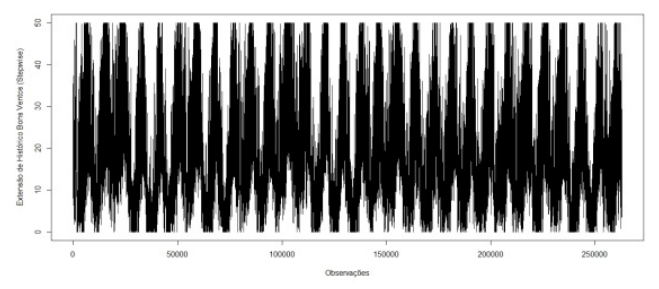

(b)

Figura F-1: Extensão de histórico da geração eólica para a fazenda de Bons Ventos, considerando os modelos completo (a) e stepwise (b).

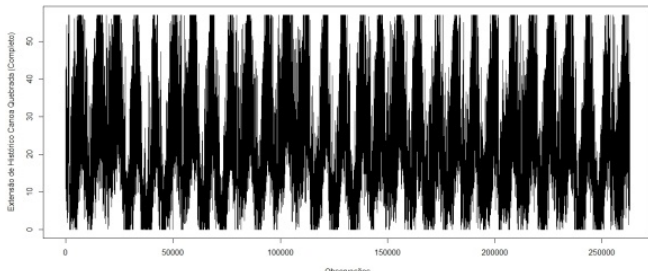

(a)

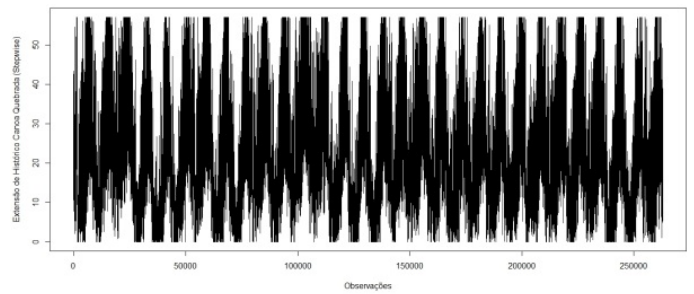

(b)

Figura F-2: Extensão de histórico da geração eólica para a fazenda de Canoa Quebrada, considerando os modelos completo (a) e stepwise (b).

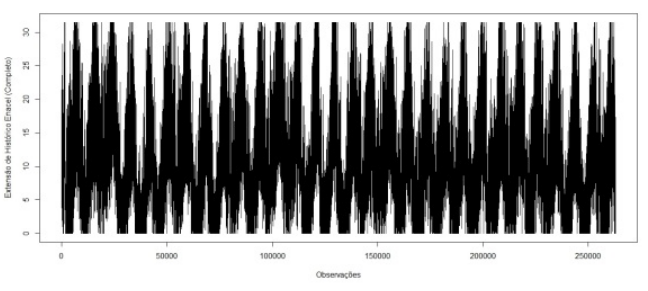

(a)

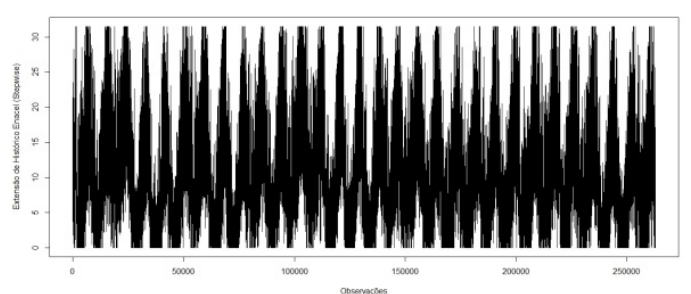

(b)

Figura F-3: Extensão de histórico da geração eólica para a fazenda de Enacel, considerando os modelos completo (a) e stepwise (b).

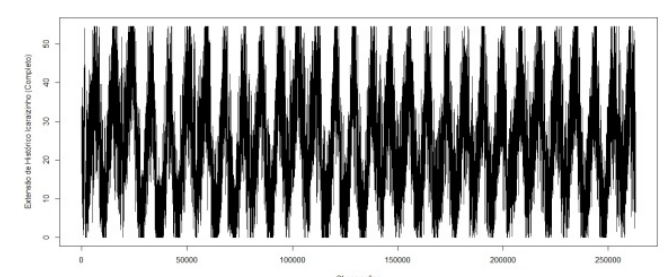

(a)

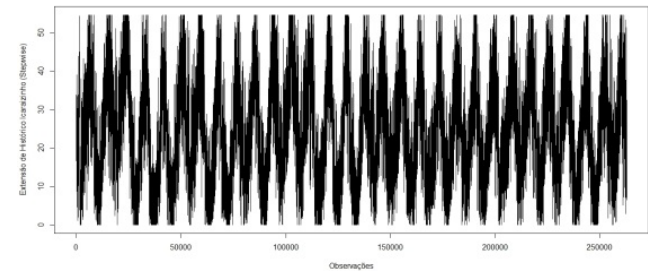

(b)

Figura F-4: Extensão de histórico da geração eólica para a fazenda de Icaraizinho, considerando os modelos completo (a) e stepwise (b). 


\section{Apêndice G - Histogramas da geração eólica observada e estimada através da extensão do histórico pelo modelo linear}

(a)

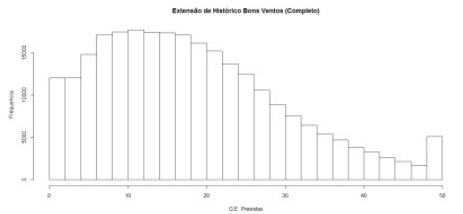

(b)

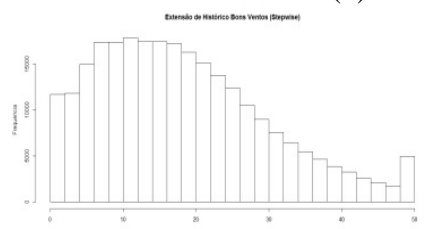

(c)

Figura G-1: Histogramas para a geração eólica estendida para 30 anos pelo modelo completo (a), pelo modelo stepwise (b) e observada (c) para a fazenda de Bons Ventos.

(a)

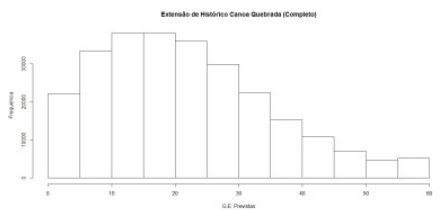

(b)

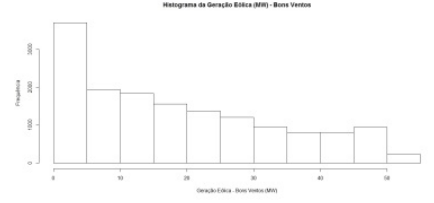

Figura G-2: Histogramas para a geração eólica estendida para 30 anos pelo modelo completo (a), pelo modelo stepwise (b) e observada (c) para a fazenda de Canoa Quebrada.

(a)

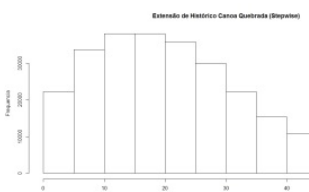

(c)

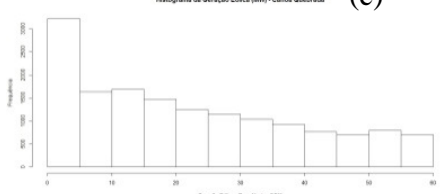

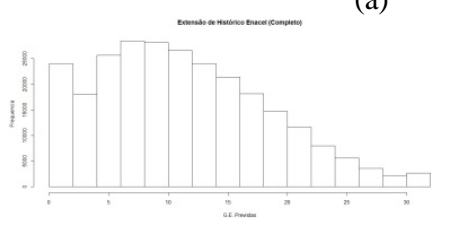

(b)

(c)

Figura G-3: Histogramas para a geração eólica estendida para 30 anos pelo modelo completo (a), pelo modelo stepwise (b) e observada (c) para a fazenda de Enacel.

(a)

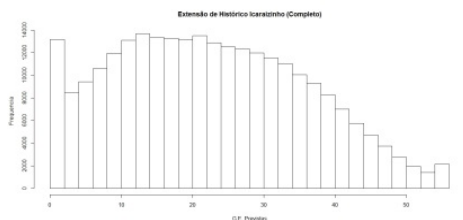

(b)

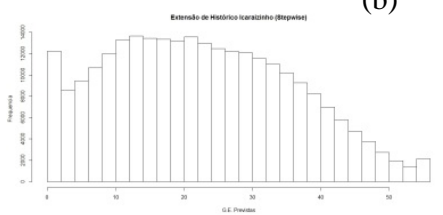

(c)

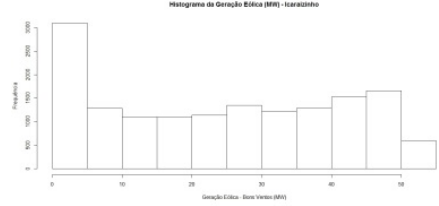

Figura G-4: Histogramas para a geração eólica estendida para 30 anos pelo modelo completo (a), pelo modelo stepwise (b) e observada (c) para a fazenda de Icaraizinho. 